\title{
Repercussão da informação nutricional sobre o comportamento de clientes de restaurantes universitários
}

Máurea Elena Missio da Silva

Dissertação apresentada ao Programa de Pós-Graduação em Saúde Pública para obtenção do título de Mestre em Saúde Pública.

Área de Concentração: Nutrição

Orientadora:

Prof. ${ }^{\text {a Dr. }}$ a Ana Maria Dianezi Gambardella

São Paulo

2006 
É expressamente proibida a comercialização deste documento tanto na sua forma impressa, como eletrônica. Sua reprodução total ou parcial é permitida exclusivamente para fins acadêmicos e científicos, desde que na reprodução figure a identificação do autor, título, instituição e ano da dissertação. 
Às minhas grandes preciosidades, Marianna, Camila e Alessandra, pela compreensão e valorização do meu esforço. 
À querida Ana (Prof. ${ }^{a}$ Dr. ${ }^{a}$ ANA MARIA DIANEZI GAMBARDELLA) entre muitas coisas, pelos ensinamentos e confiança em mim depositada.

À Prof. ${ }^{a}$ Dr. ${ }^{a}$ ROSA MARIA GODOY SERPA DA FONSECA, Coordenadora da Coseas, que sabiamente estimulou essa iniciativa dentro de um setor de prestação de serviços.

À Pili (MARIA APARECIDA LOUREIRO DE OLIVEIRA) que permitiu e incentivou esse empreendimento, além dos conselhos dados nos momentos mais difíceis.

Aos estagiários, CARLOS EDUARDO DE SOUSA, HELLEN CHRYSTINE ZANETTI MATARAZZO, JACKELINE TAGLIETA, JULIANA QUINTANILHA FAUSTINO, à bolsista MÁRCIA SAYURI KIYAMA e a técnica em nutrição e dietética MIRIAN ROSSETO, pelo entusiasmo com que conduziram as entrevistas.

À Prof. ${ }^{a}$ Dr. ${ }^{a}$ MARIA REGINA ALVES CARDOSO, mesmo com seu tempo muito ocupado, gentilmente auxiliou na definição da amostra.

Ao Prof. Dr. JOSÉ MARIA PACHECO DE SOUZA e FERNÃO DIAS DE LIMA e BRUNO ZOCA, pela paciência com que me introduziram no mundo dos números, proporções e probabilidades.

A todos os funcionários da biblioteca, em especial FRANCIS SIERRA HUSSEIN, JOSÉ ESTORNIOLO FILHO e MARIA LÚCIA EVANGELISTA DE FARIAS FERRAZ, pela competência com que me auxiliaram nas referências.

Aos funcionários do restaurante, CLEUZA, ANA, MARIA DO CARMO, ILDETE, SÔNIA, MARIA DE JESUS e OTÁVIO, pelo profissionalismo com que dirigiram o restaurante durante a minha ausência.

Aos ENTREVISTADOS, verdadeiros atores desta pesquisa.

Aos membros da banca, Prof. ${ }^{a}$ Dr. ${ }^{a}$ MARIA DE FÁTIMA NUNES MARUCCI e Prof. ${ }^{a}$ Dr. $^{a}$ ROSA MARIA GODOY SERPA DA FONSECA, que tão generosamente conduziram esse processo. 
Agradecimentos

Aos meus pais, ÁUREA HELENA MISSIO DA SILVA e MAURÍCIO LISBOA DA SILVA, por me ensinarem o poder da liberdade de escolha.

Ao meu querido irmão, MAURÍCIO LISBOA DA SILVA JR., minha cunhada, MARIA APARECIDA YOSHI SHIMANOE e aos meus sobrinhos SOSSO e DADI que, apesar da distância, sempre estiveram muito próximos.

Ao FARIAS, que surgiu exatamente nesse período de mudanças, pelo amor, carinho, tranqüilidade e apoio num momento tão importante do meu ser.

À FAMÍlIA BOUlOS (D. ${ }^{a}$ Cida, Ivete, Marcos, Tata, Jader, Fê e Gui) pela feliz presença em minha vida.

A todos NUTRICIONISTAS, AUXILIARES, TÉCNICOS, SECRETÁRIAS, colegas de trabalho da Coseas que me apoiaram direta e indiretamente nesta pesquisa.

Muito obrigada! 
"A coisa não está nem na partida, nem na chegada, mas na travessia."

Guimarães Rosa 
RESUMO 
Silva MEM. Repercussão da informação nutricional sobre o comportamento de clientes de restaurantes universitários [dissertação de mestrado]. São Paulo: Faculdade de Saúde Pública da USP; 2006.

Introdução - A informação nutricional do rótulo de embalagem de alimentos tem sido uma estratégia importante para oferecer ao consumidor informações para escolhas mais apropriadas. Partindo desse princípio, os restaurantes administrados pela Coordenadoria de Assistência Social, no ano de 2001, passaram a disponibilizar a informação de valor energético das preparações culinárias oferecidas nos restaurantes de forma a orientar e auxiliar o cliente em sua escolha. Objetivo - Avaliar o comportamento de funcionários e alunos que utilizam os restaurantes universitários em relação à informação nutricional e, em especial, referente ao valor energético das preparações culinárias oferecidas nestes. Métodos - Foi utilizada amostra sistemática. Os domínios de estudo foram constituídos por dois estratos de 600 indivíduos cada. O método de investigação foi a entrevista estruturada. As variáveis de estudo foram analisadas de forma descritiva e utilizou-se o teste Qui-quadrado para analisar associações. Resultados. Houve semelhanças entre os estratos de alunos e funcionários com maior tempo de educação formal. Não houve associação entre ler as informações nutricionais do rótulo de embalagem de alimentos e o valor energético das preparações culinárias oferecidas pelos restaurantes. A utilização da informação nutricional esteve associada a, anos de educação formal, excesso de peso, prática de atividade física esportiva, tipos de fontes de informação sobre alimentação e nutrição. Conclusão. Observou-se ser esta pesquisa de importante natureza, uma vez que não foram encontrados trabalhos específicos que avaliassem o comportamento da população universitária sobre a informação nutricional. De modo geral, as mulheres utilizam as duas 
informações nutricionais mais que os homens. No caso dos alunos, observouse pouco interesse em relação às duas informações. Entre os funcionários de menor tempo de educação formal, verificou-se maior interesse na informação de valor energético das preparações culinárias, diferente dos funcionários com maior tempo de educação formal, que lêem mais as informações nutricionais do rótulo de embalagem de alimentos.

Descritores: Informação nutricional; Valor energético; Restaurante universitário; Refeições coletivas. 
ABSTRACT 
Silva MEM. Repercussão da informação nutricional sobre o comportamento de clientes de restaurantes universitários./Repercussion of nutritional information on the behavior of the clients of university restaurants [dissertation]. São Paulo (BR): Faculdade de Saúde Pública da Universidade de São Paulo; 2006.

Introduction. The nutritional information on the labels on the packaging of foodstuffs has proved an important strategy in offering the consumer such information to make the most appropriate choices. On this basis, the restaurants managed by the Coordenadoria de Assistência Social began, in 2001, to make available to their clients information regarding the energy value of the food prepared so as to guide and help them in their choices. Objective. To assess the behavior of the staff members and students who make use of university restaurants in their response to the nutritional information provided, especially as regards the energy value of the food prepared and provided in these restaurants. Methods. Systematic sampling was used. The universe of study consisted of two strata of 600 individuals each. The structured interview was used as the method of investigation. The study variables were analyzed descriptively and the chi-squared test was used to analyze the associations. Results. There were similarities between the strata of students and staff with higher levels of education. There was no association between the reading of the labels on the packaging of foodstuffs and the energy value of the food prepared and offered by the restaurant. The use made of the nutritional information provided was associated with the level of education, over-weight, practice of physical sporting activity and kinds of sources of information on feeding habits and nutrition. Conclusion. It is clear that this research is important, as no specific studies which attempt to assess behavior related to nutritional information in a university population are available. Generally speaking, women use both kinds of 
information more than men. As regards the students, little interest was show in either kind of information. Among the staff of low level of education a greater interest was found in energy value information regarding the food served in the university restaurant than among the staff of higher levels of education who read the information on the packaging of foodstuffs more frequently.

Descriptors: Nutritional information; University restaurant; Collective meals; Energy value. 
Índice

1 - INTRODUÇÃO 22

1.1 - PANORAMA DA SAÚDE 23

1.2 - INFORMAÇÃO NUTRICIONAL DE RÓTULO DE 26 EMBALAGEM DE ALIMENTOS

1.3 - RESTAURANTE UNIVERSITÁRIO 34

1.4 - MODELO DE CLASSIFICAÇÃO DE COMPORTAMENTO 39 2 - OBJETIVOS 44

2.1 - OBJETIVO GERAL 45

2.2 - OBJETIVOS ESPECÍFICOS 45

3 - MÉTODO 46

3.1 - DELINEAMENTO DO ESTUDO 47

3.2 - POPULAÇÃO E LOCAL DE ESTUDO 47

3.3 - DEFINIÇÃO DA AMOSTRA 48

3.4 - PRÉ-TESTE 49

3.5 - TREINAMENTO DOS ENTREVISTADORES 50

3.6 - COLHEITA DE DADOS 50

3.7 - VARIÁVEIS DE ESTUDO 52

3.7.1 - Variáveis demográficas e socioeconômicas 52

3.7.2 - Variáveis de saúde $\quad 53$

3.7.3 - Variáveis de conduta/conhecimento 55

3.7.4 - Variáveis de comportamento $\quad 58$

3.8 - ANÁLISE ESTATÍSTICA 59

3.9 - MATERIAL INFORMATIVO ENCAMINHADO AOS 59 ENTREVISTADOS

3.10 - ASPECTOS ÉTICOS 60

4 - RESULTADOS 61

4.1 - RESULTADO DAS ENTREVISTAS 62

4.2 - MATERIAL INFORMATIVO ENCAMINHADO AOS 63 
ENTREVISTADOS

4.3 - CARACTERÍSTICAS DA POPULAÇÃO DE ESTUDO 63

4.3.1 - Descrição das variáveis demográficas e 63

socioeconômicas

4.3.2 - Descrição das variáveis de saúde 66

4.3.3 - Descrição das variáveis de conduta / conhecimento 71

4.4 - VARIÁVEIS DE COMPORTAMENTO 80

4.4.1 - Variáveis socioeconômicas 84

4.4.2 - Variáveis de saúde $\quad 86$

4.4.3 - Variáveis de conduta/ conhecimento 95

5 - DISCUSSÃO 105

6 - CONCLUSÕES 123

7 - CONSIDERAÇÕES 127

8 - REFERÊNCIAS 129

9 - ANEXOS 145

Anexo I Cartaz de orientação: informação de valor energético A -1 das preparações culinárias oferecidas nos restaurantes universitários

$\begin{array}{lll}\text { Anexo II Formulário de entrevista da pesquisa } & \text { A - } 3\end{array}$

Anexo III Manual de instruções para treinamento dos A - 6 entrevistadores

Anexo IV Autorização para realização de entrevista nos A-11 restaurantes universitários da Coseas/USP

Anexo V Termo de consentimento livre e esclarecido $\quad$ A - 13

Anexo VI Agradecimento pela participação na entrevista A - 15

Anexo VII Material informativo encaminhado aos entrevistados A - 17 adultos (20-59 anos): orientações básicas de alimentação e nutrição 
Anexo VIII Material informativo encaminhado aos entrevistados A - 25 idosos ( $\geq 60$ anos): orientações básicas de alimentação e nutrição

Anexo IX Aprovação da pesquisa pelo Comitê de Ética da A-33 Faculdade de Saúde Pública

Anexo X Localização dos restaurantes universitários no Campus A - 35 da cidade universitária "Armando de Sales Oliveira" 
Quadro 1 Descrição dos restaurantes universitários das

universidades públicas paulistas por tipo de administração,

número de refeições distribuídas e a presença de

informação de valor energético de preparações culinárias.

São Paulo, 2005.

Quadro 2 Freqüência de clientes dos restaurantes da Coseas/USP. 49 São Paulo, 2004.

Quadro 3 Classificação de adultos (20-59 anos) de acordo com IMC. 53

Quadro 4 Classificação de indivíduos com 60 anos e mais de acordo 54 com IMC.

Quadro 5 Critério para classificação de comportamento dos 59 entrevistados, segundo modelo transteorético. 
Tabela 1 Distribuição dos indivíduos entrevistados, por estrato, segundo 62 restaurante. São Paulo, 2005.

Tabela 2 Distribuição dos indivíduos entrevistados, segundo estrato 66 e características sócio-demográficas. São Paulo, 2005.

Tabela 3 Distribuição dos participantes, segundo estrato, sexo e 68 IMC. São Paulo, 2005.

Tabela 4 Distribuição dos participantes, segundo estrato, sexo e 69 referência de doença. São Paulo, 2005.

Tabela 5 Distribuição de freqüências nos estratos, segundo nível de 71 atividade física. São Paulo, 2005.

Tabela 6 Distribuição dos participantes, segundo estrato, sexo e 76 classificação da resposta em relação ao conceito de caloria. São Paulo, 2005.

Tabela 7 Distribuição dos participantes, segundo estrato, sexo e 78 classificação da resposta em relação ao conceito de alimentação saudável. São Paulo, 2005.

Tabela 8 Distribuição dos participantes, segundo estrato, sexo e 79 quantidade de fontes de informação sobre alimentação e nutrição. São Paulo, 2005.

Tabela 9 Distribuição dos participantes, segundo estrato, sexo e 80 grupos de fontes de informação sobre alimentação e nutrição. São Paulo, 2005.

Tabela 10 Distribuição dos participantes, segundo estrato e modelo transteorético, para comportamento de "ler o rótulo de embalagem de alimentos". São Paulo, 2005.

Tabela 11 Distribuição dos participantes, segundo estrato e modelo transteorético, para comportamento de "observar o valor energético das preparações culinárias oferecidas no 
restaurante". São Paulo, 2005.

Tabela 12 Distribuição dos participantes, segundo estrato e modelo transteorético, para comportamento de "ler o rótulo de embalagem de alimentos". São Paulo, 2005.

Tabela 13 Distribuição dos participantes, segundo estrato e modelo 84 transteorético, para comportamento de "observar o valor energético das preparações culinárias oferecidas no restaurante". São Paulo, 2005.

Tabela 14 Distribuição dos participantes, segundo estrato, sexo e 85 modelo transteorético, para comportamento de "ler o rótulo de embalagem de alimentos". São Paulo, 2005.

Tabela 15 dos participantes, segundo estrato, sexo e modelo 86 transteorético, para comportamento de "observar o valor energético das preparações culinárias oferecidas no restaurante". São Paulo, 2005.

Tabela 16 Distribuição dos participantes, segundo estrato, IMC e modelo transteorético, para comportamento de "ler o rótulo de embalagem de alimentos". São Paulo, 2005.

Tabela 17 Distribuição dos participantes, segundo estrato, IMC e 88 modelo transteorético, para comportamento de "observar o valor energético das preparações culinárias oferecidas no restaurante". São Paulo, 2005.

Tabela 18 Distribuição dos participantes, segundo estrato, referência 90 de "controle de peso" e modelo transteorético, para comportamento de "ler o rótulo de embalagem de alimentos". São Paulo, 2005.

Tabela 19 Distribuição dos participantes, segundo estrato, referência de "controle de peso" e modelo transteorético, para 
comportamento de "observar o valor energético das preparações culinárias oferecidas no restaurante". São Paulo, 2005.

Tabela 20 Distribuição dos participantes, segundo estrato, referência de ausência de doença e modelo transteorético, para comportamento de "ler o rótulo de embalagem de alimentos". São Paulo, 2005.

Tabela 21 Distribuição dos participantes, segundo estrato, referência de ausência de doença e modelo transteorético, para comportamento de "observar o valor energético das preparações culinárias oferecidas no restaurante". São Paulo, 2005.

Tabela 22 Distribuição dos participantes, segundo estrato, atividade física esportiva e modelo transteorético, para comportamento de "ler o rótulo de embalagem de alimentos". São Paulo, 2005.

Tabela 23 Distribuição dos participantes, segundo estrato, atividade física esportiva e modelo transteorético, para comportamento de "observar o valor energético das preparações culinárias oferecidas no restaurante". São Paulo, 2005.

Tabela 24 Distribuição dos participantes, segundo estrato, 96 conhecimento do conceito de caloria e modelo transteorético, para comportamento de "ler o rótulo de embalagem de alimentos". São Paulo, 2005.

Tabela 25 Distribuição dos participantes, segundo estrato, 97 conhecimento do conceito de caloria e modelo transteorético, para comportamento de "observar o valor 
energético das preparações culinárias oferecidas no restaurante". São Paulo, 2005.

Tabela 26 Distribuição dos participantes, segundo estrato, 98 conhecimento do conceito de alimentação saudável e modelo transteorético, para comportamento de "ler o rótulo de embalagem de alimentos". São Paulo, 2005.

Tabela 27 Distribuição dos participantes, segundo estrato, 99 conhecimento do conceito de alimentação saudável e modelo transteorético, para comportamento de "observar o valor energético das preparações culinárias oferecidas no restaurante". São Paulo, 2005.

Tabela 28 Distribuição dos participantes, segundo estrato, grupos de 101 fontes de informação e modelo transteorético, para comportamento de "ler o rótulo de embalagem de alimentos". São Paulo, 2005.

Tabela 29 Distribuição dos participantes, segundo estrato, grupos de 102 fontes de informação e modelo transteorético, para comportamento de "observar o valor energético das preparações culinárias oferecidas no restaurante". São Paulo, 2005. 
Figura 1 Exemplo das possibilidades da educação nutricional 29 contínua.

Figura 2 Modelo teórico, simplificado, adaptado, de comportamento 32 do consumidor.

Figura 3 Processo de mudança de comportamento, segundo modelo 42 transteorético. 
1 - INTRODUÇÃO 


\section{1 - PANORAMA DA SAÚDE}

Ao chegar no século XXI, verifica-se a mais significativa transformação nas condições de saúde da população humana da história, principalmente nos últimos cem anos (WALDMAN, 2000).

Essas transformações se traduzem na transição demográfica, que foi representada pela queda da mortalidade, seguida pela diminuição da fecundidade e pelo aumento da expectativa de vida em decorrência, o envelhecimento da população (BOBADILLA e col., 1993).

Por sua vez, a transição epidemiológica caracteriza-se pela expressiva diminuição da mortalidade infantil, em boa parte resultante do declínio também acentuado da morbimortalidade por doenças infecciosas, especialmente diarréias; pela significativa elevação das taxas de doenças crônicas não transmissíveis, particularmente as cardiovasculares, o câncer e também as enfermidades causadas por violência (FRENK e col., 1989; BOBADILLA e col., 1993). Todas essas transformações resultam de uma interação complexa de múltiplos fatores, nem todos perfeitamente conhecidos (BOBADILLA e col., 1993).

Podem também ser apontados como fatores, particularmente associados a esse amplo processo, a industrialização; modelos de desenvolvimento econômico com repercussão nos processos migratórios, na urbanização, no declínio da fecundidade, nas alterações do ambiente; ampliação do acesso à água para abastecimento público; expansão da educação e da rede de serviços de saúde; aumento da renda com melhora das condições habitacionais e da disponibilidade de alimentos, diminuindo a desnutrição; mudanças no estilo de vida, com o homem adotando hábitos mais sedentários, com o predomínio de ocupações com menor esforço físico, 
submetendo-se a situações de maior estresse e, além disso, alterando seus costumes alimentares, entre eles, a substituição de alimentos in natura por produtos industrializados, principalmente pelo aprimoramento das técnicas de preservação de alimentos, além do progressivo consumo de gorduras e de alimentos de alta densidade energética; ingresso da mulher no mercado de trabalho e maior acesso a métodos de contracepção; incorporação de novas tecnologias médicas (ADA, 1996; WALDMAN, 2000).

No Brasil, levantamentos da Rede Internacional de Informações para a Saúde (RIPSA, 2002) demonstram o aumento da taxa de mortalidade por doenças do aparelho circulatório, neoplasias malignas e por diabete melito, entre 1991 e 1998, em todas as regiões brasileiras. Verificou-se o aumento da taxa de prevalência de diabete melito, sendo que 45\% dos indivíduos desconhecem a sua condição e $22,3 \%$ das pessoas sabidamente diabéticas não fazem uso de qualquer tipo de medicamento. Nesse levantamento, não foi investigada a adaptação alimentar necessária para esse tipo de doença.

Além das doenças acima, a obesidade é uma doença que contribui de forma importante para a carga de doenças crônicas não transmissíveis e incapacidade física (WHA, 2004). Caracteriza-se pelo acúmulo de gordura corporal, resultante do desequilíbrio energético prolongado que pode ser causado pelo excesso de consumo de alimentos e/ou inatividade física, além de ser uma doença que envolve fatores sociais, comportamentais, ambientais, psicológicos, metabólicos e genéticos (WHO, 2000; DEPARTMENT OF HEALTH AND HUMAN SERVICES, 2001).

As conseqüências para a saúde vão desde condições debilitantes, como osteoartrite, dificuldade respiratória, problemas músculos-esqueléticos, problemas de pele e infertilidade, até condições graves, tais como doença 
coronariana, diabete melito tipo 2 e certos tipos de câncer (DEPARTMENT OF HEALTH AND HUMAN SERVICES, 2001; WHA, 2004). Também podem ser associados os distúrbios psicológicos, incluindo depressão, distúrbios alimentares e imagem corporal distorcida, resultando em baixa auto-estima. Além disso, os indivíduos obesos também podem ser estigmatizados e sofrerem discriminação social (SEELEY e col., 2005).

Estudos epidemiológicos têm confirmado como comportamento de risco para doenças crônicas não transmissíveis as dietas pouco saudáveis, consumo de alimentos com alta densidade energética, inatividade física e hábito de fumar (WHO, 2003).

O Brasil não possui dados acessíveis sobre gastos governamentais com o tratamento de doenças crônicas não transmissíveis, porém o governo norteamericano estima dispêndio da ordem de U\$ 250 bilhões anuais com doenças, como as cardiovasculares, câncer e diabete. Acredita-se que essa prevalência poderia diminuir pela metade, caso a população adotasse um novo estilo de vida, incluindo alimentação saudável e atividade física freqüente (ESCAMILLA, 2002).

Recentemente, o documento elaborado pela Organização Mundial de Saúd (OMS), intitulado Estratégia Global em Alimentação Saudável, Atividade Física e Saúde, sugere a formulação e implantação de linhas de ação efetivas para reduzir substancialmente as mortes e doenças em todo mundo. Entre elas: os governos devem exigir que sejam facilitadas as informações nutricionais dos rótulos de embalagem de alimentos, uma vez que os consumidores têm o direito de receber uma informação exata, padronizada, compreensível sobre o conteúdo dos produtos alimentícios que lhes permita adotar decisões saudáveis de alimentação (WHA, 2004). 


\section{2 - INFORMAÇÃO NUTRICIONAL DE RÓTULO DE EMBALAGEM DE ALIMENTOS}

A adesão do Brasil à Estratégia Global em Alimentação Saudável, Atividade Física e Saúde representa um compromisso do país com a promoção da saúde e a prevenção das doenças crônicas, dando visibilidade a essas questões na agenda da saúde pública mundial (MINISTÉRIO DA SAÚDE, 2005; GOMES e CYRILLO, 2006). Assim, o destaque da informação nutricional, constante no rótulo de embalagem de alimentos, como estratégia de promoção e proteção da saúde e o exercício do direito do consumidor, pode orientar de alguma forma a população para escolhas mais saudáveis, entre outras coisas.

Evidências indicam que a informação nutricional tem sido utilizada, em um grande número de países, como estratégia para prover aos consumidores informações sobre o produto para escolhas mais adequadas (KREUTER e col., 1997; SILVERGLADE, 1998; NEUHOUSER e col., 1999; RADAELLI, 2003a) e, em alguns casos, benefícios para saúde por meio das propriedades do alimento ou nutrientes constantes nessa informação, além de encorajar os fabricantes a desenvolver produtos mais saudáveis (HAWKES, 2004).

No entanto, outros estudos indicam a dificuldade que alguns estratos da população têm para compreender essas informações, principalmente as nutricionais (SHINE e col., 1997; WANDEL, 1997; RADAELLI, 2003a), demonstrando uma clara diferença entre ler o rótulo de embalagem de alimentos, compreensão do significado do conceito e o uso adequado das informações nutricionais.

A embalagem serve como meio de distribuição e difusão do produto, além de ser um veículo de comunicação, é o maior elo de ligação entre o produto e 
o consumidor, por isso é considerada de grande oportunidade mercadológica e de informação (SERAGINI, 1990).

O entendimento entre linguagem empregada nas embalagens de alimentos e a expectativa dos consumidores levam ao vínculo, à comunicação e, conseqüentemente, à concretização de um dado comportamento de consumo (CASTRO, 2000).

De acordo com o item três, do artigo $6 .^{\circ}$, da Lei n. ${ }^{\circ} 8.078$ de 11 de setembro de 1990 do Código de Proteção e Defesa do Consumidor, é por meio do rótulo das embalagens dos alimentos que se tem acesso à informação como quantidade, características nutricionais, composição, qualidade e riscos que os produtos poderiam apresentar (BRASIL, 1990).

No Brasil, após terem transcorrido aproximadamente três décadas, desde a promulgação do Decreto-Lei n. ${ }^{\circ} 986$ de 1969 (BRASIL, 1969) que instituiu normas básicas sobre alimentos, e na tentativa de se adequar ao padrão internacional, foi editada a Portaria n. ${ }^{\circ} 371$ do Ministério da Agricultura e do Abastecimento que aprovou o regulamento técnico específico para rotulagem de alimentos embalados (MINISTÉRIO DA SAÚDE, 1997). A partir de então vem sendo publicada uma série de regulamentações que culminaram com a Resolução da Agência Nacional de Vigilância Sanitária (ANVISA), RDC (Resolução da Diretoria Colegiada) n. ${ }^{\circ} 40$ de 2001 (MINISTÉRIO DA SAÚDE, 2001), que tornou obrigatória a informação nutricional nos rótulos de alimentos embalados na ausência do consumidor.

Atualmente, é seguida a RDC n. ${ }^{0} 259$ de 2002 que se aplica à rotulagem de todo alimento que seja comercializado, qualquer que seja sua origem, embalado na ausência do cliente, e pronto para oferta ao consumidor, 
(MINISTÉRIO DA SAÚDE, 2002). Esta será substituída, em agosto de 2006, pela RDC n. 360 de 23 de dezembro de 2003 (MINISTÉRIO DA SAÚDE, 2003), ajustada por meio de uma série de discussões entre a comunidade acadêmica, indústria de alimentos e a sociedade civil (COITINHO e col., 2002).

Essa evolução, nas normas regulamentares, foi motivada pela necessidade de adequação do mercado nacional aos parâmetros estabelecidos internacionalmente e ao novo perfil do consumidor, cada vez mais informado e exigente.

Além disso, a informação nutricional obrigatória proporciona uma valiosa estratégia de orientação que, juntamente com a educação nutricional, poderá auxiliar os consumidores a selecionar adequadamente os alimentos, não só adquiri-los como consumi-los. Para isso, faz-se necessário que seja realizado um abrangente trabalho de educação nutricional no país, utilizando os vários tipos de recursos disponíveis, respeitando as diferenças entre os vários grupos da população. É esperado que essa associação deva render significativas mudanças em prol da promoção da saúde da população (LIMA, 2003).

A oportunidade para o processo de educação nutricional pode ser realizada com base em uma variedade de fontes de informação, como mostra a Figura 1, respeitando sempre as diferenças culturais, socioeconômicas e demográficas da população. 
Figura 1 - Exemplo das possibilidades da educação nutricional contínua.

$\begin{array}{cccc}\text { Informação } & \text { Comunicação } & \text { Promoção } & \text { Intervenção } \\ \text { nutricional } & \text { nutricional } & \text { nutricional } & \text { nutricional } \\ \text { Artigos de } & \text { Informação } & \text { Programas } & \text { Projetos para } \\ \text { nutrição em } & \text { nutricional de } & \text { governamentais } & \text { grupos } \\ \text { revistas ou jornais } & \text { rótulo de } & \text { como as normas } & \text { específicos, } \\ & \text { produtos } & \text { regulamentares e } & \text { disciplina } \\ & \text { alimentícios } & \text { guias de } & \text { curricular nas } \\ & \text { embalados } & \text { alimentação } & \text { escolas }\end{array}$

Extraído de: ADA, 1996.

O processo de educação nutricional, segundo BRUNT e SCHAFER (1997), deve-se à eficiência do material educativo para orientação do entendimento das informações nutricionais do rótulo de alimentos embalados, observando, principalmente, o nível de compreensão e a bagagem prévia de informações a respeito do assunto e o nível de leitura da população.

No processo de informação e aprendizagem, fica reconhecida a importância do detalhamento cuidadoso, das informações nutricionais, ("as chamadas", alertas e notas explicativas), como eficiente e econômica medida de educação e proteção do consumidor (MILLER, 1978).

Embora os objetivos da regulamentação, em relação à informação nutricional, sejam claros, vários estudos têm observado incorreções relativas à informação nutricional, o descumprimento de dizeres obrigatórios da rotulagem numa grande variedade de produtos, inclusive aqueles para fins especiais, como o caso dos produtos para diabéticos e indivíduos com restrição de gordura na dieta, demonstrando negligência de certas indústrias nacionais como também desinformação e despreparo dos responsáveis por esses produtos (GRACIANO e col., 2000; ARAÚJO e ARAÚJO, 2001a, 2001b; 
YOSHIZAWA e col., 2003; FREITAS e col., 2004).

Essa constatação pode provocar confusão e indução do consumidor a uma falsa interpretação ou equívoco quanto à informação nutricional além da descrença em relação à informação.

Também, as constantes modificações na regulamentação, aliada à fiscalização precária, são outros fatores que contribuem para essa situação. Verifica-se a necessidade de abordar aspectos da informação nutricional de alimentos em programas de educação nutricional para conscientizar o consumidor a respeito das informações que devem ser fornecidas pelo fabricante (YOSHIZAWA e col., 2003).

Observa-se que muitas vezes o consumidor pode encontrar certa dificuldade em adequar as informações contidas nas embalagens, às suas necessidades pessoais. Talvez esse bloqueio no processo de comunicação seja decorrente da forma/formato como as informações estão dispostas na embalagem, além de falta de conhecimentos prévios de alimentação, nutrição e saúde e hábito de ler essas informações (ADA, 1996).

Embora várias publicações indiquem que haja leitura das informações do rótulo de produtos alimentícios, por uma parte da população, outros afirmam haver problemas para essa compreensão, tal preocupação é revelada por estudos realizados principalmente na Europa e Estados Unidos (HAWKES, 2004).

Nos Estados Unidos, a maioria dos alimentos embalados tem informação nutricional e um grande número de produtos alimentícios o tem de forma voluntária desde 1984. Pesquisas demonstram que o uso corrente dessa 
informação poderá resultar num decréscimo de doenças crônicas ligadas à dieta (ESCAMILLA, 2002).

Estudos têm demonstrado que a leitura das informações dos rótulos de alimentos se limita a indivíduos jovens, mulheres, pessoas com alto grau de escolaridade e indivíduos interessados em alimentação saudável (HAWKES, 2004).

Pesquisa realizada na Inglaterra constatou que o público consumidor passa a se preocupar com o custo-benefício de um produto, e está disposto a pagar mais caro por um item, desde que este forneça vantagens ao preenchimento das necessidades nutricionais consideradas adequadas para aquele indivíduo (WHEELOCK, 1992).

Estudo realizado na América Latina, em 1994, com consumidores brasileiros e chilenos, sobre produtos alimentícios e embalagens, demonstrou que os elementos empregados na rotulagem dos alimentos são determinantes na tomada de decisão dos consumidores entrevistados. Entretanto, o consumidor brasileiro, carece de trabalhos voltados para a explicação do conteúdo informativo das embalagens de alimentos. Esse fato pode indicar alternativas aos profissionais de marketing, uma vez que estes buscam identificar e traduzir as expectativas e necessidades dos consumidores em geral para promoção e elaboração de produtos (CASTRO, 2000).

O consumidor tem-se mostrado mais atento e mais exigente com a qualidade dos produtos, em virtude da amplitude de ofertas advindos da comercialização de itens nacionais e importados. $\mathrm{O}$ aprimoramento da embalagem de alimentos, como veículo de comunicação, traz benefícios ao consumidor, alternativas para questões ligadas aos problemas de saúde 
pública e, conseqüentemente, um lucrativo retorno em virtude de um investimento em qualidade (CASTRO, 2000).

A publicidade tem se apropriado do discurso técnico e o utiliza para adicionar ao produto alimentício uma vantagem de caráter terapêtico ou estético que faz com que os conceitos sobre alimentação, vinculados à saúde, sejam amplamente difundidos (GRÁCIA-ARNAIZ, 1996).

De forma simplificada, as decisões de consumo ocorrem sob influência de variáveis, como socioeconômica, crenças em relação ao produto que estão impregnadas de diversas fontes de informação sobre o assunto, a informação nutricional do rótulo de alimentos e todo o marketing oferecido pela indústria de alimentos, conforme representado na Figura 2.

Figura 2 - Modelo teórico, simplificado, adaptado, de comportamento do consumidor.

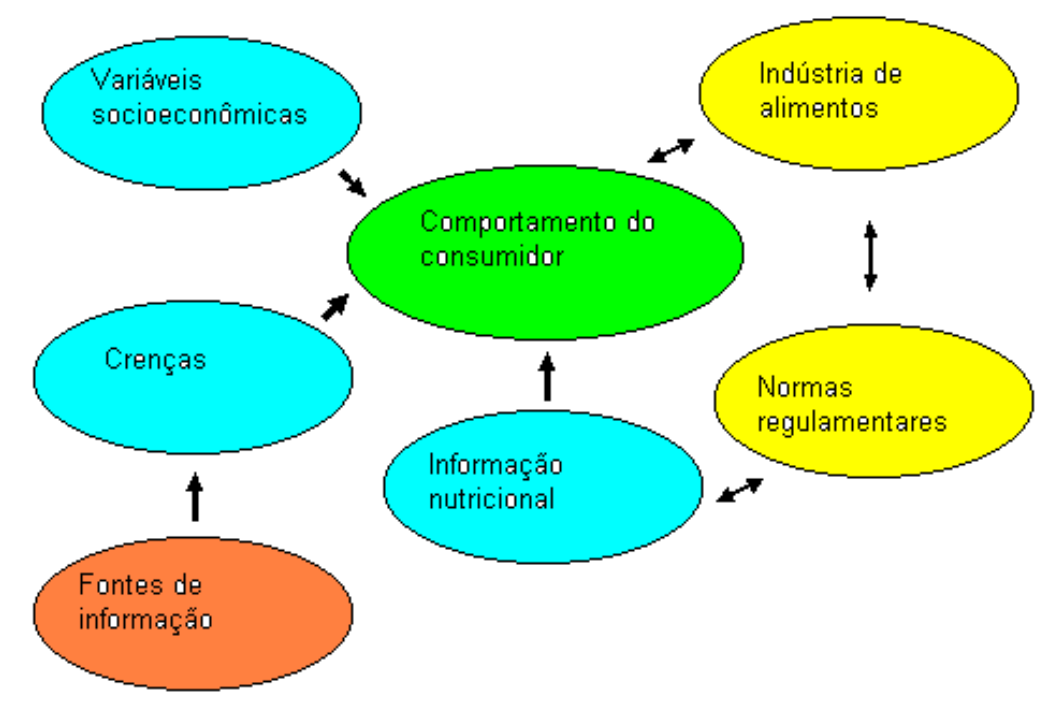

Extraído de: FERRAZ e col., 2003. 
Partindo dessa interação, a indústria de alimentos tem procurado adequar-se às exigências das normas regulamentares quanto à informação nutricional, contida nos rótulos dos alimentos para que o consumidor tenha acesso a informações de forma clara e completa.

Como já foi mencionado anteriormente, o problema da obesidade no mundo é crescente. Nos Estados Unidos, a previsão, para 2010, é de que $40 \%$ da população ou 68 milhões de pessoas estarão obesas, se mantiverem o ganho de peso atual. Hoje, quatro milhões de pessoas são obesas severas e relatórios demonstram que cada vez mais americanos fazem suas refeições fora de casa, por esse motivo colocar o valor calórico nos cardápios ajudaria a auxiliar o consumidor sobre escolhas mais saudáveis (FRUMKIN, 2003). No Brasil, Pesquisa sobre Padrões de Vida (PPV), realizada em 1999, demonstrou que as prevalências de excesso de peso passaram de $21 \%$ para $32 \%$ da população adulta (MONTEIRO e col., 2001).

Nos Estados Unidos, não há regulamentação que obrigue os restaurantes a disponibilizar a informação nutricional, se não houver alegações de saúde nas preparações oferecidas, porémo órgão americano responsável pelas regulamentações, Food and Drug Administration (FDA), encoraja esta prática (CUNNINGHAM, 2003). No Brasil, não há regulamentação para que restaurantes, de modo geral, forneçam a informação nutricional das preparações oferecidas em seus serviços como fonte de informação para o cliente.

Trabalho realizado em 1997, para avaliar os obstáculos referidos na disponibilização da informação nutricional das preparações culinárias, em cadeias de restaurantes, verificou dificuldade de várias ordens, como o tipo de tabelas de composição de alimentos para cálculos de nutrientes ou o custo 
de análises laboratoriais para identificar os valores de nutrientes das preparações culinárias; as diferenças no tamanho de porções e as variações nos recipientes utilizados para apresentar a preparação; falta de espaço no cardápio para a informação; treinamento de funcionários em relação a processos e procedimentos para a realização desse serviço; diferenças no método de produção e variações de ingredientes; custo de implantação desse serviço; falta de especialistas na área de nutrição, onde apenas 20\% das cadeias de serviços de alimentação têm o profissional para orientação da equipe de trabalho (SNEED e BURKNALTER, 1991; ALMANZA e col., 1997).

Nos Estados Unidos, entre as medidas desenvolvidas pelo governo, para conter o avanço das doenças crônicas não transmissíveis, além de outros, estão estimular nutricionistas a trabalharem em restaurantes comerciais e disseminar a informação nutricional das preparações oferecidas de forma informal, por meio de telefone, visitas domiciliares ou canais formais de informação, tais como circulares e boletins (WELLAND, 1993).

\section{3 - RESTAURANTE UNIVERSITÁRIO}

Nos últimos 30 anos, o papel dos restaurantes, principalmente os institucionais, vem se modificando em função das transformações sociais, econômicas e epidemiológicas da sociedade. Associação entre expectativas do cliente e as necessidades individuais de saúde são cada vez mais contempladas (STOKES, 1989).

Entre os objetivos desse tipo de serviço, segundo GANDRA e GAMBARDELLA (1983), destacam-se “elaborar e fornecer alimentação que seja a um só tempo suficiente, completa, harmônica, adequada às características e hábitos alimentares dos clientes, segura do ponto de vista higiênico-sanitário e que se ajuste aos limites financeiros da instituição, além disso, deve desenvolver atividades 
relacionadas à educação, pesquisa, assessoria e consultoria na área de nutrição".

Na Universidade de São Paulo (USP), os restaurantes institucionais se apresentam como restaurantes universitários. Estes são administrados pela Divisão de Alimentação, setor da Coordenadoria de Assistência Social (Coseas), órgão central diretamente ligado à reitoria.

A história da Coseas inicia-se em 1945, quando foi criado o Serviço de Inspeção de Saúde (SIS), vinculado à Cadeira de Tisiologia da Faculdade de Saúde Pública (FSP), após ter-se estabelecido a obrigatoriedade da realização de exames médicos para alunos ingressantes na Universidade.

Paralelamente, em 1948, foi criada a Divisão de Ação Social, setor ligado ao Departamento de Cultura e Ação Social da Reitoria da USP que em 1954, junto com o SIS se transforma em Instituto de Saúde e Serviço Social da Universidade (ISSU), permanecendo vinculado à Cadeira de Tisiologia.

Em 1967, o ISSU se desvincula da FSP e passa a ser ligado à Reitoria da USP. O Estatuto da USP, aprovado em 1969, transformou o ISSU em Coordenadoria de Saúde e Assistência Social - COSEAS, quando foram ampliadas suas atribuições e serviços desenvolvendo atividades que abrangiam "setor de alojamentos, setor de restaurantes, setor de esportes, setor de assistência médico-social, setor de conservação e reparos, setor de zeladoria" (USP, 2004).

Em 1975, o setor do serviço de atividades esportivas se desvincula da COSEAS e, em 1989, com o estabelecimento do Sistema de Saúde da Universidade de São Paulo, a COSEAS passou a dedicar-se especificamente às atividades de assistência social, passando a denominar-se Coordenadoria 
de Assistência Social - Coseas (USP, 2004).

Segundo o Regimento Geral da Universidade de São Paulo, compete à Coseas "promover o estudo e a solução de problemas relativos à moradia estudantil e assistência sociais da comunidade universitária; administrar o conjunto residencial estudantil da Universidade, na Capital" (USP, 1990).

Para isso, desenvolve atividades de apoio aos alunos, professores e funcionários, possibilitando a realização da missão da Universidade, voltado ao ensino, pesquisa e extensão (USP, 2004), e dentre estes, esta a administração dos restaurantes universitários.

A Divisão de Alimentação é composta por uma diretoria técnica, assessoria de planejamento, serviço de distribuição de gêneros e materiais, serviço de manutenção e unidades de alimentação e nutrição constituídas pelos restaurantes universitários.

São 12 unidades de alimentação e nutrição sendo quatro unidades produtoras e distribuidores (restaurantes Central, Instituto de Física, Escola de Enfermagem e Faculdade de Saúde Pública); três unidades distribuidoras (restaurantes Prefeitura do Campus - PCO, Faculdade de Direito - XI de Agosto e Núcleo de Recreação Infantil - NURI), sendo classificados como restaurantes universitários; três serviços diferenciados (restaurantes Selfservice e Churrascaria e bar noturno - Clube dos Professores) em sistema de autogestão; e duas unidades terceirizadas sob supervisão da Divisão de Alimentação (restaurantes do Instituto de Química e Campus zona leste).

Especificamente, os restaurantes universitários objetivam proporcionar em uma refeição, 40\% das necessidades diárias de energia com distribuição em 
55 a 70\% de carboidratos, 10 a 15\% de proteínas e 25 a 30\% de lipídeos e 40\% das necessidades diárias de cálcio e ferro (NRC, 1989), utilizando como referência o usuário padrão (FRUTUOSO e PASQUA, 1998)¹ dos restaurantes universitários administrados pela Coseas; oferecer cardápios diversificados quanto aos gêneros alimentícios, de acordo com as safras de produção, respeitando-se os hábitos alimentares dos clientes; compatibilizar os custos das refeições com o orçamento da Divisão de Alimentação por meio da produção de refeições com eficiência técnica e econômica, considerando os aspectos higiênico-sanitários de acordo com as normas regulamentares e padrões estabelecidos previamente; oferecer os serviços próximos ao local de trabalho e de estudo dos indivíduos da comunidade USP da Capital (AVEGLIANO, 1999; USP, 2004).

Considerando o papel dos restaurantes universitários e a demanda de clientes, que no ano de 2005 serviu quase um milhão e meio de refeições ${ }^{2}$, a partir de agosto de 2001, os restaurantes universitários passaram a divulgar a informação do valor energético de cada preparação culinária oferecida no balcão de distribuição de seus restaurantes por meio da etiqueta informativa ${ }^{3}$.

O objetivo foi chamar a atenção do cliente para essa informação de forma que

\footnotetext{
${ }^{1}$ Frutuoso MFP, Pasqua IC. O perfil dos usuários dos restaurantes Coseas. São Paulo; 1998. [trabalho apresentado à comissão de estágio do curso de Nutrição - Faculdade de Saúde Pública da USP].

${ }^{2}$ Relatório anual de número de refeições, Divisão de Alimentação Coseas/ USP, 2005.

${ }^{3}$ Etiqueta informativa é um display de acrílico com dimensões de $8 \times 12 \mathrm{~cm}$, com a informação nutricional que é composta por nome da preparação, porção como medida caseira e valor energético da porção da preparação culinária.
} 
ele pudesse se orientar e avaliar as escolhas no momento de fazer a refeição.

As orientações ao cliente para uso da etiqueta informativa foram apresentadas por meio de cartazes (Anexo I) dispostos em cada restaurante e no endereço eletrônico da Coseas na internet (http://www.usp.br/coseas/etiqueta.html). Este trabalho fez parte das atividades técnicas de orientação ao cliente realizado pela equipe de nutricionistas da Divisão de Alimentação.

Levantamento realizado pela Divisão de Alimentação demonstrou que essa prática é pouco difundida nos restaurantes universitários das universidades públicas estaduais tanto os administrados em sistema de autogestão, como os terceirizados, conforme apresentado no Quadro 1. 
Quadro 1 - Descrição dos restaurantes universitários das universidades públicas paulistas por tipo de administração, número de refeições distribuídas e a presença de informação de valor energético das preparações culinárias. São Paulo, $2005^{4}$.

\begin{tabular}{|c|c|c|c|c|}
\hline Universidade & $\begin{array}{c}\text { N.o de } \\
\text { Restaurantes } \\
\text { universitários }\end{array}$ & $\begin{array}{c}\text { Tipo de } \\
\text { administração }\end{array}$ & $\begin{array}{l}\text { N.o de } \\
\text { refeições } \\
\text { / dia }\end{array}$ & $\begin{array}{l}\text { Informação } \\
\text { Nutricional }\end{array}$ \\
\hline UFSCAR & $\begin{array}{l}1 \\
1\end{array}$ & $\begin{array}{l}\text { Autogestão } \\
\text { Terceirizado }\end{array}$ & $\begin{array}{c}2.800 \\
* *\end{array}$ & $\underset{* *}{\text { Não }}$ \\
\hline UNESP & $\begin{array}{l}5 \\
2\end{array}$ & $\begin{array}{l}\text { Autogestão } \\
\text { Terceirizado }\end{array}$ & $\begin{array}{c}2930 \\
720\end{array}$ & $\begin{array}{l}\text { Não } \\
\text { Não }\end{array}$ \\
\hline UNICAMP & 4 & Autogestão & 9820 & Não \\
\hline UNIFESP & 1 & Terceirizado & 1500 & Não \\
\hline USP & $\begin{array}{c}9 \\
7^{*} \\
1\end{array}$ & $\begin{array}{c}\text { Autogestão } \\
\text { Autogestão } \\
\text { Terceirizado }\end{array}$ & $\begin{array}{c}9400 \\
10000 \\
3500\end{array}$ & $\begin{array}{l}\text { Não } \\
\text { Sim } \\
\text { Não }\end{array}$ \\
\hline
\end{tabular}

UFSCAR - Universidade Federal de São Carlos

UNESP - Universidade Estadual Paulista

UNICAMP - Universidade Estadual de Campinas

UNIFESP - Universidade Federal de São Paulo

USP - Universidade de São Paulo

* apenas o Campus da Capital (Cidade Universitária Armando de Salles Oliveira, Faculdade de Saúde Pública, Escola de Enfermagem, Faculdade de Direito) fornece a informação nutricional.

** Não informado.

\section{4 - MODELO DE CLASSIFICAÇÃO DE COMPORTAMENTO}

O comportamento é definido como um conjunto de atitudes e reações de um indivíduo em face ao meio social (FERREIRA, 1999). Ele é identificado de acordo com necessidades, percepções, motivações e desejos que o indivíduo manifesta (ADA, 1996).

Diversas teorias e modelos comportamentais foram desenvolvidos como

${ }^{4}$ Matarazzo, HCZ. Rotulagem de alimentos: passado, presente e futuro. São Paulo, 2005. [trabalho 
forma de identificar o grau de comportamento do indivíduo. Exemplos dessas teorias são modelos de conhecimento, prática e atitude; teoria do aprendizado social; e modelos de ação social e marketing social.

Considerando a complexidade de elementos que determinam o comportamento, uma combinação de teorias e modelos tem sido utilizada como base de pesquisa em relação ao comportamento sobre alimentação e nutrição.

Atualmente, diversos estudos têm utilizado a classificação baseada no modelo transteorético ou modelo de escalas de mudança de comportamento (PROCHASKA e col., 1992a). Exemplos disso são: pesquisa para classificar o tabagismo durante o período de gravidez (COHEN e col., 1989), estágios de mudança de comportamento durante o tratamento do abuso de álcool (DICLEMENTE e HUGHES, 1990), estudo de programas de controle de peso (PROCHASKA e col., 1992b), redução da ingestão de gordura em dietas (STEPTOE e col., 1996), alteração do consumo de frutas e hortaliças (SORENSEN e col., 1998) e padrões de mudança de comportamento alimentar em relação à ingestão de gorduras e fibras (GREENE e col., 1994; GLANZ e col., 1994).

Para esta pesquisa foi escolhido o modelo transteorético devido à sua capacidade de classificar o comportamento baseado em atitudes referidas.

O modelo transteorético foi desenvolvido por PROCHASKA e colaboradores (1992a) no final da década de 1.970 para caracterizar o comportamento do indivíduo perante uma determinada situação. Esse modelo oferece uma 
perspectiva integrativa na estrutura intencional de comportamento de um indivíduo. A teoria define que o comportamento humano é um processo progressivo e que avança a medida que hajam estímulos e motivações.

Segundo PROCHASKA e colaboradores (1992a), são caracterizados por cinco estágios, sendo estes:

- Pré-contemplação

Estágio em que o indivíduo não tem intenção de mudança previsível de comportamento no futuro. Há resistência em organizar ou modificar o comportamento e muitas vezes ele não tem noção da situação existente sobre um dado tema.

- Contemplação

Estágio, no qual o indivíduo está consciente da existência do fato e está pensando seriamente na questão, mas ainda não está fazendo nada na prática. Em algumas situações, pessoas podem permanecer longos períodos nesse estágio. É o momento em que o indivíduo faz sérias considerações para tentar modificar o comportamento diante do fato.

- Preparação

Estágio que combina intenção e critério de comportamento. Os indivíduos estão preparados, porém não tiveram sucesso na ação. É o estágio mais próximo da ação. Foi originalmente chamado de estágio de "tomada de decisão".

- Ação

Estágio, no qual o indivíduo modifica seu comportamento diante do fato exposto. Os indivíduos são classificados neste estágio se houver sucesso na alteração do comportamento. 
- Manutenção

O indivíduo trabalha para prevenir uma recaída ou consolida os ganhos da ação. Este período é caracterizado quando a ação se mantém por um período de pelo menos seis meses.

Os autores sugerem que os estágios de mudança de comportamento não ocorrem de forma linear e sim um processo em espiral onde o indivíduo, dependendo de suas aspirações e ou motivações, podem retroceder muitas vezes no processo, segui-lo novamente até o término destas etapas (Figura 3).

Figura 3 - Processo de mudança de comportamento, segundo modelo transteorético.

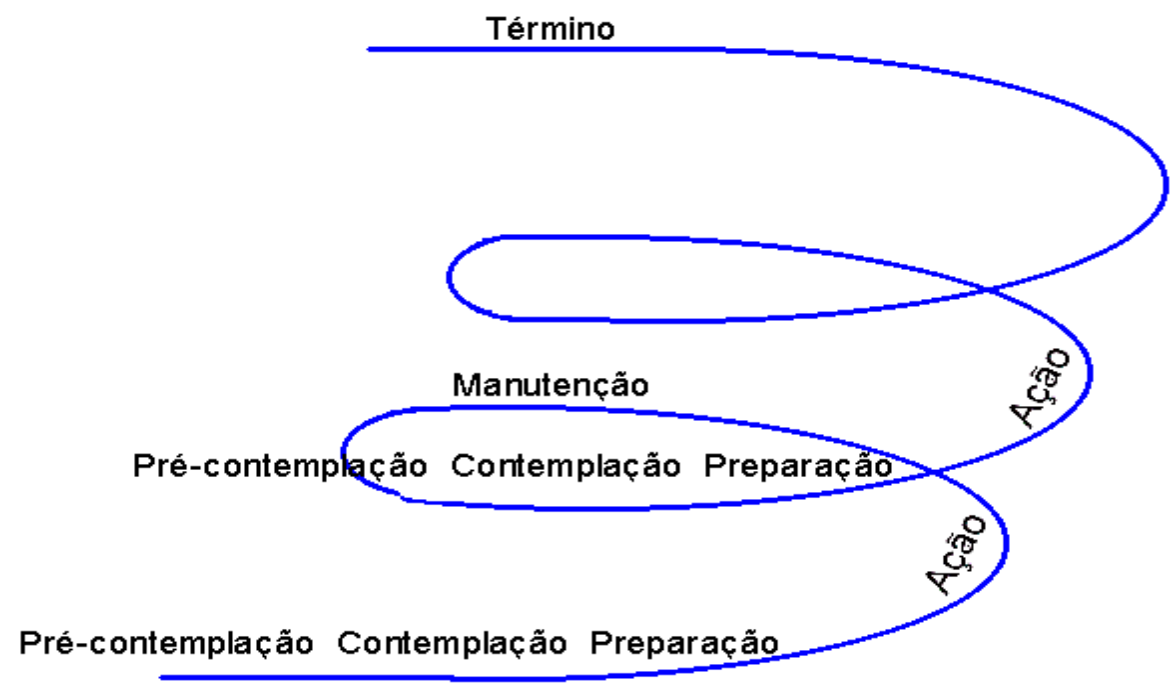

Extraído de: PROCHASKA e col., 1992a.

Os estágios de comportamento representam uma dimensão temporal que nos permite entender quando ocorre mudança de intenção e atitude no 
comportamento. Os processos de mudança de comportamento são convertidos e declarados em atividades e experiências que os indivíduos travam e na qual eles tentam modificar o comportamento perante uma situação instalada (PROCHASKA e col., 1992a).

Sob esse referencial, e considerando o papel da universidade em prover ensino, pesquisa e extensão universitária, a investigação do comportamento de alunos e funcionários da universidade que utilizam os restaurantes universitários quanto à informação de valor energético das preparações culinárias oferecidas se faz necessário. 
2 - OBJETIVOS 


\section{1 - OBJETIVO GERAL}

Analisar o comportamento de funcionários e alunos que utilizam os restaurantes universitários da USP, em relação à informação nutricional e, em especial, referente ao valor energético veiculado com as preparações culinárias servidas nos mesmos.

\section{2 - OBJETIVOS ESPECÍFICOS}

- Descrever a população, segundo as variáveis demográficas e socioeconômicas dessa população.

- Descrever a população, segundo as variáveis de saúde.

- Descrever a população, segundo as variáveis de conduta/ conhecimento.

- Descrever a população, segundo as variáveis de comportamento. 


\section{3 - MÉTODOS}




\section{1 - DELINEAMENTO DO ESTUDO}

O presente estudo apresenta característica descritiva do tipo transversal, abrangendo alunos e funcionários da USP.

\section{2 - POPULAÇÃO E LOCAL DE ESTUDO}

A população de estudo foi constituída por funcionários e alunos que utilizaram os restaurantes gerenciados pela USP, no ano de 2005.

Foram escolhidos todos os restaurantes que mantinham atividades comuns de produzir e distribuir refeições no horário do almoço nos campi da Capital. Desse modo, foram selecionados os restaurantes, Central e Física, situados na Cidade Universitária Armando de Salles Oliveira (CUASO), localizados no bairro do Butantã, zona oeste, além daqueles instalados na Escola de Enfermagem (EE) e na Faculdade de Saúde Pública, localizados no bairro de Cerqueira César, região central do município de São Paulo.

O universo foi constituído por todos os funcionários e alunos que utilizaram os restaurantes na USP, comprovados pela carteira de identificação. Foram considerados "funcionários" aqueles que exerciam qualquer atividade operacional ou administrativa, docente, pós-doutorado e "alunos" aqueles matriculados em cursos de graduação ou pós-graduação stricto sensu, oferecidos pela Universidade.

Adotou-se como critério de exclusão o não-enquadramento em alguma das situações anteriormente descritas, como, por exemplo, visitantes e alunos de cursos de extensão universitária. 


\section{3 - DEFINIÇÃO DA AMOSTRA}

Para definição da amostra foram estabelecidas proporções, com base na fórmula:

$$
\mathrm{n}=\frac{\mathrm{p} \cdot \mathrm{q} \cdot \mathrm{z}^{2}}{\mathrm{~d}^{2}}
$$

onde,

n: tamanho estimado da amostra

p: proporção de interesse no estudo

$\mathrm{q}: 1-\mathrm{p}$

Z: percentil da distribuição normal

d: erro máximo admitido em valor absoluto

Considerando a ausência de estudos anteriores sobre o assunto e que seriam estimadas várias proporções, adotou-se 0,50 como valor para p. O erro máximo admitido foi de 0,04 para um nível de confiança de 95\%. Assim a amostra foi:

$$
\begin{aligned}
& \mathrm{n}=\frac{0,50 \cdot(1-0,50) \cdot 1,96^{2}}{0,04^{2}} \\
& \mathrm{n} \cong 600 \text { indivíduos }
\end{aligned}
$$

Os domínios de estudo foram constituídos por dois estratos com 600 indivíduos cada, um para "funcionários" e outro para "alunos".

O Quadro 2 apresenta a freqüência observada dos domínios de estudo, com base no número de clientes em todos os restaurantes gerenciados pela Universidade. 
Quadro 2 - Freqüência de clientes dos restaurantes da Coseas/USP. São Paulo, 2004.

\begin{tabular}{|l|l|l|l|}
\hline Clientes & Março & Abril & Total \\
\hline Funcionários & 1.758 & 1.757 & 3.515 \\
Alunos & 7.077 & 6.097 & 13.174 \\
\hline Total & 8.835 & 7.854 & 16.689 \\
\hline
\end{tabular}

Fonte: Relatório de número de refeições, Divisão de Alimentação, 2004.

As frações de amostragem (f) utilizadas neste estudo, foram:

$$
\begin{aligned}
\mathrm{f}_{\mathrm{F}}= & \underline{\mathrm{n}_{F}}=\underline{600}=0,171 \\
& \mathrm{~N}_{\mathrm{F}}=3 \cdot 515 \\
\mathrm{f}_{\mathrm{A}}= & \underline{\mathrm{n}_{\mathrm{A}}}=\underline{600}=0,045 \\
& \mathrm{~N}_{\mathrm{A}} 13.174
\end{aligned}
$$

Para a seleção dos indivíduos, foram utilizados os seguintes intervalos de amostragem (IA) e iniciais causais (ic):

$$
\begin{aligned}
\mathrm{IA}_{\mathrm{F}}= & \underline{\mathrm{N}_{\mathrm{F}}}=\underline{3.515}=5,86 \\
& \mathrm{n}_{\underline{F}} \quad 600 \\
\mathrm{IA}_{\mathrm{A}}= & \underline{\mathrm{N}_{\mathrm{A}}}=\frac{13.174}{600}=21,96 \\
& \mathrm{n}_{\mathrm{A}} \quad \\
0,01 \subseteq & \mathrm{ic} \subseteq 5,86 \Rightarrow \text { funcionários: } 0,74 \\
0,01 \subseteq & \mathrm{ic} c_{\mathrm{A}} \subseteq 21,96 \Rightarrow \text { alunos: } 10,26
\end{aligned}
$$

Utilizou-se amostra sistemática, sem reposição de indivíduos para a realização desta pesquisa.

\section{4 - PRÉ-TESTE}

Para a coleta de dados foi adotada a técnica de entrevista estruturada, conforme formulário do Anexo II. 
No sentido de aprimorar o formulário da entrevista, realizou-se pré-teste com 30 indivíduos que freqüentavam o restaurante do Centro Tecnológico da Marinha, com administração terceirizada, situado na CUASO, uma vez que apresentava gerenciamento e cardápios semelhantes aos da Coseas e, além disso, disponibilizava informações sobre o valor energético das preparações culinárias oferecidas aos clientes.

Com base no pré-teste, elaborou-se o formulário definitivo que apresenta relação de perguntas, organizadas de modo a não provocar contágio entre as respostas, com redação invariável para todos os entrevistados. Algumas perguntas estavam interligadas e na dependência de respostas obtidas.

As perguntas do formulário foram, em sua maioria, abertas, sendo considerado, para efeito de dados, a primeira menção do entrevistado.

\section{5 - TREINAMENTO DOS ENTREVISTADORES}

Para realização das entrevistas, contou-se com a colaboração de quatro alunos, do $10 .^{\circ}$ semestre do curso de Nutrição da Faculdade de Saúde Pública da USP que desempenhavam função de estagiário e de um aluno, também do curso de Nutrição, que era bolsista trabalho da Coseas/USP.

Esses entrevistadores receberam treinamento e Manual de Instruções (Anexo III). Após cada dia de colheita, realizavam-se reuniões com os entrevistadores para discutir as dificuldades e padronizar a conduta. Todos os entrevistadores realizavam, sob forma de rodízio, as funções de abordar, convidar e entrevistar os indivíduos selecionados.

\section{6 - COLHEITA DE DADOS}

A colheita de dados foi realizada nos meses de março e abril de 2005, com 
autorização da Coseas (Anexo IV). Para facilitar a identificação do local, os formulários utilizados, para a colheita de dados, foram impressos em cores diferentes, segundo restaurantes Central, Física, EE e FSP.

Com base no cartão de identificação, o cliente do restaurante foi classificado em "funcionários" ou "alunos". Foi realizada contagem seqüencial dos indivíduos, segundo inícios causais (0,74 para "funcionários" e 10,26 para “aluno"), em intervalos de 5,86 e de 21,96, entre os respectivos estratos para realizar a seleção, identificando-os por cartão numerado na cor azul para "funcionários" e amarela para "aluno".

A abordagem e o convite foram realizados, pessoalmente, ao indivíduo para participar da pesquisa. Em cada restaurante, foi programado de forma a não repetir o dia da semana.

No caso do indivíduo selecionado aceitar participar da entrevista, recebia o cartão numerado para apresentar, após o almoço, ao entrevistador que permanecia no lado externo do restaurante.

Em função do tempo de espera na fila do restaurante para almoçar, que em algumas situações chegou até 40 minutos, indivíduos selecionados que demonstraram interesse em participar da entrevista, informavam o número telefônico para contato posterior.

Ao final da refeição, os indivíduos eram entrevistados ao lado externo do restaurante de forma a garantir a privacidade e resguardar a individualidade de cada entrevistado. Antes de iniciar a entrevista, solicitou-se concordância formal de cada entrevistado por meio do Termo de Consentimento Livre e Esclarecido (Anexo V). 
As entrevistas, que não puderam ser efetivadas no horário do almoço, foram agendadas para outra data, pessoalmente, se clientes das unidades da EE e da FSP e, por telefone, para lotados na CUASO, devido à dificuldade de deslocamento.

Considerou-se perda amostral a soma de "falha da amostra", indivíduos selecionados, que concordaram em participar da entrevista e, por algum motivo, não se apresentaram aos entrevistadores e, "recusa", aqueles que não aceitaram o convite para participar da pesquisa.

\section{7 - VARIÁVEIS DE ESTUDO}

\subsection{1 - Variáveis demográficas e socioeconômicas}

- Sexo

Foi considerada a identidade biológica do indivíduo.

\section{- Idade}

A idade foi obtida por meio da diferença entre a data da entrevista e de nascimento, em anos completos de cada indivíduo. O grupo etário foi distribuído em intervalos de vinte anos.

\section{- Ocupação}

Para os alunos foi considerada a matrícula do curso e classificado, segundo área de ciência (USP, 2005).

Considerou-se como ocupação a função referida pelo funcionário, com a correspondente designação dada pela Universidade, segundo níveis: básico, técnico, superior e docente (DRH-USP, 2005). 
Quando o estrato foi subdividido, observou-se comportamento muito semelhante entre "funcionários" de nível técnico, superior e docente, sendo estes denominados "funcionários outros" o que diferiu dos "funcionários" de nível básico, e, por esse motivo, foram denominados "funcionários básicos".

\section{- Escolaridade}

A escolaridade foi baseada no número de anos completos de instrução formal, declarado pelos indivíduos e considerando os níveis de ensino, em fundamental de zero a oito anos, médio, de nove a onze anos, e superior, maior que doze anos de estudo.

\subsection{2 - Variáveis de saúde}

Para melhor distribuição das variáveis nesta pesquisa, foram consideradas como variáveis de saúde o índice de massa corporal (IMC), referência de “controle de peso", ausência de doença e prática de atividade esportiva.

\section{- IMC}

Para o IMC [peso $(\mathrm{kg}) /(\text { estatura }(\mathrm{m}))^{2}$ ], foram utilizados os dados de peso e estatura referidos.

Para classificação dos participantes, segundo valores de IMC, adotou-se a classificação preconizada pela WHO (2003) (Quadro 3).

Quadro 3 - Classificação de adultos (20-59 anos) de acordo com IMC.

\begin{tabular}{|l|c|}
\hline Classificação & $\mathrm{IMC}\left(\mathrm{kg} / \mathrm{m}^{2}\right)$ \\
\hline Baixo peso & $<18,5$ \\
Peso adequado & $18,5-24,9$ \\
Excesso de peso & $\geq 25,0$ \\
\hline
\end{tabular}


No caso dos indivíduos com mais de 60 anos, foi utilizada a classificação recomendada pela Organização Pan-Americana de Saúde (OPAS) (MARUCCI e BARBOSA, 2003) (Quadro 4).

Quadro 4 - Classificação de indivíduos com 60 anos e mais de acordo com IMC.

\begin{tabular}{|l|c|}
\hline Classificação & $\mathrm{IMC}\left(\mathrm{kg} / \mathrm{m}^{2}\right)$ \\
\hline Baixo peso & $<23,0$ \\
Peso adequado & $23,0-28,0$ \\
Excesso de peso & $\geq 28,0$ \\
\hline
\end{tabular}

- Referência de "controle de peso"

Os indivíduos foram classificados em relação à referência de fazer, não fazer e fazer às vezes fazer "controle de peso".

\section{- Referência de ausência de doença}

Foram consideradas as referências de ausência de doenças e as queixas referidas pelo entrevistado, adotando-se o critério de Classificação Internacional de Doenças e Problemas Relacionados à Saúde, 10. ${ }^{a}$ revisão CID 10 (OMS, 1993).

\section{- Prática de atividade física esportiva}

Para estabelecer o nível de atividade física, adotou-se o proposto por MATSUDO e col. (2002), com base no tipo de atividade, freqüência e duração referida para atividade física esportiva ou caminhada:

Sedentário: não pratica atividade física esportiva ou caminhada.

Ativo: pratica atividade física moderada por mais de três dias por semana e 20 minutos por sessão; e/ou caminha cinco dias ou mais por semana por tempo superior a 30 minutos por sessão. 
- Muito ativo: pratica atividade física esportiva vigorosa por cinco dias ou mais, por mais de 30 minutos por sessão; e/ou atividade vigorosa por três dias ou mais por semana, por 20 minutos por sessão, acrescida por atividade moderada ou caminhada por mais de cinco dias por semana, por 30 minutos ou mais por sessão.

A atividade física vigorosa é definida como àquela que exige grande esforço físico (correr, ginástica aeróbica, futebol, pedalar rápido na bicicleta, basquete, carregar pesos elevados) ou qualquer atividade que aumenta muito a respiração (MATSUDO e col., 2002).

Atividade física moderada é aquela que exige menos esforço físico e que faz respirar um pouco mais forte que o normal (pedalar leve na bicicleta, nadar, dançar, ginástica aeróbica leve, vôlei recreativo, carregar pesos leves) ou qualquer atividade que aumenta levemente a respiração ou os batimentos cardíacos (MATSUDO e col., 2002).

\subsection{3 - Variáveis de conduta/ conhecimento}

Para efeito desta pesquisa, as variáveis de conduta/conhecimento foram: freqüência de utilização dos restaurantes universitários, aquisição de produtos alimentícios, leitura de rótulo de embalagem de alimentos, conhecimento do conceito de caloria e alimentação saudável, e referência de fontes de informação sobre alimentação e nutrição.

\section{- Referência de freqüiência de utilização dos restaurantes universitários}

Foi investigado o período em que os indivíduos passaram a freqüentar os restaurantes universitários, para realizar a refeição no horário do almoço e a freqüência média semanal. Sendo assim, os indivíduos foram classificados 
em antes e depois de agosto de 2001, período de disponibilização da informação de valor energético das preparações culinárias oferecidas nos restaurantes.

- Referência de aquisição de produtos alimentícios e leitura da informação nutricional

Procurou-se verificar a conduta do indivíduo sobre aquisição de produtos alimentícios, leitura do rótulo de embalagem de alimentos e tipo de informação observada. Para isso, foram classificados em comprar ou não alimentos, ter o hábito ou não de ler o rótulo de embalagens de alimentos e verificar quais informações do rótulo são observadas.

\section{- Conhecimento do conceito de caloria}

Com base na resposta sobre o conceito de caloria, adotou-se o seguinte critério de classificação:

* Correta: É a unidade padrão de energia térmica necessária para elevar a temperatura de um quilograma (um litro) de água em $1^{\circ} \mathrm{C}$ a partir de $15^{\circ} \mathrm{C}$ (SIZER e WHITNEY, 2003; FRARY e JONHSON, 2005). Essa unidade é usada para medir a quantidade de energia produzida pelos macronutrientes dos alimentos.

* Parcialmente correta: o conceito citado sem a relação com os alimentos.

* Incorreta: referência em desacordo com o conceito.

Também em relação ao conceito de caloria, foi investigado o conhecimento sobre a necessidade diária de energia para um indivíduo, sendo considerado:

Correta: a necessidade de energia de um individuo é o nível de ingestão de macronutrientes proveniente dos alimentos que se transforma em energia que irá equilibrar o gasto de energia 
quando o indivíduo possui um tamanho e composição corporal e nível de atividade física consistente com a boa saúde a longo prazo; e que irá levar em consideração a manutenção da atividade, considerando os aspectos fisiológicos, idade, sexo, estado hormonal e estado de saúde (FRARY e JONHSON, 2005).

* Parcialmente correta: a referência utilizada para cálculo do VD (Valor Diário) de referência da informação nutricional do rótulo de produtos alimentícios (MINISTÉRIO DA SAÚDE, 2001; MINISTÉRIO DA SAÚDE, 2003).

* Incorreta: referência em desacordo com o conceito.

- Conhecimento do conceito de alimentação saudável

Baseada na resposta sobre alimentação saudável, foi realizada a seguinte classificação:

* Correta: alimentação variada, com a presença de alimentos dos vários grupos da pirâmide alimentar adaptada, respeitando-se as porções de cada um dos grupos alimentares, distribuídas de forma adequada durante o dia (PHILIPPI e col., 1999).

* Parcialmente correta: referência incompleta em relação ao conceito.

* Incorreta: referência em desacordo com o conceito.

\section{- Fontes de informação sobre alimentação e nutrição}

As referências sobre as fontes de informação de alimentação e nutrição foram medidas quantitativamente e agrupadas segundo composição e equivalência:

* Meio escrito: revistas, jornais e livros.

* Meio audiovisual: televisão, rádio e meio eletrônico.

Meio pessoal: família, amigos, médicos e nutricionistas.

Meio formal: ensino médio ou superior, profissão ou formação.

Meio instrumental: valor energético das preparações culinárias 
oferecidas nos restaurantes universitários e rótulo de embalagem de alimentos.

\subsection{4 - Variáveis de comportamento}

Adotou-se o modelo transteorético para classificar o comportamento dos indivíduos, utilizando-se a combinação das respostas das questões 21 e 23, para classificar o comportamento em relação ao rótulo de embalagem de alimentos nos aspectos de hábito de leitura dessas informações e a interferência destas na aquisição de produtos alimentícios. E, as de número 24 e 26 para a atitude em relação à informação sobre o valor energético das preparações culinárias servidas nos restaurantes, em relação a observar essa informação e a interferência desta no momento de escolha dessa preparação, conforme apresentado no Quadro 5.

Foi verificado haver relação entre a classificação do comportamento dos participantes e as variáveis socioeconômicas, de saúde e de conduta/ conhecimento. 
Quadro 5 - Critério para classificação de comportamento dos entrevistados, segundo modelo transteorético.

\begin{tabular}{|c|c|c|}
\hline \multicolumn{2}{|c|}{ Questão } & \multirow{3}{*}{ Classificação do comportamento } \\
\hline \multicolumn{2}{|c|}{ Número } & \\
\hline $21 / 24$ & $23 / 26$ & \\
\hline Sim & Sim & $\begin{array}{l}\text { Manutenção (comportamento referido } \\
\text { por mais de um ano) }\end{array}$ \\
\hline Sim & Sim & $\begin{array}{l}\text { Ação (comportamento inferior a um } \\
\text { ano) }\end{array}$ \\
\hline Sim & Não & Contemplação \\
\hline Sim & Às vezes & Preparação \\
\hline Não & Não & Pré-contemplação \\
\hline Às vezes & Sim & Preparação \\
\hline Às vezes & Não & Contemplação \\
\hline Às vezes & Às vezes & Preparação \\
\hline
\end{tabular}

\section{8 - ANÁLISE ESTATÍSTICA}

Foram realizadas análises de proporções para verificar diferenças entre as variáveis quanto a sexo, idade e anos de estudo entre as entrevistas realizadas pessoalmente e posteriormente (pessoalmente ou por telefone) nos dois estratos para se verificar a similaridade no perfil dos entrevistados.

As variáveis de estudo foram analisadas de forma descritiva por meio de freqüências absoluta, relativa e medidas de tendência central e dispersão para idade e IMC.

Para verificar a relação entre as variáveis de estudo, foi realizado o teste de $x^{2}$ (Qui-quadrado) com nível de significância de 5\% para o teste estatístico.

\section{9 - MATERIAL INFORMATIVO ENCAMINHADO AOS ENTREVISTADOS}

Foi enviado, por meio físico ou eletrônico, a cada um dos participantes do 
estudo, agradecimento pela participação na pesquisa (Anexo VI), acompanhado pelo valor do IMC calculado e orientações básicas sobre alimentação e nutrição (Anexo VII e VIII).

\subsection{0 - ASPECTOS ÉTICOS}

A pesquisa foi aprovada pelo Comitê de Ética da Faculdade de Saúde Pública, conforme Resolução 196 (CONSELHO NACIONAL DE SAÚDE, 1996) (Anexo IX).

Clientes dos restaurantes da Coseas que solicitaram informações adicionais sobre alimentação e nutrição foram encaminhados aos serviços oferecidos pela própria Universidade. 


\section{4 - RESULTADOS}




\section{1 - RESULTADO DAS ENTREVISTAS}

Foram realizadas 942 entrevistas, sendo 483 de "funcionários" e 459 de "alunos", representando 80,5\% do estrato de "funcionários" e 76,5\% do estrato de "alunos".

A maior concentração de indivíduos selecionados para o estudo freqüentava o restaurante Central, uma vez que esta unidade oferece maior número de refeições. Entretanto, conforme se observa na Tabela 1, a unidade da Física contribuiu com expressivo número de alunos selecionados e interessados pela pesquisa e pelo assunto. Entre os "funcionários", não foi observado o mesmo interesse, ao contrário, a perda amostral foi superior.

De modo geral, o número de entrevistas não efetivadas, por perdas ou recusas, foi superior entre os "alunos".

Tabela 1 - Distribuição dos indivíduos selecionados, segundo estrato e restaurante. São Paulo, 2005.

\begin{tabular}{lcccccccc}
\hline \multirow{2}{*}{ Restaurantes } & \multicolumn{3}{c}{ Entrevistas efetivadas } & \multicolumn{3}{c}{ Perdas da amostra } \\
\cline { 2 - 9 } & \multicolumn{1}{c}{ Funcionários } & \multicolumn{2}{c}{ Alunos } & \multicolumn{2}{c}{ Funcionários } & \multicolumn{2}{c}{ Alunos } \\
\cline { 2 - 9 } & FA & FR & FA & FR & FA & FR & FA & FR \\
\hline Central & 247 & 41,2 & 206 & 34,3 & 95 & 15,8 & 102 & 17,0 \\
Física & 77 & 12,8 & 191 & 31,8 & 4 & 0,7 & 33 & 5,5 \\
EE & 69 & 11,5 & 42 & 7,0 & 10 & 1,7 & 6 & 1,0 \\
FSP & 90 & 15,0 & 20 & 3,3 & 8 & 1,3 & - & - \\
\hline Total & 483 & 80,5 & 459 & 76,4 & 117 & 19,5 & 141 & 23,5 \\
\hline
\end{tabular}

FA - freqüência absoluta

FR - freqüência relativa' 


\section{2 - MATERIAL INFORMATIVO ENCAMINHADO AOS ENTREVISTADOS}

Os agradecimentos pela participação na entrevista foram acompanhados do valor do IMC calculado, bem como informações e orientações básicas sobre alimentação e nutrição aos entrevistados, no mês de julho de 2005. Foi possível encaminhar para 95,2\% do estrato de "funcionários" e 91,2\% para o estrato de "alunos", uma vez que muitos não foram encontrados.

"Alunos" retribuíram os agradecimentos, solicitando serviços gratuitos que oferecessem informações sobre o assunto, e os "funcionários", na maioria docente, ressaltando a importância de assuntos dessa natureza.

\section{3 - CARACTERÍSTICA DA POPULAÇÃO DE ESTUDO}

Foram realizadas as análises de proporções das variáveis, sexo, idade, anos de estudo formal e as variáveis de comportamento, entre aqueles que foram entrevistados no momento imediatamente após o almoço e posteriormente, nos dois estratos, não tendo sido verificada diferença estatística entre "funcionários", somente entre os "alunos". Desse modo, o grupo de "funcionários" foi constituído por 483 indivíduos, sendo uma amostra representativa e o de "alunos" por 420 indivíduos, uma amostra não representativa.

\subsection{1 - Descrição das variáveis demográficas e socioeconômicas \\ - Sexo e idade}

Conforme se verifica na Tabela 2, a maioria dos indivíduos foi composta por homens nos dois estratos. O valor médio da idade dos "funcionários" foi de 40,4 anos, para ambos os sexos $(\mathrm{DP}=10,63$ para homens e $\mathrm{DP}=10,10$ para 
mulheres). Entre os "alunos", a média foi de 22,6 (DP=5,41) e 22,8 (DP=5,07) anos respectivamente, para os indivíduos do sexo masculino e feminino.

No estrato de "alunos", a maioria dos homens encontrava-se no restaurante da Física, seguido do restaurante Central, enquanto entre as mulheres o fato se inverte sendo a maior concentração no restaurante Central, seguido do restaurante da Física. Essa distribuição de sexo pode ser explicada pelo fato do restaurante da Física estar localizado no Instituto de Física, próximo ao complexo da Politécnica e rodeado pelos Institutos de Eletrotécnica e Energia (IEE), Astronômico e Geofísico (IAG), de Matemática e Estatística (IME) e Oceanográfico que ministram cursos tradicionalmente com maior presença masculina (Anexo X).

Por sua vez, a localização do restaurante Central é próxima à Faculdade de Educação, Educação Física, Instituto de Estudos Brasileiros, Faculdade de Filosofia, Letras e Ciências Humanas (FFLCH), Instituto de Psicologia e Escola de Comunicação e Artes (ECA) que ministram cursos tradicionalmente com maior presença feminina (Anexo X).

Os restaurantes FSP e EE participaram da pesquisa com aproximadamente o mesmo número absoluto de indivíduos, 109 e 110 respectivamente, para o restaurante FSP e EE. Esses dois restaurantes caracterizam-se por predominância de mulheres nos dois estratos, com maior participação de "funcionários" sendo, 82,6\% $(\mathrm{n}=90)$ e $62,7 \% \quad(\mathrm{n}=69)$ para FSP e EE, respectivamente, do que de "alunos" na representação da amostra.

\section{- Ocupação e escolaridade}

Os "funcionários", identificados por nível básico, eram, em sua maioria, motoristas entre os homens e, entre as mulheres, auxiliares de serviços 
gerais. No nível técnico, as funções mais referidas pelos homens foram técnico administrativo e de informática e, entre as mulheres, secretária, técnica acadêmica e administrativa. Os indivíduos que exerciam as funções de nível superior mais encontradas entre os homens que freqüentavam os restaurantes foram de especialista de laboratório e engenheiro e entre o sexo feminino, bibliotecária.

A maioria dos "alunos" que freqüentava os restaurantes da Coseas encontrava-se cursando graduação; os homens, na área de ciências exatas (cursos de engenharia e física) e as mulheres, biológicas (cursos de psicologia e odontologia). 
Tabela 2 - Distribuição dos indivíduos entrevistados, segundo estrato e características sócio-demográficas. São Paulo, 2005.

\begin{tabular}{|c|c|c|c|c|c|c|c|c|}
\hline \multirow[t]{5}{*}{ Classificação } & \multicolumn{4}{|c|}{ Funcionários } & \multicolumn{4}{|c|}{ Alunos } \\
\hline & \multicolumn{4}{|c|}{ Sexo } & \multicolumn{4}{|c|}{ Sexo } \\
\hline & \multirow{2}{*}{\multicolumn{2}{|c|}{$\frac{\text { masculino }}{n=270}$}} & \multirow{2}{*}{\multicolumn{2}{|c|}{$\begin{array}{c}\text { feminino } \\
\mathrm{n}=213\end{array}$}} & \multirow{2}{*}{\multicolumn{2}{|c|}{$\frac{\text { masculino }}{n=269}$}} & \multirow{2}{*}{\multicolumn{2}{|c|}{$\begin{array}{c}\text { feminino } \\
\mathrm{n}=151\end{array}$}} \\
\hline & & & & & & & & \\
\hline & FA & FR & FA & FR & FA & FR & FA & FR \\
\hline \multicolumn{9}{|l|}{-Idade (anos): } \\
\hline $20-40$ & 134 & 49,6 & 110 & 51,6 & 265 & 98,5 & 147 & 97,3 \\
\hline $41-60$ & 127 & 47,0 & 95 & 44,6 & 4 & 1,5 & 4 & 2,6 \\
\hline 61 e mais & 9 & 3,3 & 8 & 3,7 & - & - & - & - \\
\hline \multicolumn{9}{|l|}{ - Restaurante } \\
\hline Central & 157 & 58,1 & 90 & 42,2 & 113 & 42,0 & 62 & 41,1 \\
\hline Física & 53 & 19,6 & 24 & 11,3 & 145 & 53,9 & 40 & 26,5 \\
\hline FSP & 34 & 12,6 & 56 & 26,3 & 6 & 2,2 & 13 & 8,6 \\
\hline $\mathrm{EE}$ & 26 & 9,6 & 43 & 20,2 & 5 & 1,9 & 36 & 23,8 \\
\hline \multicolumn{9}{|l|}{ •Ocupação } \\
\hline Básico & 104 & 38,5 & 63 & 29,6 & - & - & - & - \\
\hline Técnico & 118 & 43,7 & 106 & 49,8 & - & - & - & - \\
\hline Superior & 34 & 12,6 & 29 & 13,6 & - & - & - & - \\
\hline Docente & 14 & 5,2 & 15 & 7,0 & - & - & - & - \\
\hline \multicolumn{9}{|l|}{ •Curso } \\
\hline Graduação & - & - & - & - & 224 & 83,3 & 124 & 82,1 \\
\hline \multicolumn{9}{|l|}{ •Área do curso } \\
\hline Ciências Humanas & - & - & - & - & 63 & 23,4 & 47 & 31,1 \\
\hline Ciências Exatas & - & - & - & - & 168 & 62,5 & 34 & 22,5 \\
\hline Ciências & - & - & - & - & 38 & 14,1 & 70 & 46,3 \\
\hline \multicolumn{9}{|l|}{ Biológicas } \\
\hline - Escolaridade & & & & & & & & \\
\hline Fundamental & 29 & 10,7 & 16 & 7,5 & - & - & - & - \\
\hline Médio & 121 & 44,8 & 74 & 34,7 & - & - & - & - \\
\hline Superior & 120 & 44,4 & 123 & 57,7 & 269 & 100,0 & 151 & 100,0 \\
\hline
\end{tabular}

FA - freqüência absoluta

FR - freqüência relativa

\subsection{2 - Descrição das variáveis de saúde}

- IMC

Não foi possível o cálculo do IMC de cinco indivíduos, devido à falta de 
informação de peso ou estatura.

As médias de IMC e o desvio padrão no estrado de "funcionários", tanto para homens como para mulheres, foram superiores em relação ao estrato de "alunos".

Os valores médios de IMC $\left(\mathrm{kg} / \mathrm{m}^{2}\right)$ mostraram-se diferentes entre os estratos. Entre os "funcionários" do sexo masculino $\left(25,81 \mathrm{~kg} / \mathrm{m}^{2}\right.$ e $\left.\mathrm{DP}=3,58 \mathrm{~kg} / \mathrm{m}^{2}\right)$ apresentou-se superior e do feminino $\left(24,81 \mathrm{~kg} / \mathrm{m}^{2}\right.$ e $\left.\mathrm{DP}=4,67 \mathrm{~kg} / \mathrm{m}^{2}\right)$ adequado. Os "alunos" apresentaram valores inferiores aos "funcionários" $\left(23,15 \mathrm{~kg} / \mathrm{m}^{2}\right.$ e $\mathrm{DP}=2,99 \mathrm{~kg} / \mathrm{m}^{2}$ para homens $)$ e $\left(21,71 \mathrm{~kg} / \mathrm{m}^{2}\right.$ e $\mathrm{DP}=3,04$ $\mathrm{kg} / \mathrm{m}^{2}$ para mulheres).

Como se observa na Tabela 3, encontrou-se maior prevalência de indivíduos com excesso de peso entre os "funcionários" do sexo masculino. Maiores proporções de "funcionários" do sexo feminino e "alunos", de ambos os sexos, apresentaram valores de IMC que foram classificados com peso adequado.

No estrato de "funcionários", constatou-se a presença de 10 indivíduos com IMC $\geq 40 \mathrm{~kg} / \mathrm{m}^{2}$, sendo superior entre as mulheres $(2,8 \% \mathrm{n}=6)$. Entre os "alunos" não foram observados indivíduos com essa classificação de IMC.

Foi observado maior número de indivíduos com baixo peso no estrato de "alunos", sendo superior entre as mulheres nos dois estratos.

No presente estudo, foi observada associação $\left(x^{2}=55,344 \mathrm{p}=0,000\right)$ entre IMC e escolaridade, sendo que $54,8 \%$ da população estudada, que têm ensino fundamental, apresentaram excesso de peso e 69,1\%, que têm ensino 
superior, foram classificados como peso adequado.

Tabela 3 - Distribuição dos participantes, segundo estrato, sexo e IMC. São Paulo, 2005.

\begin{tabular}{lcccccccc}
\hline Classificação & \multicolumn{4}{c}{ Funcionários } & \multicolumn{4}{c}{ Alunos } \\
\cline { 2 - 9 } IMC $\left(\mathrm{kg} / \mathrm{m}^{2}\right)$ & \multicolumn{4}{c}{ Sexo } & Mexo \\
& Masculino & Feminino & Masculino & Feminino \\
\cline { 2 - 9 } & FA & FR & FA & FR & FA & FR & FA & FR \\
\hline Baixo peso & 1 & 0,4 & 7 & 3,3 & 8 & 3,0 & 15 & 10,0 \\
Peso adequado & 124 & 46,3 & 124 & 58,5 & 201 & 75,0 & 116 & 77,3 \\
Excesso de peso & 143 & 53,4 & 81 & 38,2 & 59 & 22,0 & 19 & 12,7 \\
\hline Total & 268 & 100 & 212 & 100 & 268 & 100 & 150 & 100 \\
\hline
\end{tabular}

FA - freqüência absoluta

FR - freqüência relativa

\section{- Referência de "controle de peso"}

De modo geral, as representantes do sexo feminino, de ambos estratos, mostraram maior preocupação com o controle de peso corporal do que os do sexo masculino, uma vez que 37,5\% (n=80) do estrato de "funcionários" e $27,1 \%(n=41)$ de "alunos" informaram controlar o peso. Os homens $(67,4 \%$ n=182 para "funcionários" e 77,3\% n=208 para “alunos), por sua vez, alegaram ser "desnecessário" ou "difícil" controlar o peso.

Verifica-se que a referência de "não fazer controle de peso" passa a ser preocupante, principalmente entre os homens no estrato de "funcionários", uma vez que mais da metade apresentou excesso de peso $(53,3 \% n=143)$.

\section{- Referência de ausência de doença}

A proporção de indivíduos que referiu presença de doença foi maior entre o 
estrato de "funcionários" $(36,4 \% \mathrm{n}=180)$ do que entre "alunos" $(19,0 \% \mathrm{n}=80)$ (Tabela 4). Esse fato pode ser devido à relação com a idade, no estrato de "funcionários" a idade média foi de 40,4 anos, enquanto entre os "alunos" foi de 22,7 anos.

Tabela 4 - Distribuição dos participantes, segundo estrato, sexo e referência de doença. São Paulo, 2005.

\begin{tabular}{|c|c|c|c|c|c|c|c|c|}
\hline \multirow[t]{4}{*}{ Referência } & \multicolumn{4}{|c|}{ Funcionários } & \multicolumn{4}{|c|}{ Alunos } \\
\hline & \multicolumn{4}{|c|}{ Sexo } & \multicolumn{4}{|c|}{ Sexo } \\
\hline & \multicolumn{2}{|c|}{ Masculino } & \multicolumn{2}{|c|}{ Feminino } & \multicolumn{2}{|c|}{ Masculino } & \multicolumn{2}{|c|}{ Feminino } \\
\hline & FA & FR & FA & FR & FA & FR & FA & FR \\
\hline $\begin{array}{l}\text { Sem referência } \\
\text { de doença }\end{array}$ & 182 & 67,4 & 121 & 56,8 & 223 & 83,0 & 117 & 77,5 \\
\hline D50-Anemia & - & - & 2 & 2,2 & 1 & 2,2 & 6 & 17,6 \\
\hline $\begin{array}{l}\text { E03- } \\
\text { Hipotiroidismo }\end{array}$ & - & - & 2 & 2,2 & - & - & - & - \\
\hline E10-Diabete & 15 & 17,0 & 7 & 7,6 & 5 & 10,9 & 2 & 5,9 \\
\hline E66-Obesidade & - & - & 5 & 5,4 & - & - & - & - \\
\hline E73- & - & - & 1 & 1,1 & - & - & - & - \\
\hline $\begin{array}{l}\text { Intolerância à } \\
\text { lactose }\end{array}$ & & & & & & & & \\
\hline $\begin{array}{l}\text { E74-Triglicéride } \\
\text { elevado }\end{array}$ & 1 & 1,1 & - & - & - & - & - & - \\
\hline $\begin{array}{l}\text { E75-Colesterol } \\
\text { elevado }\end{array}$ & 30 & 34,1 & 22 & 23,9 & 2 & 4,3 & 6 & 17,6 \\
\hline $\begin{array}{l}\text { G72-Dor na } \\
\text { coluna }\end{array}$ & 10 & 11,4 & 6 & 6,5 & 8 & 17,4 & 4 & 11,8 \\
\hline I15-Hipertensão & 22 & 25,0 & 21 & 22,8 & 6 & 13,0 & - & - \\
\hline I95-Hipotensão & - & - & 1 & 1,1 & 1 & 2,2 & 3 & 8,8 \\
\hline K29-Gastrite & 3 & 3,4 & - & - & 2 & 4,3 & 3 & 8,8 \\
\hline Outros & 7 & 8,0 & 25 & 27,2 & 21 & 45,7 & 10 & 29,4 \\
\hline Total & 270 & 100 & 213 & 100 & 269 & 100 & 151 & 100 \\
\hline
\end{tabular}

FA - freqüência absoluta

FR - freqüência relativa 


\section{- Prática de atividade física esportiva}

Conforme demonstrado na Tabela 5, os homens, de ambos estratos, mostraram-se menos sedentários que as mulheres. Os "alunos", do sexo masculino, informaram ser mais ativos que as mulheres, com $46,5 \%$ de ativos e $21,5 \%$ de muito ativos, enquanto entre as mulheres $58,9 \%$ foram classificadas como sedentárias.

Foi detectada semelhança entre atividade física esportiva referida por homens e mulheres do estrato de "funcionários", uma vez que as maiores proporções de indivíduos encontradas foram para caminhada (31,8\% e $56,5 \%$, respectivamente para o sexo masculino e feminino).

As mulheres, de ambos estratos, ao contrário dos homens, informaram não participar de atividades físicas esportivas coletivas (futebol, vôlei, entre outras).

Verificou-se que, em ambos os estratos e ambos os sexos, a maior freqüência referida para as atividades físicas foi de duas a três vezes por semana e com duração de até uma hora.

$\mathrm{Na}$ presente pesquisa, observou-se que, embora as mulheres tenham apresentado preocupações em relação à saúde e referir fazer "controle de peso", a atividade física esportiva não faz parte dos instrumentos para atingir esses objetivos. Porém, não foram investigados os motivos que levam os indivíduos serem mais sedentários.

Foi observada associação entre atividade física e escolaridade $\left(x^{2}=10,868\right.$ p=0,028), sendo que 56,8\% da população, que têm o ensino fundamental, foram classificados como indivíduos sedentários, e 55,7\%, que têm ensino 
superior, foram classificados como indivíduos ativos.

Tabela 5 - Distribuição dos participantes, segundo estrato, sexo e nível de atividade física esportiva. São Paulo, 2005.

\begin{tabular}{lcccccccc}
\hline Nível de & \multicolumn{4}{c}{ Funcionários } & \multicolumn{4}{c}{ Alunos } \\
\cline { 2 - 9 } $\begin{array}{l}\text { atividade física } \\
\text { esportiva }\end{array}$ & \multicolumn{4}{c}{ Sexo } & Mexo \\
& Masculino & Feminino & Masculino & Feminino \\
\cline { 2 - 9 } & FA & FR & FA & FR & FA & FR & FA & FR \\
\hline Sedentário & 119 & 44,1 & 121 & 56,8 & 86 & 32,0 & 89 & 58,9 \\
Ativo & 79 & 29,2 & 55 & 25,8 & 125 & 46,5 & 50 & 33,1 \\
Muito ativo & 72 & 26,7 & 37 & 17,4 & 58 & 21,5 & 12 & 8,0 \\
\hline Total & 270 & 100 & 213 & 100 & 269 & 100 & 151 & 100 \\
\hline
\end{tabular}

FA - freqüência absoluta

FR - freqüência relativa

\subsection{3 - Descrição das variáveis de conduta/conhecimento}

- Referência de freqüência de utilização dos restaurantes universitários

No estrato de "funcionários", a maioria dos indivíduos $(77,0 \%$, n=208 de homens e 79,3\%, n=169 de mulheres) começou a utilizar os restaurantes universitários antes de agosto de 2001. Deste estrato, grande número (76,3\%, $\mathrm{n}=206$ dos homens e 66,7\%, n=142 das mulheres) utilizava o restaurante quatro vezes ou mais por semana.

Entre os "alunos", o perfil se modifica, pois a maioria $(81,8 \% \mathrm{n}=220$ dos homens e $82,8 \% \mathrm{n}=125$ das mulheres) começou a utilizar o restaurante depois de agosto de 2001. Esse fato, pode ser devido à atividades que os "alunos" desenvolvem, em princípio, por período determinado na Universidade. A exemplo do verificado entre "funcionários", a maioria utilizava o restaurante 
quatro vezes ou mais por semana $(65,1 \% n=175$ dos homens e 58,9\% $n=89$ das mulheres), porém sendo menor o uso, em termos relativos, ao estrato de "funcionários". Os homens, nos dois estratos, utilizavam com maior freqüência os restaurantes universitários.

- Referência de aquisição de produtos alimentícios e leitura de informação nutricional

A maioria dos indivíduos, nos dois estratos, informou participar na aquisição de alimentos. Entretanto, a proporção de mulheres do estrato de "funcionários" que compra alimentos foi maior que qualquer outro grupo, isto é, 95,3\% ou 203 mulheres. É possível que, por esse motivo, foram também as mulheres desse estrato que informaram estar habituadas a ler o rótulo dos alimentos adquiridos no mercado $(65,7 \% \mathrm{n}=140)$. Os homens, nos dois estratos, prescindem da leitura de rótulos.

Interessante verificar que a justificativa para leitura de rótulo de embalagem de alimentos é diferente entre estrato e sexo: homens do estrato de "funcionários" preocupam-se com a validade e, mulheres, com a lista de ingredientes do produto. Os "alunos", por sua vez, estão interessados na informação nutricional dos produtos.

Aqueles que referiram "às vezes ler o rótulo de alimentos", o fizeram apenas com os produtos "que não conhecem" no estrato "funcionários" e entre os "alunos", o motivo foi "curiosidade".

As informações nutricionais presentes no rótulo de produtos alimentícios foram observadas por $68,1 \%(n=184)$ dos homens e $84,0 \% \quad(n=179)$ de mulheres no estrato de "funcionários". Também entre os "alunos", essa referência foi expressiva $(75,5 \% \mathrm{n}=203$ dos homens e 88,1\% $\mathrm{n}=133$ das 
mulheres). Verificando-se que a prevalência entre as mulheres foi maior nos dois estratos.

A informação mais observada foi "validade" $(70,6 \% n=130$ dos homens e $67,0 \% \mathrm{n}=120$ das mulheres), seguida de "lista de ingredientes do produto" (14,3\% n=27 dos homens e 13,4\% n=24 das mulheres), respectivamente para os "funcionários". Porém, entre os "alunos", foi "informação de calorias" $(33,1 \% n=52$ para homens e $42,7 \% n=47$ para mulheres) e "validade" $(28,7 \%$ $n=45$ entre os homens e $40,9 \% n=45$ para mulheres).

Observou-se que, na compreensão dos indivíduos entrevistados nesta pesquisa, a validade é uma informação nutricional.

Apesar da elevada percentagem de indivíduos que referiram ler a informação nutricional dos rótulos de embalagem de alimentos, a interferência na compra ou consumo foi inferior.

Entre os homens e mulheres que referiram que a informação nutricional interfere na sua escolha $(43,7 \% n=80$ de homens e 55,6 n=99 de mulheres), os maiores motivos foram "escolher alimentos com menor quantidade de calorias" e "escolher alimentos mais ricos em nutrientes", demonstrando uma preocupação qualitativa na escolha do alimento.

No caso da informação do valor energético das preparações culinárias oferecidas pelos restaurantes, foi menos observada do que as informações do rótulo de produtos alimentícios nos dois estratos $(61,5 \% \mathrm{n}=166$ dos homens e 68,1\% n=145 das mulheres no estrato de "funcionários" e 50,6\% n=136 dos homens e 59,6\% n=90 das mulheres no estrato de "alunos"). Observa-se que esta referência foi maior entre os "funcionários" e entre as mulheres dos dois 
estratos.

Não houve significância estatística entre o tempo e freqüência de uso dos restaurantes universitários e observar a informação do valor energético das preparações oferecidas pelos restaurantes.

Os "funcionários" justificaram o fato para "ter idéia do que estavam consumindo" (48,8\% n=81 dos homens e 57,2\% n=83 das mulheres), seguido de "a informação estar localizada na frente do balcão" (25,9\% n= 43 dos homens e 17,9\% $\mathrm{n}=26$ das mulheres). Os "alunos" justificaram por "curiosidade" (44,9\% n=61 dos homens e 31,1\% n=28 das mulheres). Em termos qualitativos, houve interesse maior dos "funcionários" em relação à essa informação.

A "falta de interesse pelo assunto" foi a maior justificativa para o fato de não observar essa informação nos restaurantes, nos dois estratos. Entre os "funcionários", os homens referiram que a "aparência" da preparação é que interfere na aquisição.

As mulheres, por sua vez, referiram que a informação interfere na sua escolha, para "substituir ou diminuir a quantidade de preparação" oferecida.

Entre os "alunos", 78\% referiram que a informação não interfere, pois "serve sempre a mesma quantidade" ou "apenas o que tem vontade".

\section{- Conhecimento do conceito de caloria}

A maioria dos indivíduos entrevistados considera a informação de caloria importante $(83,3 \% \mathrm{n}=225$ dos homens e 93,0\% $\mathrm{n}=198$ das mulheres para "funcionários" e 71,4\% n=192 dos homens e 86,1\% n=130 das mulheres para 
“alunos").

Para os "funcionários", a informação é importante para "poder controlar o peso" (44,0\% n=99 dos homens e 50,0\% n=99 das mulheres). Embora os "alunos" tenham referido que a informação de caloria é importante, a justificativa demonstrou pouca utilização em termos pessoais, uma vez que esse grupo considera que a informação é importante "para quem faz dieta ou tem restrições com alimentos" (40,6\% n=78 dos homens e 42,0\% n=55 das mulheres).

A maioria dos indivíduos que referiu não considerar a informação de caloria importante, justificou por "não ter problemas de saúde" entre os "funcionários" e "alunos", porém, as mulheres do estrato de "alunos" "consideraram que essa informação sozinha não é importante", demonstrando haver uma preocupação maior para outros tipos de informação.

Os indivíduos consideraram que a informação de valor energético das preparações culinárias oferecidas nos restaurantes universitários é suficiente e está disposta de forma visível. No entanto, manifestaram interesses sobre o assunto. Os "funcionários" referiram ter interesse em "informações gerais sobre saúde", sendo a maior referência para informações básicas sobre alimentação e nutrição. Para os "alunos", os interesses se mostraram mais específicos sobre os "macronutrientes dos alimentos", principalmente tipos de carboidratos e proteínas, seguido de informações mais específicas sobre os tipos de gorduras como ácidos graxos trans e gorduras saturadas e insaturadas. Além disso, foram feitas sugestões para motivar o maior uso dessa informação, por meio de cartazes e a distribuição de panfletos com informações, além do valor energético, outras informações sobre alimentação 
e nutrição.

A maioria dos indivíduos que referiu conhecer conceito de caloria em ambos estratos $(67,4 \% n=182$ dos homens e $68,5 \% n=146$ das mulheres no estrato de "funcionários" e 85,5\% n=230 dos homens e 82,1\% n=124 das mulheres no estrato de "alunos").

Entretanto, de acordo com a Tabela 6, a maioria dos indivíduos, no estrato de "funcionários", em ambos os sexos, referiu de forma incorreta o conceito, relacionando o conceito somente em relação ao teor de gorduras dos alimentos. Entre os "alunos", a maioria respondeu parcialmente ao conceito, sendo a maior referência para definição física do termo, sem qualquer relação com os alimentos.

Entre aqueles que responderam corretamente ao conceito de caloria, houve prevalência entre as mulheres, conforme Tabela 6.

Tabela 6 - Distribuição dos participantes, segundo estrato, sexo e classificação da resposta em relação ao conceito de caloria. São Paulo, 2005.

\begin{tabular}{lcccccccc}
\hline & \multicolumn{3}{c}{ Funcionários } & \multicolumn{5}{c}{ Alunos } \\
\hline Classificação das & \multicolumn{4}{c}{ Sexo } & \multicolumn{5}{c}{ Sexo } \\
\cline { 2 - 9 } respostas & \multicolumn{3}{c}{ Masculino } & Feminino & Masculino & Feminino \\
\cline { 2 - 9 } & FA & FR & FA & FR & FA & FR & FA & FR \\
\hline Incorreto & 94 & 51,6 & 77 & 52,7 & 44 & 19,1 & 36 & 29,0 \\
Parcialmente & 70 & 38,5 & 58 & 39,7 & 169 & 73,5 & 75 & 60,5 \\
correto & & & & & & & & \\
Correto & 18 & 9,9 & 11 & 8,5 & 17 & 7,4 & 13 & 10,5 \\
\hline Total & 182 & 100 & 146 & 100 & 230 & 100 & 124 & 100 \\
\hline
\end{tabular}

FA - freqüência absoluta

FR - freqüência relativa 
Também foi verificada maior prevalência entre os "alunos" e as mulheres nos dois estratos que referiram saber a quantidade de calorias fornecidas pelos alimentos que são necessárias para um indivíduo, por dia $(47,0 \%$ n=127 dos homens e $68,1 \%$ n=145 das mulheres e entre os "funcionários" e 71,4\% n=192 dos homens e $85,0 \% n=108$ das mulheres entre os "alunos").

Observou-se que entre aqueles que responderam incorretamente o fizeram por informar valores superiores a $3.000 \mathrm{kcal}$ ou inferiores a $100 \mathrm{kcal}$.

Entre os que a resposta foi classificada como parcialmente correta, utilizaram a referência de $2.500 \mathrm{kcal}$, que é o valor diário utilizado para o cálculo das percentagens de nutrientes nos rótulos de produtos alimentícios (MINISTÉRIO DA SAÚDE, 2001).

Entre os que responderam corretamente sobre a quantidade necessária de calorias para um indivíduo, verificou-se que foi maior a prevalência entre mulheres.

\section{- Conhecimento do conceito de alimentação saudável}

Como se observa na Tabela 7, em termos relativos, foi maior a prevalência de indivíduos que referiram conhecer o conceito de alimentação saudável do que o conceito de calorias $(95,2 \% \mathrm{n}=257$ dos homens e 95,8\% $\mathrm{n}=204$ das mulheres no estrato de "funcionários" e 91,4\% n=246 dos homens e 98,0\% $\mathrm{n}=148$ das mulheres no estrato de "alunos").

No entanto, ao solicitar exemplo de alimentação saudável, foi grande o número de indivíduos que não souberam responder corretamente. A prevalência das respostas foi basicamente em relação ao teor de gordura de uma alimentação, sendo superior entre os homens dos dois estratos e entre os "funcionários". 
Entre os homens houve pouca referência às frutas, verduras e legumes na alimentação, diferente das mulheres.

Tabela 7 - Distribuição dos participantes, segundo estrato, sexo e classificação da resposta em relação ao conceito de alimentação saudável. São Paulo, 2005.

\begin{tabular}{lcccccccc}
\hline Classificação das & \multicolumn{4}{c}{ Funcionários } & \multicolumn{5}{c}{ Alunos } \\
\cline { 2 - 9 } respostas & \multicolumn{4}{c}{ Sexo } & \multicolumn{5}{c}{ Sexo } \\
& Masculino & Feminino & Masculino & Feminino \\
\cline { 2 - 10 } & FA & FR & FA & FR & FA & FR & FA & FR \\
\hline Incorreto & 131 & 51,0 & 61 & 29,9 & 103 & 41,9 & 53 & 35,8 \\
Parcialmente & 110 & 42,8 & 125 & 61,3 & 133 & 54,1 & 83 & 56,1 \\
correto & 16 & 6,2 & 18 & 8,8 & 10 & 4,1 & 12 & 8,1 \\
Correto & 257 & 100 & 204 & 100 & 246 & 100 & 148 & 100 \\
\hline Total & & & & & & & & \\
\hline
\end{tabular}

FA - freqüência absoluta

FR - freqüência relativa

- Fontes de informação sobre alimentação e nutrição

A maior prevalência foi para indivíduos que referiram até duas fontes de informação, conforme se verifica na Tabela 8, porém entre as mulheres foi maior a prevalência para mais de três fontes de informação sobre o assunto. 
Tabela 8 - Distribuição dos participantes, segundo estrato, sexo e quantidade de fontes de informação sobre alimentação e nutrição. São Paulo, 2005.

\begin{tabular}{lcccccccc}
\hline Quantidade de & \multicolumn{4}{c}{ Funcionários } & \multicolumn{5}{c}{ Alunos } \\
\cline { 2 - 9 } fontes de \\
informação & \multicolumn{4}{c}{ Sexo } & \multicolumn{5}{c}{ Sexo } \\
& Masculino & Feminino & Masculino & Feminino \\
\cline { 2 - 10 } & FA & FR & FA & FR & FA & FR & FA & FR \\
\hline Nenhuma & 7 & 2,6 & 11 & 5,2 & 10 & 3,7 & 11 & 7,3 \\
1 a 2 fontes & 193 & 71,5 & 117 & 54,9 & 179 & 66,5 & 73 & 48,3 \\
3 e mais & 70 & 25,9 & 85 & 39,9 & 80 & 29,7 & 67 & 44,4 \\
\hline Total & 270 & 100 & 213 & 100 & 269 & 100 & 151 & 100 \\
\hline
\end{tabular}

FA - freqüência absoluta

FR - freqüência relativa

O meio audiovisual foi o mais referido no estrato de "funcionários" e o meio escrito no estrato de "alunos", conforme Tabela 9. Vale ressaltar que entre o sexo feminino, $45,6 \%(n=62)$ das referências ao meio audiovisual foram em relação à internet e 61,2\% (n=60) das referências ao meio pessoal foram para profissionais da área (médicos e nutricionistas), no estrato de "funcionários.

Surpreendentemente, não foi observada maior prevalência nas referências em relação à internet entre os "alunos" (29,0\%, n=45 dos homens e 25,7\%, $\mathrm{n}=35$ das mulheres) uma vez ser esse recurso bastante utilizado nesse grupo etário. 
Tabela 9 - Distribuição dos participantes, segundo estrato, sexo e grupos de fontes de informação sobre alimentação e nutrição. São Paulo, 2005.

\begin{tabular}{lcccccccc}
\hline Grupos de fontes & \multicolumn{4}{c}{ Funcionários } & \multicolumn{4}{c}{ Alunos } \\
\cline { 2 - 9 } de informação & \multicolumn{4}{c}{ Sexo } & \multicolumn{4}{c}{ Sexo } \\
& \multicolumn{3}{c}{ Masculino } & Feminino & Masculino & Feminino \\
\cline { 2 - 9 } & FA & FR & FA & FR & FA & FR & FA & FR \\
\hline Meio escrito & 125 & 31,6 & 136 & 33,5 & 140 & 30,5 & 109 & 35,7 \\
Meio audiovisual & 145 & 36,6 & 136 & 33,3 & 137 & 29,9 & 94 & 30,8 \\
Meio pessoal & 63 & 15,9 & 98 & 24,0 & 102 & 22,2 & 41 & 13,4 \\
Meio formal & 30 & 7,6 & 34 & 8,3 & 49 & 10,7 & 50 & 16,4 \\
Meio instrumental & 33 & 8,3 & 4 & 0,9 & 31 & 6,7 & 11 & 3,6 \\
\hline Total & 396 & 100 & 408 & 100 & 459 & 100 & 305 & 100 \\
\hline
\end{tabular}

FA - freqüência absoluta

FR - freqüência relativa

\section{4 - VARIÁVEIS DE COMPORTAMENTO}

$\mathrm{Na}$ classificação do comportamento dos indivíduos, segundo o modelo transteorético, em relação a "ler o rótulo de produtos alimentícios" (Tabela 10) e "observar o valor energético das preparações culinárias oferecidas no restaurante" (Tabela 11) a ocupação, nos diferentes subníveis dos estratos, demonstrou associação significante.

As diferenças de classificação de comportamento entre as ocupações se deram principalmente pela diferença de anos de estudo formal. Observou-se que a maioria de funcionários de nível técnico estava cursando ou já havia cursado o nível superior. 
Tabela 10 - Distribuição dos participantes, segundo estrato e modelo transteorético, para comportamento de "ler o rótulo de embalagem de alimentos". São Paulo, 2005.

\begin{tabular}{|c|c|c|c|c|c|c|c|c|c|c|c|c|}
\hline \multirow[t]{3}{*}{ Ocupação } & \multicolumn{12}{|c|}{ Classificação } \\
\hline & \multicolumn{2}{|c|}{$\begin{array}{c}\text { Pré- } \\
\text { contemplação }\end{array}$} & \multicolumn{2}{|c|}{ Contemplação } & \multicolumn{2}{|c|}{ Preparação } & \multicolumn{2}{|c|}{ Ação } & \multicolumn{2}{|c|}{ Manutenção } & \multicolumn{2}{|c|}{ Total } \\
\hline & $\begin{array}{l}\text { FA } \\
\end{array}$ & FR & FA & FR & FA & FR & FA & FR & FA & FR & FA & FR \\
\hline \multicolumn{13}{|l|}{-Aluno } \\
\hline graduação & 75 & 36,4 & 122 & 42,7 & 44 & 37,6 & 29 & 55,8 & 78 & 32,2 & 348 & 38,5 \\
\hline Pós-graduação & 11 & 5,3 & 28 & 9,9 & 6 & 5,1 & 5 & 9,6 & 22 & 9,1 & 72 & 8,0 \\
\hline \multicolumn{13}{|l|}{ •Funcionário } \\
\hline Básico & 56 & 27,2 & 49 & 17,1 & 19 & 16,2 & 9 & 17,3 & 34 & 14,1 & 167 & 18,5 \\
\hline Técnico & 50 & 24,3 & 65 & 22,7 & 31 & 26,5 & 7 & 13,5 & 71 & 29,3 & 224 & 24,8 \\
\hline Superior & 10 & 4,9 & 17 & 5,9 & 14 & 12,0 & 1 & 1,9 & 21 & 8,7 & 63 & 7,0 \\
\hline Docente & 4 & 1,9 & 5 & 1,7 & 3 & 2,6 & 1 & 1,9 & 16 & 6,6 & 29 & 3,2 \\
\hline Total & 206 & 100 & 286 & 100 & 117 & 100 & 52 & 100 & 242 & 100 & 903 & 100 \\
\hline
\end{tabular}

FA - freqüência absoluta

FR - freqüência relativa

$x^{2}=50,677 p=0,000$ 
Tabela 11 - Distribuição dos participantes, segundo estrato e modelo transteorético, para comportamento de “observar o valor energético das preparações culinárias oferecidas no restaurante”. São Paulo, 2005.

\begin{tabular}{|c|c|c|c|c|c|c|c|c|c|c|c|c|}
\hline \multirow[t]{3}{*}{ Ocupação } & \multicolumn{12}{|c|}{ Classificação } \\
\hline & \multicolumn{2}{|c|}{$\begin{array}{c}\text { Pré- } \\
\text { contemplação }\end{array}$} & \multicolumn{2}{|c|}{ Contemplação } & \multicolumn{2}{|c|}{ Preparação } & \multicolumn{2}{|c|}{ Ação } & \multicolumn{2}{|c|}{ Manutenção } & \multicolumn{2}{|c|}{ Total } \\
\hline & FA & FR & FA & FR & FA & FR & FA & FR & FA & FR & FA & FR \\
\hline \multicolumn{13}{|l|}{-Aluno } \\
\hline graduação & 128 & 48,1 & 144 & 40,7 & 14 & 29,8 & 43 & 40,2 & 19 & 14,7 & 348 & 38,5 \\
\hline Pós-graduação & 27 & 10,1 & 31 & 8,8 & 1 & 2,1 & 10 & 9,3 & 3 & 2,3 & 72 & 8,0 \\
\hline \multicolumn{13}{|l|}{ •Funcionário } \\
\hline Básico & 37 & 13,9 & 66 & 18,6 & 8 & 17,0 & 20 & 18,7 & 36 & 27,9 & 167 & 18,8 \\
\hline Técnico & 50 & 18,8 & 83 & 23,4 & 18 & 38,3 & 26 & 24,3 & 47 & 36,4 & 224 & 24,8 \\
\hline Superior & 18 & 6,8 & 23 & 6,5 & 4 & 8,5 & 6 & 5,6 & 12 & 9,3 & 63 & 7,0 \\
\hline Docente & 6 & 2,3 & 7 & 2,0 & 2 & 4,3 & 2 & 1,9 & 12 & 9,3 & 29 & 3,2 \\
\hline Total & 266 & 100 & 354 & 100 & 47 & 100 & 107 & 100 & 129 & & 903 & 100 \\
\hline
\end{tabular}

FA - freqüência absoluta

FR - freqüência relativa

$x^{2}=79,593 \quad p=0,000$

Após a subdivisão, a associação manteve-se estatisticamente significativa para a classificação dos dois comportamentos (Tabelas 12 e 13).

Observou-se similaridade de comportamento entre as classificações quanto a "ler o rótulo de embalagem de alimentos" e "observar o valor energético das preparações culinárias oferecidas no restaurante" entre ocupação "alunos" e "funcionários outros" cuja classificação aparece em estágios mais avançados que para os "funcionários básicos". Esse fato pode ser devido à diferença de anos de educação formal dos grupos de ocupação.

Na ocupação "funcionários básicos", verifica-se um antagonismo entre os comportamentos de "ler o rótulo de embalagem de alimentos" (Tabela 12) e “observar o valor energético das preparações culinárias oferecidas no 
restaurante" (Tabela 13). Este comportamento pode ser devido à quantidade e complexidade de informações constantes nos rótulos dos alimentos embalados e a referência desse grupo em "não ter hábito de ler estas informações". Em relação ao comportamento de "observar o valor energético das preparações culinárias oferecidas no restaurante", esse fato pode estar relacionado por ser apenas uma informação e ser apresentada diariamente nos restaurantes.

Tabela 12 - Distribuição dos participantes, segundo estrato e modelo transteorético, para comportamento de "ler o rótulo de embalagem de alimentos". São Paulo, 2005.

\begin{tabular}{|c|c|c|c|c|c|c|c|c|c|c|c|}
\hline \multirow[t]{3}{*}{ Ocupação } & \multicolumn{11}{|c|}{ Classificação } \\
\hline & \multicolumn{2}{|c|}{$\begin{array}{c}\text { Pré- } \\
\text { contemplação }\end{array}$} & \multicolumn{2}{|c|}{ Contemplação } & \multicolumn{2}{|c|}{ Preparação } & \multicolumn{2}{|c|}{ Ação } & \multicolumn{2}{|c|}{ Manutenção } & Total \\
\hline & FA & $\mathrm{FR}$ & FA & FR & FA & FR & FA & FR & FA & FR & $\begin{array}{ll}\text { FA } & \text { FR } \\
\end{array}$ \\
\hline Aluno & 86 & 41,7 & 150 & 52,4 & 50 & 42,8 & 34 & 65,4 & 100 & 41,3 & 42046,5 \\
\hline $\begin{array}{l}\text { Funcionários } \\
\text { básico }\end{array}$ & 56 & 27,2 & 49 & 17,2 & 19 & 16,2 & 9 & 17,3 & 34 & 14,0 & $167 \quad 18,5$ \\
\hline $\begin{array}{l}\text { Funcionários } \\
\text { outros }\end{array}$ & 64 & 31,1 & 87 & 30,4 & 48 & 41,0 & 9 & 17,3 & 108 & 44,7 & 31635,0 \\
\hline Total & 206 & 100 & 286 & 100 & 117 & 100 & 52 & 100 & 242 & 100 & 903100 \\
\hline
\end{tabular}

Entre os "alunos", verificou-se comportamento menos avançado em relação a “observar o valor energético das preparações culinárias oferecidas no restaurante" (Tabela 13). Os mesmos justificaram que lêem essa informação apenas por "curiosidade".

Os funcionários, de um modo geral, parecem estar mais atentos a essa 
informação, diferente dos "alunos".

Tabela 13 - Distribuição dos participantes, segundo estrato e modelo transteorético, para comportamento de “observar o valor energético das preparações culinárias oferecidas no restaurante”. São Paulo, 2005.

\begin{tabular}{|c|c|c|c|c|c|c|c|c|c|c|c|}
\hline \multirow[t]{3}{*}{ Ocupação } & \multicolumn{11}{|c|}{ Classificação } \\
\hline & \multicolumn{2}{|c|}{$\begin{array}{c}\text { Pré- } \\
\text { contemplação }\end{array}$} & \multicolumn{2}{|c|}{ Contemplação } & \multicolumn{2}{|c|}{ Preparação } & \multicolumn{2}{|c|}{ Ação } & \multicolumn{2}{|c|}{ Manutenção } & Total \\
\hline & FA & $\mathrm{FR}$ & FA & FR & FA & FR & FA & FR & FA & $\begin{array}{l}\text { FR } \\
\end{array}$ & FA \\
\hline Aluno & 155 & 58,3 & 175 & 49,5 & 15 & 31,9 & 53 & 49,5 & 22 & 17,0 & $420 \quad 46,5$ \\
\hline $\begin{array}{l}\text { Funcionários } \\
\text { básico }\end{array}$ & 37 & 13,9 & 66 & 18,6 & 8 & 17,0 & 20 & 18,7 & 36 & 27,9 & $167 \quad 18,5$ \\
\hline $\begin{array}{l}\text { Funcionários } \\
\text { outros }\end{array}$ & 74 & 27,8 & 113 & 31,9 & 24 & 51,1 & 34 & 31,8 & 71 & 55,0 & 31635,0 \\
\hline Total & 266 & 100 & 354 & 100 & 47 & 100 & 107 & 100 & 129 & 100 & 903100 \\
\hline
\end{tabular}

FA - freqüência absoluta

FR - freqüência relativa

$x^{2}=67,717$ e $p=0,000$

\subsection{1 - Variáveis socioeconômicas}

- Sexo

De acordo com a Tabela 14, as mulheres apresentaram comportamento avançado em relação aos homens nas três ocupações.

Entre os "funcionários básicos", embora os resultados sugiram um estágio mais avançado entre as mulheres, não houve significância estatística dos dados.

Verifica-se semelhança de comportamento entre os estágios de classificação para "alunos" e "funcionários outros", havendo significância estatística nessa análise. 
Observa-se que, entre as mulheres, o comportamento de "ler o rótulo de produtos alimentícios" (Tabela 14) foi mais avançado em relação à atitude de “observar o valor energético das preparações culinárias oferecidas no restaurante" (Tabela 15) entre as ocupações. Esse fato pode sugerir uma valorização maior da informação nutricional nos produtos alimentícios.

Tabela 14 - Distribuição dos participantes, segundo estrato, sexo e modelo transteorético, para comportamento de "ler o rótulo de embalagem de alimentos". São Paulo, 2005.

\begin{tabular}{|c|c|c|c|c|c|c|c|c|c|c|c|c|c|}
\hline \multirow[t]{3}{*}{ Ocupação } & \multirow[t]{3}{*}{ Sexo } & \multicolumn{12}{|c|}{ Classificação } \\
\hline & & \multicolumn{2}{|c|}{$\begin{array}{c}\text { Pré- } \\
\text { contemplação }\end{array}$} & \multicolumn{2}{|c|}{ Contemplação } & \multicolumn{2}{|c|}{ Preparação } & \multicolumn{2}{|c|}{ Ação } & \multicolumn{2}{|c|}{ Manutenção } & \multicolumn{2}{|c|}{ Total } \\
\hline & & FA & $\mathrm{FR}$ & FA & FR & FA & FR & FA & FR & FA & FR & FA & FR \\
\hline \multirow[t]{2}{*}{ Alunos $^{a}$} & Feminino & 20 & 13,2 & 42 & 27,8 & 18 & 11,9 & 14 & 9,3 & 57 & 37,7 & 151 & 100 \\
\hline & Masculino & 66 & 24,5 & 108 & 40,2 & 92 & 11,9 & 20 & 7,4 & 43 & 16,0 & 269 & 100 \\
\hline \multirow{2}{*}{$\begin{array}{l}\text { Funcionários } \\
\text { básicos }{ }^{b}\end{array}$} & Feminino & 15 & 23,8 & 19 & 30,2 & 10 & 15,9 & 5 & 7,9 & 14 & 22,2 & 63 & 100 \\
\hline & Masculino & 41 & 39,4 & 30 & 28,9 & 9 & 8,7 & 4 & 3,8 & 20 & 19,2 & 104 & 100 \\
\hline \multirow{2}{*}{$\begin{array}{l}\text { Funcionários } \\
\text { outros }^{c}\end{array}$} & Feminino & 18 & 12,0 & 35 & 23,3 & 27 & 18,0 & 4 & 2,7 & 66 & 44,0 & 150 & 100 \\
\hline & Masculino & 46 & 27,7 & 52 & 31,3 & 21 & 12,7 & 5 & 3,0 & 42 & 25,3 & 166 & 100 \\
\hline
\end{tabular}

FA - freqüência absoluta

FR - freqüência relativa
a. $\mathrm{x}^{2}=29,79 \mathrm{p}=0,000$
b. $\mathrm{x}^{2}=6,06 \mathrm{p}=0,194$
c. $\mathrm{x}^{2}=21,01 \mathrm{p}=0,000$

Como se observa na Tabela 15, o comportamento de "observar o valor calórico das preparações oferecidas no restaurante", a maior prevalência foi para o comportamento de "contemplação" em todas as categorias de ocupação, em ambos os sexos, sugerindo que essa informação não interfere na atitude dos indivíduos. Observa-se que as mulheres apresentaram atitudes mais avançadas que os homens em todas as ocupações. Não houve significância estatística para ocupação de "funcionários básicos". 
Embora seja maior entre as mulheres a referência de "observar a informação de valor energético do restaurante", de considerar a informação de calorias importante e a referência em termos de saúde para uso dessa informação, a atitude também foi de "contemplação", sugerindo que deva haver meios para que essa informação possa ser mais bem utilizada.

Tabela 15 - Distribuição dos participantes, segundo estrato, sexo e modelo transteorético, para comportamento de "observar o valor energético das preparações culinárias oferecidas no restaurante”. São Paulo, 2005.

\begin{tabular}{|c|c|c|c|c|c|c|c|c|c|c|c|c|c|}
\hline \multirow[t]{3}{*}{ Ocupação } & \multirow[t]{3}{*}{ Sexo } & \multicolumn{12}{|c|}{ Classificação } \\
\hline & & \multicolumn{2}{|c|}{$\begin{array}{c}\text { Pré- } \\
\text { contemplação }\end{array}$} & \multicolumn{2}{|c|}{ Contemplação } & \multicolumn{2}{|c|}{ Preparação } & \multicolumn{2}{|c|}{ Ação } & \multicolumn{2}{|c|}{ Manutenção } & \multicolumn{2}{|c|}{ Total } \\
\hline & & FA & FR & FA & FR & FA & FR & FA & FR & FA & FR & FA & FR \\
\hline \multirow[t]{2}{*}{ Alunos $^{\mathrm{a}}$} & Feminino & 48 & 31,8 & 51 & 33,8 & 9 & 5,9 & 27 & 17,9 & 16 & 10,6 & 151 & 100 \\
\hline & Masculino & 107 & 39,8 & 124 & 46,1 & 6 & 2,2 & 26 & 9,7 & 6 & 2,2 & 269 & 100 \\
\hline \multirow{2}{*}{$\begin{array}{l}\text { Funcionários } \\
\text { básicos }^{b}\end{array}$} & Feminino & 13 & 20,6 & 22 & 34,9 & 3 & 4,8 & 9 & 14,3 & 16 & 25,4 & 63 & 100 \\
\hline & Masculino & 24 & 23,1 & 44 & 42,3 & 5 & 4,8 & 11 & 10,6 & 20 & 19,2 & 104 & 100 \\
\hline \multirow{2}{*}{$\begin{array}{l}\text { Funcionários } \\
\text { outrosc }\end{array}$} & Feminino & 25 & 16,7 & 48 & 32,0 & 15 & 10,0 & 19 & 12,6 & 43 & 28,7 & 150 & 100 \\
\hline & Masculino & 49 & 29,5 & 65 & 39,2 & 9 & 5,4 & 15 & 9,0 & 28 & 16,9 & 166 & 100 \\
\hline
\end{tabular}

FA - freqüência absoluta

FR - freqüência relativa
a. $\mathrm{x}^{2}=27,06 \mathrm{p}=0,000$
b. $x^{2}=1,74 \quad p=0,774$
c. $\mathrm{x}^{2}=14,71 \mathrm{p}=0,005$

\subsection{2 - Variáveis de Saúde}

- IMC

Conforme se observa na Tabela 16, entre os "alunos", o valor do IMC parece não interferir no comportamento do indivíduo sendo que a maior prevalência é o estágio de contemplação e é semelhante para todas as classificações de IMC. Entretanto, entre os indivíduos com excesso de peso 26,9\% encontraram-se no estágio de "manutenção". O mesmo ocorreu entre 
os "funcionários outros". Não houve significância estatística dos dados.

De forma inversa, entre os "funcionários básicos", os indivíduos com "excesso de peso" ficaram classificados em estágios menos avançados de comportamento em relação às outras classificações de $\mathrm{IMC}$, sendo a atitude de "pré-contemplação", porém não houve significância estatística dos dados.

Tabela 16 - Distribuição dos participantes, segundo estrato, IMC e modelo transteorético, para comportamento de "ler o rótulo de embalagem de alimentos". São Paulo, 2005.

\begin{tabular}{|c|c|c|c|c|c|c|c|c|c|c|c|c|c|}
\hline \multirow[t]{3}{*}{ Ocupação } & \multirow[t]{3}{*}{ IMC } & \multicolumn{12}{|c|}{ Classificação } \\
\hline & & \multicolumn{2}{|c|}{$\begin{array}{c}\text { Pré- } \\
\text { contemplação }\end{array}$} & \multicolumn{2}{|c|}{ Contemplação } & \multicolumn{2}{|c|}{ Preparação } & \multicolumn{2}{|c|}{ Ação } & \multicolumn{2}{|c|}{ Manutenção } & \multicolumn{2}{|c|}{ Total } \\
\hline & & FA & $F R$ & FA & FR & FA & FR & FA & FR & FA & FR & FA & FR \\
\hline \multirow[t]{4}{*}{ Alunos ${ }^{a}$} & Baixo peso & 5 & 21,8 & 9 & 39,2 & 3 & 13,0 & 3 & 13,0 & 3 & 13,0 & 23 & 100 \\
\hline & $\begin{array}{l}\text { Peso } \\
\text { adequado }\end{array}$ & 65 & 20,5 & 117 & 36,9 & 34 & 10,7 & 25 & 7,9 & 76 & 24,0 & 317 & 100 \\
\hline & $\begin{array}{l}\text { Excesso de } \\
\text { peso }\end{array}$ & 15 & 19,2 & 23 & 29,5 & 13 & 16,7 & 6 & 7,7 & 21 & 26,9 & 78 & 100 \\
\hline & Baixo peso & 1 & 25,0 & 2 & 50,0 & - & - & 1 & 25,0 & - & - & 4 & 100 \\
\hline \multirow[t]{2}{*}{$\begin{array}{l}\text { Funcionários } \\
\text { básicos }{ }^{\mathrm{b}}\end{array}$} & $\begin{array}{l}\text { Peso } \\
\text { adequado }\end{array}$ & 23 & 30,7 & 24 & 32,0 & 9 & 12,0 & 6 & 8,0 & 13 & 17,3 & 75 & 100 \\
\hline & $\begin{array}{l}\text { Excesso de } \\
\text { peso }\end{array}$ & 31 & 35,6 & 23 & 26,4 & 10 & 11,5 & 2 & 2,3 & 21 & 24,2 & 87 & 100 \\
\hline \multirow{3}{*}{$\begin{array}{l}\text { Funcionários } \\
\text { outros }^{c}\end{array}$} & Baixo peso & - & - & - & - & 1 & 25,0 & - & - & 3 & 75,0 & 4 & 100 \\
\hline & $\begin{array}{l}\text { Peso } \\
\text { adequado }\end{array}$ & 33 & 19,1 & 43 & 24,8 & 33 & 19,1 & 2 & 1,2 & 62 & 35,8 & 173 & 100 \\
\hline & $\begin{array}{l}\text { Excesso de } \\
\text { peso }\end{array}$ & 29 & 21,3 & 44 & 32,4 & 14 & 10,3 & 6 & 4,4 & 43 & 31,6 & 136 & 100 \\
\hline
\end{tabular}

FA - freqüência absoluta

FR - freqüência relativa
a. $\mathrm{x}^{2}=5,15 \quad \mathrm{p}=0,7411$
b. $\mathrm{x}^{2}=8,93 \quad \mathrm{p}=0,348$
c. $x^{2}=13,32 p=0,101$

A Tabela 17 mostra que houve associação entre a classificação de IMC e a atitude de "observar o valor energético das preparações culinárias oferecidas 
no restaurante", apenas entre os "alunos".

Foi observado que, as maiores prevalências foram para a classificação de "contemplação" para todas as ocupações. A exceção foi entre os "alunos" classificados como baixo peso. Os "funcionários básicos" e "funcionários outros", que estavam com excesso de peso, apresentaram uma movimentação em direção a comportamentos mais avançados, embora não haja significância estatística dos dados dessas duas classificações.

Tabela 17 - Distribuição dos participantes, segundo estrato, IMC e modelo transteorético, para comportamento de "observar o valor energético das preparações culinárias oferecidas no restaurante”. São Paulo, 2005.

\begin{tabular}{|c|c|c|c|c|c|c|c|c|c|c|c|c|c|}
\hline \multirow[t]{3}{*}{ Ocupação } & \multirow[t]{3}{*}{ IMC } & \multicolumn{12}{|c|}{ Classificação } \\
\hline & & \multicolumn{2}{|c|}{$\begin{array}{c}\text { Pré- } \\
\text { contemplação }\end{array}$} & \multicolumn{2}{|c|}{ Contemplação } & \multicolumn{2}{|c|}{ Preparação } & \multicolumn{2}{|c|}{ Ação } & \multicolumn{2}{|c|}{ Manutenção } & \multicolumn{2}{|c|}{ Total } \\
\hline & & FA & FR & FA & FR & FA & FR & FA & FR & FA & FR & FA & FR \\
\hline \multirow[t]{4}{*}{ Alunos ${ }^{a}$} & Baixo peso & 13 & 56,5 & 5 & 21,7 & 4 & 17,4 & - & - & 1 & 4,4 & 23 & 100 \\
\hline & $\begin{array}{l}\text { Peso } \\
\text { adequado }\end{array}$ & 129 & 38,8 & 135 & 42,6 & 6 & 1,9 & 38 & 12,0 & 15 & 4,7 & 317 & 100 \\
\hline & $\begin{array}{l}\text { Excesso de } \\
\text { peso }\end{array}$ & 19 & 24,4 & 33 & 42,3 & 5 & 6,4 & 15 & 19,2 & 6 & 7,7 & 78 & 100 \\
\hline & Baixo peso & 1 & 25,0 & 3 & 75,0 & - & - & - & - & - & - & 4 & 100 \\
\hline \multirow[t]{2}{*}{$\begin{array}{l}\text { Funcionários } \\
\text { básicos }^{\mathrm{b}}\end{array}$} & $\begin{array}{l}\text { Peso } \\
\text { adequado }\end{array}$ & 20 & 26,7 & 32 & 42,7 & 4 & 5,3 & 4 & 5,3 & 15 & 20,0 & 75 & 100 \\
\hline & $\begin{array}{l}\text { Excesso de } \\
\text { peso }\end{array}$ & 16 & 18,4 & 31 & 35,6 & 4 & 4,6 & 16 & 18,4 & 20 & 23,0 & 87 & 100 \\
\hline \multirow{3}{*}{$\begin{array}{l}\text { Funcionários } \\
\text { outros }^{c}\end{array}$} & Baixo peso & 1 & 25,0 & 1 & 25,0 & 1 & 25,0 & - & - & 1 & 25,0 & 4 & 100 \\
\hline & $\begin{array}{l}\text { Peso } \\
\text { adequado }\end{array}$ & 41 & 23,7 & 68 & 39,3 & 12 & 6,9 & 11 & 6,4 & 41 & 23,7 & 173 & 100 \\
\hline & $\begin{array}{l}\text { Excesso de } \\
\text { peso }\end{array}$ & 36 & 22,1 & 44 & 32,3 & 11 & 8,1 & 22 & 16,2 & 29 & 21,3 & 136 & 100 \\
\hline
\end{tabular}

FA - freqüência absoluta

FR - freqüência relativa
a. $x^{2}=31,51 \quad p=0,000$
b. $x^{2}=10,50 \quad p=0,231$
c. $x^{2}=10,56 \quad p=0,228$ 


\section{- Referência de "controle de peso"}

"Alunos" e "funcionários outros" que referiram fazer controle de peso, mesmo que eventualmente, apresentaram comportamento semelhante e mais avançado. Pode-se inferir que "ler o rótulo de produtos alimentícios" pode auxiliar na manutenção de peso dos indivíduos (Tabela 18). Houve significância estatística na associação.

Entre os "funcionários básicos", essa relação não foi observada, pois a maior prevalência foi para atitude menos avançada. No entanto, também foi observada que entre aqueles que referiram fazer "controle de peso", mesmo que eventualmente, foi maior para atitudes mais avançadas, embora, não tenha havido significância estatística dos dados. 
Tabela 18 - Distribuição dos participantes, segundo estrato, referência de "controle de peso" e modelo transteorético, para comportamento de "ler o rótulo de embalagem de alimentos". São Paulo, 2005.

\begin{tabular}{|c|c|c|c|c|c|c|c|c|c|c|c|c|c|}
\hline \multirow[t]{3}{*}{ Ocupação } & \multirow{3}{*}{$\begin{array}{l}\text { Referência } \\
\text { de } \\
\text { "controle } \\
\text { de peso" }\end{array}$} & \multicolumn{12}{|c|}{ Classificação } \\
\hline & & \multicolumn{2}{|c|}{$\begin{array}{c}\text { Pré- } \\
\text { contemplação }\end{array}$} & \multicolumn{2}{|c|}{ Contemplação } & \multicolumn{2}{|c|}{ Preparação } & \multicolumn{2}{|c|}{ Ação } & \multicolumn{2}{|c|}{ Manutenção } & \multicolumn{2}{|c|}{ Total } \\
\hline & & FA & FR & FA & FR & FA & FR & FA & FR & FA & FR & FA & FR \\
\hline \multirow[t]{3}{*}{ Alunos $^{a}$} & Sim & 10 & 10,5 & 27 & 28,4 & 14 & 14,8 & 12 & 12,6 & 32 & 33,7 & 95 & 100 \\
\hline & Às vezes & 3 & 18,8 & 2 & 12,5 & 4 & 25,0 & 1 & 6,2 & 6 & 37,5 & 16 & 100 \\
\hline & Não & 73 & 23,6 & 121 & 39,2 & 32 & 10,4 & 21 & 6,8 & 62 & 20,1 & 309 & 100 \\
\hline \multirow{3}{*}{$\begin{array}{l}\text { Funcionários } \\
\text { básicos }^{b}\end{array}$} & Sim & 19 & 35,8 & 14 & 26,4 & 3 & 5,7 & 4 & 7,6 & 13 & 24,5 & 53 & 100 \\
\hline & Às vezes & 1 & 11,1 & 2 & 22,2 & 3 & 33,3 & 1 & 11,1 & 2 & 22,2 & 9 & 100 \\
\hline & Não & 36 & 34,3 & 33 & 31,4 & 13 & 12,4 & 4 & 3,8 & 19 & 18,1 & 105 & 100 \\
\hline \multirow{3}{*}{$\begin{array}{l}\text { Funcionários } \\
\text { outros }^{c}\end{array}$} & Sim & 14 & 12,7 & 26 & 23,6 & 18 & 16,4 & 3 & 2,7 & 49 & 44,6 & 110 & 100 \\
\hline & Às vezes & 1 & 7,7 & 2 & 15,4 & 4 & 30,8 & 1 & 7,7 & 5 & 38,4 & 13 & 100 \\
\hline & Não & 49 & 25,4 & 59 & 30,6 & 26 & 13,5 & 5 & 2,6 & 54 & 27,9 & 193 & 100 \\
\hline
\end{tabular}

FA - freqüência absoluta

FR - freqüência relativa
a. $\mathrm{x}^{2}=24,63 \quad \mathrm{p}=0,002$
b. $\mathrm{x}^{2}=9,57 \quad \mathrm{p}=0,297$
c. $\mathrm{x}^{2}=17,93 \mathrm{p}=0,022$

Houve associação entre todas as categorias entre a variável "controle de peso" e atitude de "observar o valor energético das preparações culinárias oferecidas no restaurante" (Tabela 19).

Embora a maior prevalência entre os "alunos" seja para a atitude de "contemplação", observa-se que, entre aqueles que referiram fazer controle de peso, as atitudes foram menos avançadas ocorrendo o inverso entre a ocupação "funcionários básicos" e "funcionários outros". 
Tabela 19 - Distribuição dos participantes, segundo estrato, referência de "controle de peso" e modelo transteorético, para comportamento de “observar o valor energético das preparações culinárias oferecidas no restaurante". São Paulo, 2005.

\begin{tabular}{|c|c|c|c|c|c|c|c|c|c|c|c|c|c|}
\hline \multirow[t]{3}{*}{ Ocupação } & \multirow{3}{*}{$\begin{array}{l}\text { Referência } \\
\text { de } \\
\text { "controle } \\
\text { de peso" }\end{array}$} & \multicolumn{12}{|c|}{ Classificação } \\
\hline & & \multicolumn{2}{|c|}{$\begin{array}{c}\text { Pré- } \\
\text { contemplação }\end{array}$} & \multicolumn{2}{|c|}{ Contemplação } & \multicolumn{2}{|c|}{ Preparação } & \multicolumn{2}{|c|}{ Ação } & \multicolumn{2}{|c|}{ Manutenção } & \multicolumn{2}{|c|}{ Total } \\
\hline & & $\begin{array}{c}\text { FA } \\
\end{array}$ & FR & FA & FR & FA & FR & FA & FR & FA & FR & FA & FR \\
\hline \multirow[t]{3}{*}{ Alunos $^{a}$} & Sim & 28 & 29,5 & 30 & 31,6 & 6 & 6,3 & 25 & 26,3 & 6 & 6,3 & 85 & 100 \\
\hline & Às vezes & 4 & 25,0 & 7 & 43,8 & - & - & 1 & 6,2 & 4 & 25,0 & 16 & 100 \\
\hline & Não & 123 & 39,8 & 138 & 44,7 & 9 & 2,9 & 27 & 8,7 & 12 & 3,9 & 309 & 100 \\
\hline \multirow{3}{*}{$\begin{array}{l}\text { Funcionários } \\
\text { básicos }^{\text {b }}\end{array}$} & Sim & 11 & 20,8 & 11 & 20,8 & 5 & 9,4 & 14 & 26,4 & 12 & 22,6 & 53 & 100 \\
\hline & Às vezes & - & - & 2 & 22,2 & - & - & 2 & 22,2 & 5 & 55,6 & 9 & 100 \\
\hline & Não & 26 & 24,8 & 53 & 50,5 & 3 & 2,8 & 4 & 3,8 & 19 & 18,1 & 105 & 100 \\
\hline \multirow{3}{*}{$\begin{array}{l}\text { Funcionários } \\
\text { outros }^{c}\end{array}$} & Sim & 18 & 16,4 & 29 & 26,4 & 10 & 9,1 & 14 & 12,7 & 39 & 35,4 & 110 & 100 \\
\hline & Às vezes & 2 & 15,4 & 5 & 38,4 & 2 & 15,4 & 2 & 15,4 & 2 & 15,4 & 13 & 100 \\
\hline & Não & 54 & 28,0 & 79 & 40,9 & 12 & 6,2 & 18 & 9,3 & 30 & 15,6 & 193 & 100 \\
\hline
\end{tabular}

FA - freqüência absoluta

FR - freqüência relativa
a. $x^{2}=40,24 \quad p=0,000$
b. $x^{2}=35,89 \quad p=0,000$
c. $\mathrm{x}^{2}=24,13 \mathrm{p}=0,002$

\section{- Referência de ausência de doença}

Não foi observada associação entre referência de saúde e atitude de "ler o rótulo de produtos alimentícios" (Tabela 20).

Embora a maior prevalência seja para atitude de "contemplação" nas três categorias de ocupação, observa-se que entre os funcionários ("básicos” e "outros"), aqueles que referiram problemas de doença, as atitudes foram mais avançadas em relação àqueles que referiram ausência de doença. Diferente dos "alunos", nos quais o comportamento menos avançado foi para aqueles que referiram não ter problemas de saúde. 
Tabela 20 - Distribuição dos participantes, segundo estrato, referência de ausência de doença e modelo transteorético, para comportamento de "ler o rótulo de embalagem de alimentos". São Paulo, 2005.

\begin{tabular}{|c|c|c|c|c|c|c|c|c|c|c|c|c|c|}
\hline \multirow[t]{3}{*}{ Ocupação } & \multirow{3}{*}{$\begin{array}{l}\text { Referência } \\
\text { de } \\
\text { ausência } \\
\text { de doença }\end{array}$} & \multicolumn{12}{|c|}{ Classificação } \\
\hline & & \multicolumn{2}{|c|}{$\begin{array}{c}\text { Pré- } \\
\text { contemplação }\end{array}$} & \multicolumn{2}{|c|}{ Contemplação } & \multicolumn{2}{|c|}{ Preparação } & \multicolumn{2}{|c|}{ Ação } & \multicolumn{2}{|c|}{ Manutenção } & \multicolumn{2}{|c|}{ Total } \\
\hline & & FA & FR & FA & FR & FA & FR & FA & FR & FA & FR & FA & FR \\
\hline \multirow[t]{2}{*}{ Alunosa } & Sim & 20 & 25,0 & 33 & 41,2 & 6 & 7,5 & 13 & 16,3 & 8 & 10,0 & 80 & 100 \\
\hline & Não & 135 & 39,7 & 142 & 41,8 & 9 & 2,6 & 40 & 11,8 & 14 & 4,1 & 340 & 100 \\
\hline Funci & Sim & 12 & 16,4 & 25 & 34,3 & 2 & 2,7 & 15 & 20,5 & 19 & 26,1 & 73 & 100 \\
\hline básicos ${ }^{b}$ & Não & 25 & 26,6 & 41 & 43,6 & 6 & 6,4 & 5 & 5,3 & 17 & 18,1 & 94 & 100 \\
\hline Funcionários & Sim & 22 & 20,6 & 34 & 31,8 & 5 & 4,7 & 20 & 18,7 & 26 & 24,3 & 107 & 100 \\
\hline outrosc & Não & 52 & 24,9 & 79 & 37,8 & 19 & 9,1 & 14 & 6,7 & 45 & 21,5 & 209 & 100 \\
\hline
\end{tabular}

FA - freqüência absoluta

FR - freqüência relativa
a. $\mathrm{x}^{2}=9,14 \quad \mathrm{p}=, 1279$
b. $x^{2}=1,83 \quad p=0,767$
c. $x^{2}=8,72 \quad p=0,241$

As maiores prevalências não diferiram em relação às referências de ausência de doença ou saúde para o comportamento de "observar o valor energético das preparações culinárias oferecidas no restaurante" entre as ocupações. As maiores prevalências demonstraram que o comportamento é diferente entre as ocupações. Entre os "alunos", a atitude foi "contemplação", entre os "funcionários básicos" foi "pré-contemplação e "funcionários outros" foi "manutenção, embora tenha havido associação estatística na ocupação "funcionários outros". (Tabela 21). 
Tabela 21 - Distribuição dos participantes, segundo estrato, referência de ausência de doença e modelo transteorético, para comportamento de “observar o valor energético das preparações culinárias oferecidas no restaurante". São Paulo, 2005.

\begin{tabular}{|c|c|c|c|c|c|c|c|c|c|c|c|c|c|}
\hline \multirow[t]{3}{*}{ Ocupação } & \multirow{3}{*}{$\begin{array}{l}\text { Referência } \\
\text { de } \\
\text { ausência } \\
\text { de doença }\end{array}$} & \multicolumn{12}{|c|}{ Classificação } \\
\hline & & \multicolumn{2}{|c|}{$\begin{array}{c}\text { Pré- } \\
\text { contemplação }\end{array}$} & \multicolumn{2}{|c|}{ Contemplação } & \multicolumn{2}{|c|}{ Preparação } & \multicolumn{2}{|c|}{ Ação } & \multicolumn{2}{|c|}{ Manutenção } & \multicolumn{2}{|c|}{ Total } \\
\hline & & FA & FR & FA & FR & FA & FR & FA & FR & FA & FR & FA & FR \\
\hline \multirow[t]{2}{*}{ Alunos ${ }^{a}$} & Sim & 10 & $\overline{12,5}$ & 29 & 36,2 & 13 & 16,3 & 4 & 5,0 & 24 & 30,0 & 80 & 100 \\
\hline & Não & 76 & 22,3 & 121 & 35,6 & 37 & 10,9 & 30 & 8,8 & 76 & 22,4 & 340 & 100 \\
\hline \multirow{2}{*}{$\begin{array}{l}\text { Funcionáriso } \\
\text { básicos }^{b}\end{array}$} & Sim & 25 & 34,2 & 19 & 26,0 & 11 & 15,1 & 4 & 5,5 & 14 & 19,2 & 73 & 100 \\
\hline & Não & 31 & 33,0 & 30 & 31,9 & 8 & 8,5 & 5 & 5,3 & 20 & 21,3 & 94 & 100 \\
\hline \multirow{2}{*}{$\begin{array}{l}\text { Funcionários } \\
\text { outros }^{c}\end{array}$} & Sim & 24 & 22,4 & 31 & 29,0 & 10 & 9,3 & 4 & 3,8 & 38 & 35,5 & 107 & 100 \\
\hline & Não & 40 & 19,1 & 56 & 26,8 & 38 & 18,2 & 5 & 2,4 & 70 & 33,5 & 209 & 100 \\
\hline
\end{tabular}

FA - freqüência absoluta

FR - freqüência relativa
a. $\mathrm{x}^{2}=4,51 \quad \mathrm{p}=0,824$
b. $x^{2}=8,37 \quad p=0,257$
c. $\mathrm{x}^{2}=13,72 \mathrm{p}=0,000$

\section{- Prática de atividade física esportiva}

Entre os "alunos" e "funcionários básicos", a maior prevalência não diferiu entre aqueles que referiram atividade física e os indivíduos classificados como sedentários. Diferente dos "funcionários outros", que demonstraram que entre os indivíduos classificados como ativos, a atitude foi mais avançada em relação aos sedentários, havendo uma associação positiva nessa relação (Tabela 22). 
Tabela 22 - Distribuição dos participantes, segundo estrato, atividade física esportiva e modelo transteorético, para comportamento de "ler o rótulo de embalagem de alimentos". São Paulo, 2005.

\begin{tabular}{|c|c|c|c|c|c|c|c|c|c|c|c|c|c|}
\hline \multirow[t]{3}{*}{ Ocupação } & \multirow{3}{*}{$\begin{array}{l}\text { Referência } \\
\text { de atividade } \\
\text { física } \\
\text { esportiva }\end{array}$} & \multicolumn{12}{|c|}{ Classificação } \\
\hline & & \multicolumn{2}{|c|}{$\begin{array}{c}\text { Pré- } \\
\text { contemplação }\end{array}$} & \multicolumn{2}{|c|}{ Contemplação } & \multicolumn{2}{|c|}{ Preparação } & \multicolumn{2}{|c|}{ Ação } & \multicolumn{2}{|c|}{ Manutenção } & \multicolumn{2}{|c|}{ Total } \\
\hline & & FA & FR & FA & FR & FA & FR & FA & FR & FA & FR & FA & FR \\
\hline \multirow[t]{2}{*}{ Alunos $^{a}$} & Sedentário & 36 & 20,6 & 60 & 34,3 & 22 & 12,6 & 16 & 9,1 & 41 & 23,4 & 175 & 100 \\
\hline & Ativos* & 50 & 20,4 & 90 & 36,7 & 28 & 11,4 & 18 & 7,4 & 59 & 24,1 & 245 & 100 \\
\hline \multirow{2}{*}{$\begin{array}{l}\text { Funcionários } \\
\text { básicos }^{\mathrm{b}}\end{array}$} & Sedentário & 30 & 34,1 & 28 & 31,8 & 12 & 13,6 & 3 & 3,4 & 15 & 17,1 & 88 & 100 \\
\hline & Ativos* & 26 & 32,9 & 21 & 26,6 & 7 & 8,9 & 6 & 7,6 & 19 & 24,0 & 79 & 100 \\
\hline \multirow{2}{*}{$\begin{array}{l}\text { Funcionários } \\
\text { outrosc }^{c}\end{array}$} & Sedentário & 37 & 24,3 & 49 & 32,2 & 20 & 13,2 & 1 & 0,7 & 45 & 29,6 & 152 & 100 \\
\hline & Ativos* & 27 & 16,4 & 38 & 23,2 & 28 & 17,1 & 8 & 4,9 & 63 & 38,4 & 164 & 100 \\
\hline
\end{tabular}

${ }^{*}$ pela semelhança de comportamento, foram considerados os ativos e muito ativos.

FA - freqüência absoluta

FR - freqüência relativa
a. $x^{2}=3,262$
$\mathrm{p}=0,812$
b. $\mathrm{x}^{2}=4,635 \quad \mathrm{p}=0,253$
c. $\mathrm{x}^{2}=13,070 \mathrm{p}=0,008$

As maiores prevalências ocorreram para o comportamento de "contemplação" em todas as ocupações, independente da referência de haver ou não prática de atividade física esportiva (Tabela 23).

Não houve significância estatística para o grupo de "alunos" e "funcionários básicos" entre prática de atividade física esportiva e comportamento de “observar o valor energético das preparações culinárias oferecidas no restaurante".

Entre os "funcionários outros", houve tendência de associação estatística e foi observado que, entre os indivíduos ativos, movimentação para comportamentos mais avançados, o que ocorreu também, nas outras ocupações. 
Tabela 23 - Distribuição dos participantes, segundo estrato, atividade física esportiva e modelo transteorético, para comportamento de "observar o valor energético das preparações culinárias oferecidas no restaurante". São Paulo, 2005.

\begin{tabular}{|c|c|c|c|c|c|c|c|c|c|c|c|c|c|}
\hline \multirow[t]{3}{*}{ Ocupação } & \multirow{3}{*}{$\begin{array}{l}\text { Referência } \\
\text { de atividade } \\
\text { física } \\
\text { esportiva }\end{array}$} & \multicolumn{12}{|c|}{ Classificação } \\
\hline & & \multicolumn{2}{|c|}{$\begin{array}{c}\text { Pré- } \\
\text { contemplação }\end{array}$} & \multicolumn{2}{|c|}{ Contemplação } & \multicolumn{2}{|c|}{ Preparação } & \multicolumn{2}{|c|}{ Ação } & \multicolumn{2}{|c|}{ Manutenção } & \multicolumn{2}{|c|}{ Total } \\
\hline & & $\mathrm{FA}$ & FR & FA & FR & FA & FR & FA & FR & FA & FR & FA & FR \\
\hline \multirow[t]{2}{*}{ Alunosa } & Sedentário & 66 & 37,7 & 73 & 41,7 & 7 & 4,0 & 22 & 12,6 & 7 & 4,0 & 175 & 100 \\
\hline & Ativos* & 89 & 36,3 & 102 & 41,6 & 8 & 3,3 & 31 & 12,6 & 15 & 6,2 & 245 & 100 \\
\hline \multirow{2}{*}{$\begin{array}{l}\text { Funcionários } \\
\text { básicosb }\end{array}$} & Sedentário & 23 & 26,1 & 37 & 42,1 & 1 & 1,1 & 9 & 10,2 & 18 & 20,5 & 88 & 100 \\
\hline & Ativos* & 14 & 17,7 & 29 & 36,7 & 7 & 8,9 & 11 & 13,9 & 18 & 22,8 & 79 & 100 \\
\hline \multirow{2}{*}{$\begin{array}{l}\text { Funcionários } \\
\text { outrosc }^{c}\end{array}$} & Sedentário & 42 & 27,7 & 56 & 36,8 & 11 & 7,3 & 15 & 9,9 & 28 & 18,4 & 152 & 100 \\
\hline & Ativos* & 32 & 19,5 & 57 & 34,8 & 13 & 7,9 & 19 & 11,6 & 43 & 26,2 & 164 & 100 \\
\hline \multicolumn{14}{|c|}{$\begin{array}{l}{ }^{*} \text { pela semelhança de comport } \\
\text { FA - freqüência absoluta } \\
\text { FR - freqüência relativa }\end{array}$} \\
\hline & $\begin{array}{ll}\text { a. } & x^{2}=2,124 \\
\text { b. } & x^{2}=8,622 \\
\text { c. } & x^{2}=10,907\end{array}$ & $\begin{array}{l}p=0, \\
p=0, \\
p=0,\end{array}$ & & & & & & & & & & & \\
\hline
\end{tabular}

\subsection{3 - Variáveis de conduta/ conhecimento}

\section{- Conhecimento do conceito de caloria}

Conforme se verifica na Tabela 24, entre os "alunos", as maiores prevalências não diferiram para conhecimento ou não do conceito de caloria. Vale a pena lembrar que, nesse grupo, a importância do conceito foi referida de forma indireta, ou seja, “a informação de caloria é importante para quem necessita de controle de peso" e no caso, 75,8\% desse grupo, foi classificado com IMC de eutrófico. No entanto, não houve significância estatística dos dados.

Já entre os "funcionários básicos" e "funcionários outros", observa-se uma relação positiva, as maiores prevalências demonstraram que indivíduos que 
referiram de forma parcialmente correta ou correta, foram classificados em estágios mais avançados de comportamento. Houve significância estatística entre as duas ocupações.

Tabela 24 - Distribuição dos participantes, segundo estrato, conhecimento do conceito de caloria e modelo transteorético, para comportamento de "ler o rótulo de embalagem de alimentos". São Paulo, 2005.

\begin{tabular}{|c|c|c|c|c|c|c|c|c|c|c|c|c|c|}
\hline \multirow[t]{3}{*}{ Ocupação } & \multirow{3}{*}{$\begin{array}{l}\text { Conheci- } \\
\text { mento do } \\
\text { conceito } \\
\text { de caloria }\end{array}$} & \multicolumn{12}{|c|}{ Classificação } \\
\hline & & \multicolumn{2}{|c|}{$\begin{array}{c}\text { Pré- } \\
\text { contemplação }\end{array}$} & \multicolumn{2}{|c|}{ Contemplação } & \multicolumn{2}{|c|}{ Preparação } & \multicolumn{2}{|c|}{ Ação } & \multicolumn{2}{|c|}{ Manutenção } & \multicolumn{2}{|c|}{ Total } \\
\hline & & FA & $\mathrm{FR}$ & FA & FR & FA & $\begin{array}{l}\text { FR } \\
\end{array}$ & FA & FR & FA & FR & FA & FR \\
\hline \multirow[t]{2}{*}{ Alunos ${ }^{a}$} & Incorreto & 14 & 17,3 & 28 & 34,6 & 10 & 12,3 & 7 & 8,6 & 22 & 27,2 & 81 & 100 \\
\hline & Correto* & 55 & 19,9 & 99 & 35,7 & 35 & 12,6 & 22 & 8,0 & 66 & 23,8 & 277 & 100 \\
\hline \multirow{2}{*}{$\begin{array}{l}\text { Funcionários } \\
\text { básicos }\end{array}$} & Incor & 25 & 34,2 & 23 & 31,5 & 9 & 12,3 & 4 & 5,5 & 12 & 16,5 & 73 & 100 \\
\hline & Correto* & 4 & 12,5 & 5 & 15,6 & 5 & 15,6 & 3 & 9,4 & 15 & 46,9 & 32 & 100 \\
\hline \multirow{2}{*}{$\begin{array}{l}\text { Funcionários } \\
\text { outrosc }^{c}\end{array}$} & Incorreto & 23 & 23,5 & 34 & 34,7 & 12 & 12,2 & 4 & 4,1 & 25 & 25,5 & 98 & 100 \\
\hline & Correto* & 19 & 15,2 & 27 & 21,6 & 17 & 13,6 & 4 & 3,2 & 58 & 46,4 & 125 & 100 \\
\hline
\end{tabular}

* pela semelhança de comportamento, foram considerados os corretos e parcialmente corretos.

FA - freqüência absoluta

FR - freqüência relativa
a. $x^{2}=0,565 \quad p=0,967$
b. $\mathrm{x}^{2}=14,616 \mathrm{p}=0,006$
c. $\mathrm{x}^{2}=12,075 \mathrm{p}=0,017$

Observa-se que entre os "alunos", nas maiores prevalências, houve uma diferença entre aqueles que responderam de forma correta (ou parcialmente correta), tendo atitudes mais avançadas para comportamento de "observar o valor energético das preparações culinárias oferecidas no restaurante", embora não tenha havido significância estatística dos dados (Tabela 25).

Entre os "funcionários básicos" e "funcionários outros", não houve diferença de comportamento nas maiores prevalências em relação às referências do 
conceito caloria e todos estavam na escala de "contemplação". Observa-se que para comportamento no estágio de "manutenção" houve maior concentração de indivíduos que responderam de forma correta ou parcialmente correta o termo. Também não houve significância estatística nas duas ocupações.

Tabela 25 - Distribuição dos participantes, segundo estrato, conhecimento do conceito de caloria e modelo transteorético, para comportamento de "observar o valor energético das preparações culinárias oferecidas no restaurante". São Paulo, 2005.

\begin{tabular}{|c|c|c|c|c|c|c|c|c|c|c|c|c|c|}
\hline \multirow[t]{3}{*}{ Ocupação } & \multirow{3}{*}{$\begin{array}{l}\text { Conheci- } \\
\text { mento do } \\
\text { conceito de } \\
\text { caloria }\end{array}$} & \multicolumn{12}{|c|}{ Classificação } \\
\hline & & \multicolumn{2}{|c|}{$\begin{array}{c}\text { Pré- } \\
\text { contemplação }\end{array}$} & \multicolumn{2}{|c|}{ Contemplação } & \multicolumn{2}{|c|}{ Preparação } & \multicolumn{2}{|c|}{ Ação } & \multicolumn{2}{|c|}{ Manutenção } & \multicolumn{2}{|c|}{ Total } \\
\hline & & $\mathrm{FA}$ & FR & FA & FR & FA & FR & FA & FR & FA & FR & FA & FR \\
\hline \multirow[t]{2}{*}{ Alunos ${ }^{a}$} & Incorreto & 35 & 43,2 & 31 & 38,3 & 1 & 1,2 & 9 & 11,1 & 5 & 6,2 & 81 & 100 \\
\hline & Correto* & 96 & 34,7 & 118 & 42,6 & 9 & 3,2 & 39 & 14,1 & 15 & 5,4 & 277 & 100 \\
\hline \multirow{2}{*}{$\begin{array}{l}\text { Funcionários } \\
\text { básicos }^{\mathrm{b}}\end{array}$} & Incorreto & 11 & 15,1 & 33 & 45,2 & 4 & 5,5 & 9 & 12,3 & 16 & 21,9 & 73 & 100 \\
\hline & Correto* & 4 & 12,5 & 12 & 37,5 & 2 & 6,2 & 4 & 12,5 & 10 & 31,3 & 32 & 100 \\
\hline \multirow{2}{*}{$\begin{array}{l}\text { Funcionários } \\
\text { outrosc }^{c}\end{array}$} & Incorreto & 22 & 22,4 & 33 & 33,7 & 6 & 6,1 & 15 & 15,3 & 22 & 22,5 & 98 & 100 \\
\hline & Correto* & 25 & 20,0 & 41 & 32,8 & 10 & 8,0 & 15 & 12,0 & 34 & 27,2 & 125 & 100 \\
\hline
\end{tabular}

* pela semelhança de comportamento, foram considerados os corretos e parcialmente corretos.

FA - freqüência absoluta

FR - freqüência relativa
a. $\mathrm{x}^{2}=2,922 \mathrm{p}=0,571$
b. $\mathrm{x}^{2}=1,217 \quad \mathrm{p}=0,875$
c. $\mathrm{x}^{2}=1,379 \mathrm{p}=0,848$

\section{- Conhecimento do conceito de alimentação saudável}

Como se observa da Tabela 26, embora as maiores prevalências estejam na atitude de contemplação, as diferenças se apresentaram inversamente nos extremos da classificação.

Para aqueles que desconhecem o conceito da expressão alimentação 
saudável, apresentaram comportamento "piores" ou menos avançadas do que aqueles que conhecem o significado da expressão nas três ocupações, embora exista associação apenas para a ocupação de "alunos" e "funcionários outros".

Tabela 26 - Distribuição dos participantes, segundo estrato, conhecimento do conceito de alimentação saudável e modelo transteorético, para comportamento de "ler o rótulo de embalagem de alimentos". São Paulo, 2005.

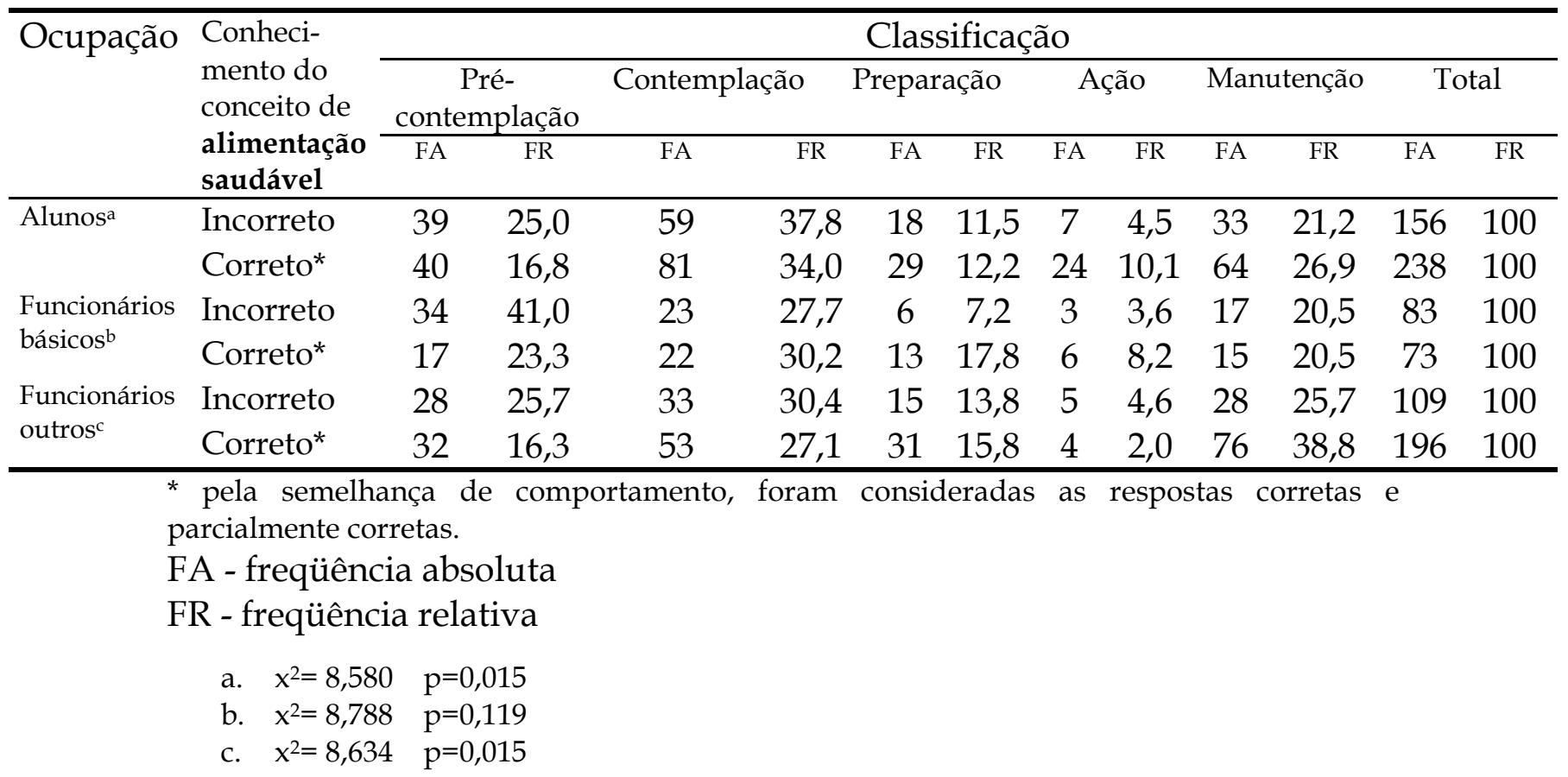

Na Tabela 27, observa-se que, entre os "alunos", houve diferença nas maiores prevalências, demonstrando que aqueles indivíduos que deram exemplos corretos de alimentação saudável estavam em estados mais avançados de comportamento em relação a "observar o valor energético das preparações culinárias oferecidas no restaurante". 
Entre "funcionários básicos" e "funcionários outros", as maiores prevalências foram para o comportamento de "contemplação" independente de as respostas serem classificadas como corretas ou incorretas. No entanto, houve associação estatística entre o grupo de "funcionários outros" para o estágio de "manutenção", demonstrando que o conhecimento da expressão interfere de forma positiva no comportamento.

Tabela 27 - Distribuição dos participantes, segundo estrato, conhecimento do conceito de alimentação saudável e modelo transteorético, para comportamento de "observar o valor energético das preparações culinárias oferecidas no restaurante". São Paulo, 2005.

\begin{tabular}{|c|c|c|c|c|c|c|c|c|c|c|c|c|c|}
\hline \multirow[t]{3}{*}{ Ocupação } & \multirow{3}{*}{$\begin{array}{l}\text { Conheci- } \\
\text { mento do } \\
\text { conceito de } \\
\text { alimentação } \\
\text { saudável }\end{array}$} & \multicolumn{12}{|c|}{ Classificação } \\
\hline & & \multicolumn{2}{|c|}{$\begin{array}{c}\text { Pré- } \\
\text { contemplação }\end{array}$} & \multicolumn{2}{|c|}{ Contemplação } & \multicolumn{2}{|c|}{ Preparação } & \multicolumn{2}{|c|}{ Ação } & \multicolumn{2}{|c|}{ Manutenção } & \multicolumn{2}{|c|}{ Total } \\
\hline & & FA & $\mathrm{FR}$ & FA & FR & FA & FR & FA & FR & FA & FR & FA & FR \\
\hline \multirow[t]{2}{*}{ Alunos ${ }^{a}$} & Incorreto & 62 & 39,7 & 60 & 38,5 & 3 & 1,9 & 24 & 15,4 & 7 & 4,5 & 156 & 100 \\
\hline & Correto & 82 & 34,5 & 102 & 42,9 & 12 & 5,0 & 27 & 11,3 & 15 & 6,3 & 238 & 100 \\
\hline \multirow{2}{*}{$\begin{array}{l}\text { Funcionários } \\
\text { básicos }{ }^{b}\end{array}$} & Incorreto & 12 & 14,4 & 37 & 44,6 & 3 & 3,6 & 11 & 13,3 & 20 & 24,1 & 83 & 100 \\
\hline & Correto & 18 & 24,7 & 28 & 38,4 & 5 & 6,8 & 7 & 9,6 & 15 & 20,5 & 73 & 100 \\
\hline \multirow{2}{*}{$\begin{array}{l}\text { Funcionários } \\
\text { outrosc }^{c}\end{array}$} & Incorreto & 27 & 24,8 & 46 & 42,2 & 5 & 4,6 & 13 & 11,9 & 18 & 16,5 & 109 & 100 \\
\hline & Correto & 45 & 23,0 & 62 & 31,6 & 16 & 8,2 & 21 & 10,7 & 52 & 26,5 & 196 & 100 \\
\hline
\end{tabular}

* pela semelhança de comportamento, foram considerados os corretos e parcialmente corretos.

FA - freqüência absoluta

FR - freqüência relativa
a. $\mathrm{x}^{2}=5,317 \mathrm{p}=0,638$
b. $\mathrm{x}^{2}=3,924 \quad \mathrm{p}=0,290$
c. $\mathrm{x}^{2}=6,73 \quad \mathrm{p}=0,067$

\section{- Fontes de informação sobre alimentação e nutrição}

Observa-se, na Tabela 28, que, em todas as ocupações, a maior prevalência foi para fonte escrita, seguida da audiovisual. Além disso, na fonte escrita, a 
maior prevalência foi para escala mais avançada de classificação, o estágio de "manutenção" para todas as ocupações.

Entre os "alunos", embora as maiores prevalências para as outras fontes (audiovisual, pessoal, formal e instrumental) estejam na classificação de "contemplação", houve uma movimentação para escala de "manutenção".

Entre os "funcionários outros", a maior prevalência em todas as fontes estavam no comportamento mais avançada, a escala de "manutenção".

Verifica-se que mesmo que sejam complexas as informações do rótulo de embalagem de alimentos, os comportamentos que tem atitudes mais avançadas, ficaram entre os "funcionários outros".

Entre os "funcionários básicos", as fontes de informação interferiram no comportamento de formas diferentes. Para a fonte de informação pessoal, as maiores prevalências foram para comportamentos menos avançados. As demais para o estágio de "contemplação". 
Tabela 28 - Distribuição dos participantes, segundo estrato, grupos de fontes de informação e modelo transteorético, para comportamento de "ler o rótulo de embalagem de alimentos". São Paulo, 2005.

\begin{tabular}{|c|c|c|c|c|c|c|c|c|c|c|c|c|c|}
\hline \multirow[t]{3}{*}{ Ocupação } & \multirow{3}{*}{$\begin{array}{l}\text { Grupos de } \\
\text { fontes de } \\
\text { informação }\end{array}$} & \multicolumn{12}{|c|}{ Classificação } \\
\hline & & \multicolumn{2}{|c|}{$\begin{array}{c}\text { Pré- } \\
\text { contemplação }\end{array}$} & \multicolumn{2}{|c|}{ Contemplação } & \multicolumn{2}{|c|}{ Preparação } & \multicolumn{2}{|c|}{ Ação } & \multicolumn{2}{|c|}{ Manutenção } & \multicolumn{2}{|c|}{ Total } \\
\hline & & FA & FR & FA & FR & FA & FR & FA & FR & FA & FR & FA & FR \\
\hline \multirow{6}{*}{$\begin{array}{l}\text { Alunos }^{a} \\
n=881\end{array}$} & Escrita & 51 & 15,0 & 101 & 29,8 & 48 & 14,2 & 37 & 10,9 & 102 & 30,1 & 339 & 100 \\
\hline & Audiovisual & 42 & 17,9 & 81 & 34,6 & 28 & 12,1 & 23 & 9,8 & 60 & 25,6 & 234 & 100 \\
\hline & Pessoal & 35 & 21,2 & 66 & 40,0 & 22 & 13,4 & 8 & 4,8 & 34 & 20,6 & 165 & 100 \\
\hline & Formal & 16 & 15,7 & 34 & 33,4 & 10 & 9,8 & 8 & 7,8 & 34 & 33,3 & 102 & 100 \\
\hline & Instrumental & 6 & 14,6 & 17 & 41,5 & 5 & 12,2 & 6 & 14,6 & 7 & 17,1 & 41 & 100 \\
\hline & Escrita & 18 & 17,1 & 23 & 21,9 & 21 & 20,0 & 7 & 6,7 & 36 & 34,3 & 105 & 100 \\
\hline \multirow{4}{*}{$\begin{array}{l}\text { Funcionários } \\
\text { básicos }^{\mathrm{b}} \\
\mathrm{n}=285\end{array}$} & Audiovisual & 13 & 18,6 & 23 & 32,8 & 14 & 20,0 & 3 & 4,3 & 17 & 24,3 & 70 & 100 \\
\hline & Pessoal & 21 & 35,0 & 17 & 28,3 & 9 & 15,0 & 3 & 5,0 & 10 & 16,7 & 60 & 100 \\
\hline & Formal & 6 & 22,2 & 12 & 44,4 & 1 & 3,7 & 1 & 3,7 & 7 & 26,0 & 27 & 100 \\
\hline & Instrumental & 4 & 17,4 & 12 & 52,2 & 2 & 8,7 & 1 & 4,3 & 4 & 17,4 & 23 & 100 \\
\hline \multirow{5}{*}{$\begin{array}{l}\text { Funcionários } \\
\text { outrosc }^{c} \\
n=665\end{array}$} & Escrita & 38 & 14,3 & 71 & 26,7 & 34 & 12,8 & 9 & 3,4 & 114 & 42,8 & 266 & 100 \\
\hline & Audiovisual & 40 & 18,1 & 58 & 26,2 & 33 & 14,9 & 6 & 2,7 & 84 & 38,1 & 221 & 100 \\
\hline & Pessoal & 23 & 19,0 & 24 & 19,8 & 19 & 15,7 & 8 & 6,7 & 47 & 38,8 & 121 & 100 \\
\hline & Formal & 4 & 10,5 & 10 & 26,3 & 8 & 21,1 & 1 & 2,6 & 15 & 39,5 & 38 & 100 \\
\hline & Instrumental & 3 & 15,8 & 6 & 31,6 & 2 & 10,5 & 2 & 10,5 & 6 & 31,6 & 19 & 100 \\
\hline
\end{tabular}

FA - freqüência absoluta

FR - freqüência relativa
a. $x^{2}=48,24 \quad p=0,000$
b. $x^{2}=24,17 \quad p=0,002$
c. $x^{2}=40,13 \quad p=0,000$

Diferente do comportamento de "ler o rótulo de embalagem de alimentos", verifica-se, na Tabela 29, que "observar o valor energético das preparações culinárias oferecidas no restaurante" entre "alunos" e "funcionários outros", as maiores prevalências das diferentes fontes de informação foram para comportamento de "contemplação".

Entre os "alunos", as fontes de informação interferiram de forma inversa no comportamento dos indivíduos que "observam o valor energético das 
preparações culinárias oferecidas no restaurante", sendo que quanto mais avançado o comportamento menor foram as fontes de informação referidas. Observa-se também que a maior prevalência da fonte instrumental foi classificada em comportamentos menos avançados, "pré-contemplação", demonstrando mais uma vez a pouca importância dessa informação nesses grupos especificamente.

Inversamente ao comportamento dos "alunos", entre os "funcionários básicos" e "funcionários outros" as fontes de informação interferiram de forma positiva no comportamento, estando estes em atitudes mais avançadas de comportamento. 
Tabela 29 - Distribuição dos participantes, segundo estrato, grupos de fontes de informação e modelo transteorético, para comportamento de “observar o valor energético das preparações culinárias oferecidas no restaurante". São Paulo, 2005.

\begin{tabular}{|c|c|c|c|c|c|c|c|c|c|c|c|c|c|}
\hline \multirow[t]{3}{*}{ Ocupação } & \multirow{3}{*}{$\begin{array}{l}\text { Grupos de } \\
\text { fontes de } \\
\text { informação }\end{array}$} & \multicolumn{12}{|c|}{ Classificação } \\
\hline & & \multicolumn{2}{|c|}{$\begin{array}{c}\text { Pré- } \\
\text { contemplação }\end{array}$} & \multicolumn{2}{|c|}{ Contemplação } & \multicolumn{2}{|c|}{ Preparação } & \multicolumn{2}{|c|}{ Ação } & \multicolumn{2}{|c|}{ Manutenção } & \multicolumn{2}{|c|}{ Total } \\
\hline & & FA & FR & FA & FR & FA & FR & FA & FR & FA & FR & FA & FR \\
\hline \multirow{6}{*}{$\begin{array}{l}\text { Alunos }^{a} \\
\mathrm{n}=881\end{array}$} & Escrita & 98 & 28,9 & 142 & 41,9 & 21 & 6,2 & 59 & 17,4 & 19 & 5,6 & 339 & 100 \\
\hline & Audiovisual & 69 & 29,5 & 110 & 47,0 & 4 & 1,7 & 35 & 15,0 & 16 & 6,8 & 234 & 100 \\
\hline & Pessoal & 59 & 35,8 & 75 & 45,5 & 5 & 3,0 & 17 & 10,3 & 9 & 5,4 & 165 & 100 \\
\hline & Formal & 34 & 33,3 & 40 & 39,2 & 6 & 5,9 & 12 & 11,8 & 10 & 9,8 & 102 & 100 \\
\hline & Instrumental & 17 & 41,5 & 13 & 31,7 & 2 & 4,9 & 6 & 14,6 & 3 & 7,3 & 41 & 100 \\
\hline & Escrita & 11 & 10,5 & 44 & 41,9 & 11 & 10,5 & 11 & 10,5 & 28 & 26,6 & 105 & 100 \\
\hline \multirow{4}{*}{$\begin{array}{l}\text { Funcionários } \\
\text { básicos }^{\mathrm{b}} \\
\mathrm{n}=285\end{array}$} & Audiovisual & 12 & 17,1 & 32 & 45,7 & 3 & 4,3 & 7 & 10,0 & 16 & 22,9 & 70 & 100 \\
\hline & Pessoal & 15 & 25,0 & 11 & 18,3 & 4 & 6,7 & 10 & 16,7 & 20 & 33,3 & 60 & 100 \\
\hline & Formal & 4 & 14,8 & 9 & 33,3 & 1 & 3,7 & 5 & 18,5 & 8 & 29,6 & 27 & 100 \\
\hline & Instrumental & 2 & 8,7 & 14 & 60,9 & - & - & 4 & 17,4 & 3 & 13,0 & 23 & 100 \\
\hline \multirow{5}{*}{$\begin{array}{l}\text { Funcionários } \\
\text { outros }^{c} \\
n=665\end{array}$} & Escrita & 57 & 21,4 & 90 & 33,8 & 19 & 7,1 & 26 & 9,8 & 74 & 27,8 & 266 & 100 \\
\hline & Audiovisual & 49 & 22,2 & 76 & 34,4 & 21 & 9,5 & 25 & 11,3 & 50 & 22,6 & 221 & 100 \\
\hline & Pessoal & 19 & 15,7 & 45 & 37,2 & 12 & 9,9 & 20 & 16,5 & 25 & 20,7 & 121 & 100 \\
\hline & Formal & 9 & 23,7 & 13 & 34,2 & 2 & 5,3 & 3 & 7,9 & 11 & 28,9 & 38 & 100 \\
\hline & Instrumental & 3 & 15,8 & 9 & 47,4 & - & - & 3 & 15,8 & 4 & 21,0 & 19 & 100 \\
\hline
\end{tabular}

FA - freqüência absoluta

FR - freqüência relativa

$\begin{array}{ll}\text { a. } x^{2}=43,01 & p=0,000 \\ \text { b. } x^{2}=27,13 & p=0,001 \\ \text { c. } x^{2}=32,62 & p=0,000\end{array}$

De modo geral, os comportamentos observados entre "ler o rótulo de produtos alimentícios" (Tabela 28) e "observar o valor energético das preparações culinárias oferecidas no restaurante" (Tabela 29) não apresentaram associação.

Verifica-se que "observar o valor energético das preparações culinárias oferecidas no restaurante" (Tabela 29) tem contribuído para o 
comportamento dos indivíduos, principalmente na ocupação de "funcionários básicos". Além disso, esse grupo, principalmente no sexo masculino, apresentou excesso de peso e pouca prática de atividade física esportiva, contribuindo para situações de risco em relação à saúde. 


\section{5 - DISCUSSÃO}


Não houve nenhuma desistência durante o processo da entrevista, isso pode ser atribuído ao fato da garantia de sigilo das informações ser durante o turno de trabalho ou estudo e em horário que não prejudicou o desenvolvimento das funções de "funcionários" e "alunos" da universidade (ELL e col., 1999).

Por meio do perfil socioeconômico desta população, principalmente anos de educação formal, conclui-se condições mínimas para leitura e entendimento de informações, previamente disponibilizadas, como as constantes no rótulo de embalagem de alimentos e o valor energético das preparações culinárias presentes nos restaurantes universitários.

Estudo realizado por FUJIMORI e colaboradores (1994), entre universitárias do curso de Enfermagem da USP, demonstrou que 24\% das alunas foram classificadas com excesso de peso, $64 \%$ em peso adequado e $12 \%$ em baixo peso. Mais de uma década depois, os dados parecem se modificar relativamente, mostrando ligeiro declínio na proporção de alunas com classificação de baixo peso e evidência na diminuição da proporção de excesso de peso.

Já entre os "alunos" do sexo masculino, valores de excesso de peso $(22,0 \%)$ são maiores do que entre as mulheres e indicam ser um grupo que deva ser monitorado. Também foi observada maior prevalência de excesso de peso em homens no estrato de "funcionários" e associação inversa entre anos de educação formal.

Pesquisa realizada entre bancários de instituição pública, no Estado do Rio de Janeiro, com perfil semelhante ao grupo etário, proporção de sexo e anos de educação formal, observou que a média de IMC foi de $25,1 \mathrm{~kg} / \mathrm{m}^{2}$ para 
homens e $23,3 \mathrm{~kg} / \mathrm{m}^{2}$ para mulheres. Além disso, os homens apresentaram maior freqüência de excesso de peso do que as mulheres (ELL e col., 1999). Estes valores se mostraram semelhantes aos encontrados nesta pesquisa. A diferença ocorreu na associação entre anos de educação formal e a classificação de IMC que verificou ser quanto maior a escolaridade, maior também o IMC entre os bancários da pesquisa acima relatada.

O resultado da PPV demonstrou que na região Sudeste do Brasil, as prevalências de excesso de peso são de $40 \%$ da população, sendo também superior entre os homens adultos e apresenta uma positiva associação entre obesidade e renda, isto é, quanto maior a renda, maior o peso. Já entre as mulheres, da mesma região, a obesidade foi associada, inversamente, somente aos anos de educação formal significando quanto menor os anos de educação formal, maior o peso (MONTEIRO, 2001).

Conforme relatado por MONTEIRO (2003), a prevalência da obesidade no sexo masculino aumenta uniforme e intensamente, em todos os estratos sociais, ao longo dos inquéritos nacionais. Além disso, os autores relataram que a escolaridade é a chave que responde pela associação inversa, atualmente encontrada no Brasil, entre nível socioeconômico e obesidade no caso das mulheres.

Outro estudo, de análise das prevalências de excesso de peso por região, demonstrou ser maior na região Sul e Sudeste do Brasil. Analisando os indicadores por sexo, observou-se maior prevalência de excesso de peso entre os homens em relação às mulheres (MINISTÉRIO DA SAÚDE, 2004).

A proporção de homens com excesso de peso, nesta pesquisa, é preocupante na medida em que representa um risco de morbidade e mortalidade com 
enorme custo social.

Em relação à prática de atividade física, estudo realizado no Estado de São Paulo (MATSUDO e col,. 2002), com indivíduos de ambos os sexos e idade entre 14 e 77 anos de idade, selecionados em 29 cidades, não encontrou diferença significante entre os sexos no grupo de sedentários, apresentando uma realidade diferente ao encontrado no presente estudo.

Esse fato pode ser devido a avaliação ter sido feita apenas para a prática de atividade física esportiva e não em outros tipos de atividade física, como, por exemplo, a atividade física realizada para executar atividades domésticas. Atividades estas, ainda realizadas predominantemente por mulheres.

Não foi observada relação entre idade e prática de atividade física esportiva entre as mulheres dos dois estratos, considerando indivíduos ativos e muito ativos. MATSUDO e colaboradores (2002) também observaram não haver relação entre o nível de atividade física e a idade cronológica no sexo feminino com exceção dos indivíduos classificados como "muito ativos", para os quais a atividade diminui de acordo com o aumento do grupo etário.

Entre os homens, observou-se que a prática de atividade física esportiva foi maior entre os indivíduos mais jovens. O que não foi observado por MATSUDO e colaboradores (2002), cujo aumento da atividade física ocorreu com o aumento da idade. A exceção foi entre os indivíduos considerados "muito ativos" que, como no caso das mulheres, diminuem a atividade física com o aumento da idade.

De acordo com estudo realizado por CASPERSEM e colaboradores (2000), nos Estados Unidos, as mulheres reportam ser fisicamente, mais ativas (27\%) 
do que os homens $(21 \%)$ e variações importantes ocorrem em função da etnia. O Departamento de Saúde Pública, desse país, refere que 40\% dos adultos não realizam atividade física esportiva (CDC, 2001), valores semelhantes aos encontrados nesse estudo.

Outros trabalhos referiram que o sedentarismo também é mais encontrado em mulheres, idosos e indivíduos com menor escolaridade (CRESPO e col., 2000; MISIGOJ-DURAKOVIA e col., 2000; GOMES e col., 2001).

Anos de educação formal apresentou associação com a prática de atividade física, nesta pesquisa, fato também encontrado por CASPERSON e colaboradores (1997), citado por MATSUDA e colaboradores (2002), que observaram associação entre diminuição da inatividade física e anos de educação formal, que passou de $37 \%$ entre os que cursavam o ensino médio, para $14 \%$ entre aqueles que cursavam o ensino universitário.

Dados similares foram encontrados em moradores do município do Rio de Janeiro, descritos por GOMES e colaboradores (2001), onde a atividade física de lazer, em indivíduos, de ambos os sexos, variou de 6,1\% a 17,8\%, para indivíduos de zero a cinco anos de educação formal, para 24,8\% a 39,6\% para o grupo com mais de dez anos de educação formal.

A inatividade física tem apresentado a maior prevalência entre os fatores de risco para morbi-mortalidade cardiovascular (MATSUDO e col., 2002). Estimular prática de atividade física de lazer ou esportiva, de forma acessível, seria, boa estratégia para prevenção de doenças crônicas não transmissíveis.

Nesta pesquisa, foram as mulheres que mais referiram fazer compras de 
alimentos. Em estudo realizado por COUTINHO e MONTEIRO (2002), com mulheres, freqüentadoras de supermercados, do Distrito Federal, observaram que a realização das compras por si só já favorece a leitura dos rótulos e isso ocorre de maneira mais eficiente quando o indivíduo a realiza com o auxílio de um acompanhante.

Ao que se refere "ter o hábito de ler o rótulo de embalagem de alimentos", os valores encontrados foram semelhantes a outros estudos realizados no Brasil.

Na cidade de Belo Horizonte, estudo realizado com freqüentadores de supermercados, verificou que $62 \%$ dos consumidores liam o rótulo de produtos alimentícios (FERRAZ e col., 2003).

Estudo realizado em Vila Formosa, região da cidade de São Paulo, apontou que $59,5 \%$ das mulheres referiram consultar o rótulo dos alimentos que compram. Observou-se que as mulheres que referiram ler o rótulo apresentavam maior escolaridade e escolhas mais saudáveis de alimentos (GOMES e CYRILLO, 2006).

Como também, estudo realizado no Canadá, verificou que $70 \%$ dos indivíduos pesquisados referiram ler o rótulo, o que também ocorre mais em mulheres e em indivíduos com alto nível de escolaridade e renda (HEALTH CANADA, 1998).

Embora vários estudos tenham demonstrado que os indivíduos referem ler a informação nutricional durante as compras, também foi observado que essa prática não ocorre de forma sistêmica (HEALTH CANADA, 1998; COUTINHO e MONTEIRO, 2002) e muitas vezes apenas quando se compra o alimento pela primeira vez (PATERSON e col., 2002). 
Na região da cidade de São Paulo, estudo verificou que a maior informação lida no rótulo foi a validade $(87,6 \%)$, seguida de lista de ingredientes e informação nutricional (27\%) (GOMES e CYRILLO, 2006). Esses dados foram percentualmente inferiores ao encontrado em estudo nacional (50\%) da Pesquisa do Instituto Nacional de Câncer, porém na mesma ordem de importância para os pesquisados (MINISTÉRIO DA SAÚDE, 2004).

Na presente pesquisa, verificou-se que as informações observadas diferem entre os estratos. Os "funcionários" do sexo masculino referiram observar a informação de validade e as mulheres, a lista de ingredientes. Entre os "alunos", a maior referência foi para a informação nutricional, mais especificamente, a informação de valor calórico do alimento.

Em estudos internacionais observaram que, entre os americanos, $71 \%$ da amostra liam a informação nutricional (GUTHRIE e col., 1995) e, entre os consumidores irlandeses, $37 \%$ relataram fazer dessa informação suas escolhas (SHINE e col., 1997).

No presente estudo, foi pequena a referência do preço como interferência na aquisição de alimentos (6,0\% no estrato de "funcionários" e 3,0\% no estrato de "alunos") sem distinção de sexo. Em estudo realizado por COUTINHO e MONTEIRO (2002), o preço foi apontado como o item de maior influência para aquisição dos produtos alimentícios, sendo maior em indivíduos com atividade autônoma, aposentados e donas de casa. Entre os indivíduos com ocupação de estudante, a maior referência foi para o "sabor" do alimento. Vale ressaltar que os "funcionários" e "alunos" dos estratos desta pesquisa tiveram perfil diferente ao encontrada no estudo mencionado.

Ainda na pesquisa realizada por COUTINHO e MONTEIRO (2002), 
observou-se que consumidores consideram "muito" influente a informação nutricional para aquisição do alimento, principalmente entre o sexo feminino.

No que diz respeito à informação do valor energético das preparações culinárias oferecidas pelos restaurantes, estas são menos observadas do que as informações nutricionais de rótulos de embalagem de alimentos e têm menos interferência em suas escolhas de um modo geral. Entretanto, os "funcionários" foram os que mais referiram observar essa informação. A hipótese para o fato está na diferença de perfil dos estratos, "funcionários" têm mais idade, estão com IMC mais elevado e referem mais presença de doenças, além disso, essa informação é única, em relação à variedade de itens das informações nutricionais dos rótulos de embalagem de alimentos.

$\mathrm{Na}$ investigação sobre o conceito de caloria, houve diferença em referir o conceito de caloria e demonstrar o conhecimento sobre o assunto. Esse comportamento também foi descrito na pesquisa realizada no Distrito Federal, onde 73,6\% referiram ter alguma fonte de informação sobre o valor energético constante no rótulo de embalagens de produtos alimentícios, 16\% não souberam dizer a definição, 44,6\% relataram o conceito adequado do termo, e apenas 4,9\% demonstraram o conhecimento de forma correta (COUTINHO e MONTEIRO, 2002). Os resultados revelaram que na população estudada do Distrito Federal, mesmo afirmando conhecer o conceito, não o empregavam de maneira adequada. Pode-se inferir que as mensagens não são veiculadas com forma ou conteúdo adequados nas embalagens de alimentos para o público em geral, além da deficiência de conhecimentos básicos sobre alimentação e nutrição de modo que os indivíduos possam utilizar essa informação de forma a auxiliar nas escolhas saudáveis de consumo de alimentos. 
Vários estudos demonstraram que as informações veiculadas no rótulo de embalagem de alimentos variam muito, principalmente no que diz respeito a conceitos positivos e negativos e atribuições e méritos à saúde de alguns alimentos, fazendo com que os indivíduos se tornem cada vez mais céticos em relação às informações e muitas vezes confusos com a diversidade de conceitos difundidos pela mídia (CASOTTI e col., 1998).

Estudo que avaliou as representações sociais da alimentação e saúde e suas repercussões no comportamento alimentar, realizado entre funcionários públicos na região central da cidade de São Paulo, verificou que há uma valorização de elementos da alimentação, tais como "gordura" e "colesterol", independente do sexo, idade ou qualquer condição aparente de doença, confirmando como grandes malefícios destes tempos, principalmente, se integradas às experiências vivenciadas com problemas de saúde (GARCIA, 1997).

O mesmo foi observado, na presente pesquisa, entre o grupo de "funcionários", principalmente os homens que fizeram uma relação direta entre o conceito de alimentação saudável e o teor de gordura dos alimentos.

Esse dado também foi semelhante à pesquisa realizada com população adulta, no Distrito Federal, que investigou os benefícios e barreiras em adotar uma alimentação saudável. Nesse estudo, foi observado também que a maior referência, para o conceito do termo, foi a associação ao "consumo de frutas e hortaliças" em 38,1\% dos casos, sendo essa menção superior entre as mulheres (42,9\%) (RADAELLI, 2003a), como também foi encontrado neste trabalho.

Nesta presente pesquisa foi observado, principalmente entre os 
"funcionários", que, embora considerassem a informação de valor energético das preparações culinárias dos restaurantes universitários satisfatória, houve referência de necessidade de informações complementares sobre o assunto, principalmente a relação dos alimentos para a prevenção de doenças e informações básicas sobre alimentação e nutrição.

A análise das fontes de informação sobre alimentação e nutrição utilizadas pelos diferentes grupos sociais pode auxiliar na definição de estratégias de promoção de educação nutricional mais eficazes.

Verificou-se que não houve citação dos participantes da pesquisa, no presente estudo, as fontes como órgãos do governo, por exemplo, Ministério da Saúde e Secretaria da Saúde, apesar destes utilizarem instrumentos disponíveis e facilitados como os endereços eletrônicos na internet. Além disso, não foi objetivo do presente estudo investigar o grau de credibilidade dado pelos participantes sobre as fontes de informação consultadas.

De acordo com ADAN e HERZLICH (2001), citado por COUTINHO e MONTEIRO (2002), constatou ser uma realidade o problema das relações entre representação e ação, entre o "dizer" e o "fazer" no que diz respeito aos aspectos relacionados à saúde e a relação entre informação e comportamento é extremamente complexa, não sendo possível desvinculá-la de outros elementos, como a estrutura social, sistemas de valor e referências culturais do indivíduo. Cuidar da saúde e da alimentação pode ser uma decisão individual baseada em sentimentos, informação ou norma, mas é preciso entender a dificuldade envolvida, compreender suas implicações relacionais estabelecidas pela cultura do grupo ao qual pertence o indivíduo.

A comunicação em massa é reconhecida como eficiente na formação de 
hábitos alimentares em coletividades, mas esse potencial é pouco explorado pelas entidades governamentais, permitindo à indústria de alimentos uma grande ocupação da mídia (ADA, 2002). Entretanto, a prioridade da indústria de alimentos é o marketing comercial e não promoção de alimentação saudável, o que ocasiona o incentivo ao consumo de alimentos com alta densidade energética e gordura (ROBINSON e col., 1998 e KRONEMBERG e col., 2000).

Estudo realizado, pelo Instituto de Alimentação Européia, demonstrou que as mulheres, os indivíduos com idade entre 35 e 45 anos e com pelo menos o ensino médio completo são os que procuram, com mais freqüência, informação sobre alimentação saudável. As fontes mais referidas nessa pesquisa foram televisão/rádio (29\%), revistas/jornais (27\%), profissionais de saúde (26\%) e informação nutricional de rótulo de alimentos (22\%) (ALMEIDA e col., 1997), resultado muito semelhante ao encontrado na presente pesquisa.

No Distrito Federal, pesquisa desenvolvida por RADAELLI (2003b),observou que a escolaridade apresentou relação significativa com os tipos de fontes de consultas como revistas, jornais, internet, profissionais de saúde, como nutricionistas, rótulo de embalagens de alimentos, parentes e amigos, livros e ensino médio e superior. Cerca de 30\% dos estudantes e 16\% dos indivíduos que estavam empregados citaram a internet.

Esse resultado foi diferente ao encontrado na presente pesquisa, cujos "funcionários" referiram mais de que os "alunos" o uso da internet. Talvez esse resultado seja pelo tipo de atividade desenvolvida na Universidade no qual o recurso do computador seja muito utilizado entre os "funcionários". 
Também como foi observado, em pesquisa desenvolvida por RADAELLI (2003b), a mulher, além de declarar procurar informação com maior freqüência que os homens, também apresenta variedade maior entre as fontes consultadas, semelhante à presente pesquisa. A exceção foi em relação à referência ao meio instrumental, em que os homens do estrato de "funcionários" referiram mais essa fonte de informação.

As fontes mais especializadas, como profissionais de saúde, nutricionistas e médicos (meio pessoal), ensino médio e superior (meio formal) foram as menos citadas. Os fatores que podem ter influenciado a pouca consulta de tais fontes são o difícil acesso a profissionais da área, carência ou falha na divulgação de informações, tanto no ensino médio como no superior. Situação semelhante também foi verificada em outros estudos que investigaram a influência da informação sobre comportamentos saudáveis de alimentação em população adulta (ALMEIDA e col., 1997; ADA, 2002; BUTTRISS e col., 2004).

Em âmbito nacional, inquérito realizado em 1996, restrito a mulheres em idade reprodutiva, pôde evidenciar que acesso a informações, medidascom base no hábito de ler jornais e assistir a programas educativos transmitidos pela televisão, mostrou significativa e inversamente associadas ao risco da obesidade nesse grupo (MONTEIRO e col., 2003).

Estudos sobre o impacto da informação nutricional, sobre o comportamento dos indivíduos, têm verificado que a informação de valor energético é a mais observada pelos indivíduos que lêem o rótulo de embalagem de alimentos e referem ser uma informação clara e objetiva (COUTINHO e MONTEIRO, 2002; RADAELLI, 2003b). 
$\mathrm{Na}$ presente pesquisa, as mulheres referiram ler as informações nutricionais disponíveis nos rótulos de embalagem de alimentos e as de valor energético apresentados pelos restaurantes universitários. Pode-se inferir que esse fato se dê em virtude de ser a mulher a responsável pela alimentação, muitas vezes da família, o que é observado, também, em vários outros estudos internacionais e nacional (NEUHOUSER e col., 1999; TURRELL e col., 2002; MINISTÉRIO DA SAÚDE, 2005).

SATIA e colaboradores (2005) observaram que ler as informações do rótulo de embalagem de alimentos só está associado entre aqueles indivíduos com excesso de peso, mas que estão fazendo controle para diminuir o peso.

Estudo realizado na região sudeste do país confirmou a existência de uma tendência acelerada do risco da obesidade nas populações masculina e feminina de baixa escolaridade, e a recente estabilização ou mesmo diminuição de risco de obesidade entre mulheres de média e alta escolaridade (MONTEIRO e col., 2003).

O excesso de peso implica que a concentração de doenças nos estratos sociais menos favorecidos, isto é, de menor renda e escolaridade, terão enormes repercussões futuras sobre a distribuição social da carga total de doenças no Brasil (MONTEIRO e col., 2003).

A projeção dos resultados de estudos, efetuados nas últimas três décadas, é indicativa de um comportamento claramente epidêmico do problema do excesso de peso. A observação seqüenciada dos resultados descritos entre 1975 e 1996 indica que a ocorrência do problema praticamente triplicou entre homens e mulheres maiores de vinte anos do Nordeste e homens do sudeste. No Sudeste, entre 1989 e 1996, a evolução progressiva se deteve, tendo, 
inclusive, um pequeno declínio entre as mulheres adultas. É evidente que as diferenciações geográficas e sociais expressam esse comportamento (BATISTA FILHO e HISSIN, 2003).

Ter comportamento de leitura, compreensão e uso da informação nutricional pode auxiliar de alguma forma na estabilização ou reversão desse quadro.

Estudo realizado por COUTINHO e MONTEIRO (2002) investigou a população adulta freqüentadora de supermercados, do Distrito Federal, e não encontrou relação entre o hábito de consultar rótulos de produtos alimentícios e doenças crônicas transmissíveis referidas, embora 40,4\% referiram hipertensão arterial, 23,2\% cardiopatias e 21,6\% excesso de peso.

Estudo realizado com americanos de origem africana, na Carolina do Norte, demonstrou que indivíduos com alta e moderada atividade física fazem uso das informações dos rótulos de embalagem de alimentos em suas escolhas de consumo (SATIA e col., 2005).

Entrevista realizada entre alunos de um curso de especialização da USP verificou que $76 \%$ dos indivíduos liam as informações dos rótulos dos produtos alimentícios e a informação mais lida foi o valor energético do alimento $(55 \%)$ e $51 \%$ relataram fazer suas escolhas com base nessa informação (TEIXEIRA e col., 2003).

Em relação ao conhecimento de alimentação saudável, BONOMO e colaboradores (2003) realizaram estudo de base populacional, na região centro-oeste do estado de Minas Gerais, e observaram que os homens relataram consumir alimentos com alta densidade energética e proporcionalmente mais bebidas com teor alcoólico que as mulheres e com o 
aumento da idade aumenta o consumo de alimentos ricos em proteínas. Com o aumento da renda, ocorre tendência de aumento de consumo de alimentos ricos em lipídios, ultrapassando o limite máximo recomendado por 30\% de energia total fornecida pela alimentação. As maiores inadequações foram observadas entre os indivíduos mais idosos, os de maior escolaridade e com maior renda per capita, demonstrando que a população de estudo referiu consumir proporções muito diferentes daquelas preconizadas para uma alimentação saudável (BONOMO e col., 2003). Observou-se também que as mulheres apresentaram uma alimentação mais saudável do que a dos homens, fato também descrito em outro estudo realizado em países europeus (HORLDSWORTH e col., 2000).

O conceito de alimentação saudável tem sido divulgado à população sob várias formas: mídia, rótulo de embalagem de alimentos, profissionais da área e organizações de saúde de forma a orientar escolhas mais saudáveis em termos qualitativos e quantitativos (ADA, 2002).

Entre os "funcionários básicos", a referência da fonte pessoal ficou na escala menos avançada de classificação. Vale ressaltar que a maior referência para esta fonte foi para a família e amigos; também estão agrupados profissionais de saúde. Pesquisa, realizada por BOOG (1999) e SILVA e colaboradores (2002), descreve as dificuldades encontradas por médicos e enfermeiros para abordarem o assunto "alimentação e nutrição" a seus pacientes. Os problemas encontrados foram, entre outros, falta de embasamento teórico para analisar problemas alimentar, falta de parâmetros para discernir problemas alimentares de problemas econômicos, além do conflito entre conhecimento teórico e prático, vivenciado pessoalmente pelo profissional.

Em trabalho realizado por BOOG (1997), na analise de publicações, como da 
OMS (Organização Mundial de Saúde), OPAS e FAO (Food Agriculture Organizacion), que foram as principais fontes de informação no campo da educação nutricional para profissionais da área e analisa o papel do nutricionista em serviços de saúde, aponta como dificuldades a própria deficiência dos cursos de Nutrição para esse tipo de atendimento aos quais se misturam papéis tão diferentes na orientação nutricional e educação nutricional.

Estudos sobre mudanças de comportamento têm verificado que o suporte social, ou seja, família, amigos e ambiente de trabalho oferecem o apoio emocional, instrumental, de informação e avaliação os quais influenciam diretamente em atitudes saudáveis dos indivíduos (YETLEY e RUDETRUK, 1993; DALTROY e col., 1993).

Embora os meios de comunicação, nos últimos anos, tenham sofrido grande revolução, principalmente devido à comunicação eletrônica (REGER e col., 1999), observa-se que a mídia consiste numa das principais fontes de informação sobre alimentação e nutrição (ADA 2002). Além disso, estudo realizado por BRUG e colaboradores (2005) indica que a internet possui possibilidades estratégicas para realização de educação nutricional, uma vez que o seu acesso está cada vez maior e a busca de informações sobre saúde também.

Sendo a alimentação uma instância da vida social e afetiva dos indivíduos, pode, em muitas situações, a informação a seu respeito oscilar entre a objetividade e subjetividade, dificultando o discernimento de ambos por parte do especulador (GARCIA, 2004).

Vale a pena ressaltar, que no grupo da fonte da audiovisual, encontra-se o 
veículo de informação mundial de informação, a televisão. A informação sobre alimentação e nutrição nesse meio de comunicação veicula-se através de programas, entre eles os educativos, noticiários e anúncios de produtos alimentícios, entre outros. Pesquisa, realizada entre 1998 e 2000, observou que dos 1.395 anúncios de produtos alimentícios, 57,8\% eram de alimentos com elevados índices de gorduras, óleos, açúcares, doces e sal o que não está de acordo com as recomendações de uma alimentação saudável (ALMEIDA e col. 2002). Além disso, tem-se demonstrado associações significativas entre o número de horas diante da televisão e o peso corporal do indivíduo que, entre outras coisas, representa comportamento sedentário comum entre esse grupo (GORTMAKER e col., 1996; ROBINSON e col., 1998).

Nesta pesquisa, observou-se que quanto maior os anos de estudo formal, maior o percentual de fontes de informação, o comportamento dos indivíduos, segundo modelo transteorético, são mais avançados em relação ás informações nutricionais do rótulo de alimentos e o valor energético das preparações culinárias oferecidas nos restaurantes e que podem interferir de forma positiva quanto as atitudes em relação à alimentação saudável. Esse achado vai ao encontro de outros estudos que utilizaram o modelo transteorético para classificação dos indivíduos em relação ao comportamento (BYRD-BREDBNNER e col., 2000).

Segundo modelo transteorético e na presente pesquisa, as mulheres tiveram comportamentos mais avançados do que os homens tanto em relação a informação nutricional de rótulos de embalagem de alimentos quanto para informação de valor energético das preparações culinárias oferecidas nos restaurantes universitários. Estas proporções aumentam à medida que aumenta os anos de educação formal.

O papel do sexo em relação a escolhas de alimentos, aquisição e preparo 
continua a ser quase que exclusivamente feminino. Quando mudanças de paradigmas são necessárias, uma vez que a mulher assume atividades no ambiente de trabalho remunerado ou de estudo e no espaço doméstico, acumulando a responsabilidade da alimentação, muitas vezes da família.

O principal desafio na formulação e na implantação de estratégias para a promoção da alimentação saudável passa necessariamente pela avaliação de papéis dos sexos, os valores e o sentido do tempo, devendo ser criados mecanismos de suporte social para a desconcentração dessa atribuição como exclusivamente feminina (MINISTÉRIO DA SAÚDE, 2005).

Estudo realizado, na Carolina do Norte, demonstrou associação entre anos de educação formal, idade e a leitura das informações do rótulo de embalagem de alimentos. Esse fator se acentuou mais entre as mulheres que observaram a informação nutricional do rótulo de embalagem de alimentos e validade do produto. Além disso, fatores psicosociais como satisfação com o peso, condições de saúde referidas e relação da alimentação com outras doenças, como, o câncer, também estiveram associados ao hábito de ler as informações do rótulo de embalagem de alimentos (SATIA e col., 2005).

Também entre aqueles que referem fazer "controle de peso", presença de doença, praticar atividade física esportiva e que relatam o conceito de caloria e alimentação saudável de forma correta, estão associados a atitudes mais avançadas em relação as duas informações investigadas pela pesquisa e assim na manutenção da saúde. 


\section{6 - CONCLUSÕES}


Observou-se ser esta pesquisa de importante natureza, uma vez que não foram encontrados trabalhos específicos que avaliassem o comportamento sobre informação nutricional em população universitária.

Após análise dos dados, verificou-se comportamento diferente entre os estratos, "alunos" e "funcionários". Estes, por sua vez, também apresentaram comportamento diferente entre si, e tal fato se deveu, principalmente, ao tempo de educação formal dos indivíduos.

Verificou-se não haver associação entre "ler a informação nutricional de rótulo de embalagem de alimentos" e observar a informação de "valor energético de preparações culinárias oferecidas nos restaurantes universitários" entre os indivíduos.

Entre os "alunos" observou-se pouco interesse em relação às duas informações.

No caso dos "funcionários", os que tiveram maior tempo de educação formal ("funcionários outros") utilizaram mais a informação nutricional dos rótulos de embalagem de alimentos. Entre os "funcionários" de menor tempo de educação formal ("funcionários básicos"), utilizaram mais a informação de valor energético de preparações culinárias oferecidas nos restaurantes universitários para que fizessem suas escolhas.

Embora haja diferenças de comportamento entre os dois estratos, observouse que as mulheres utilizaram mais as duas informações, em relação aos homens.

Indivíduos com maior escolaridade e com excesso de peso, utilizaram mais 
as informações nutricionais do rótulo de embalagem de alimentos. Particularmente, os funcionários com excesso de peso utilizaram mais as informações de valor energético das preparações culinárias oferecidas no restaurante.

O mesmo comportamento foi observado para indivíduos que referiram fazer "controle de peso".

Os funcionários, de modo geral, que referiram problemas de saúde utilizaram mais as informações nutricionais do rótulo de embalagem de alimentos.

Já os indivíduos, que referem problemas de saúde, e de maior tempo de estudo formal ("alunos" e "funcionários outros"), utilizaram mais a informação de valor energético das preparações culinárias oferecidas no restaurante.

Indivíduos que praticam atividade física esportiva têm maior tempo de educação formal e de maior grupo etário, utilizaram as duas informações.

Observou-se que embora os "alunos" sejam o grupo que mais conhecimento mostrou sobre o conceito de caloria, esse conhecimento não afeta seu comportamento em relação às duas informações.

O conhecimento de conceito de alimentação saudável está relacionado ao maior tempo de estudo formal e estes utilizam mais as duas informações.

Existe associação entre as fontes de informação, dentre elas a escrita, nos padrões de comportamento mais avançados em relação às duas informações. 
As interpretações dos resultados obtidos nessa pesquisa são complexas e análises mais profundas tornam-se necessárias para compreensão dos mecanismos que motivam a população a usar os recursos disponíveis como a informação nutricional de rótulo de produtos alimentícios embalados e informação de valor energético das preparações culinárias oferecidas nos restaurantes universitários. 


\section{7 - CONSIDERAÇÕES}


Embora existam poucas evidências de que os efeitos da informação nutricional de rótulos e alegações de saúde em alimentos sejam suficientes para mudanças de comportamentos dos indivíduos, é imprescindível investir na informação e orientação dessa população.

Para afinar o conhecimento técnico-científico à compreensão do público alvo, várias técnicas são necessárias, inclusive adequação de conceitos e nomenclaturas respeitando os aspectos sócioculturais dos diferentes grupos da sociedade (FERREIRA e col., 2001).

A utilização dos recursos disponíveis, como o Serviço Integrado de Saúde da Universidade de São Paulo (SISUSP), por meio do Hospital Universitário (HU), e a integração às atividades do Centro de Práticas Esportivas da Universidade de São Paulo (CEPEUSP), consiste em aproveitar o meio oferecido pela Universidade sem implicar na perda do conteúdo técnicocientífico e manutenção da qualidade de informação. Assim as mensagens sobre alimentação tornam-se prazerosas e praticáveis por meio da conscientização e instrumentalização quanto à leitura da informação nutricional. Além de reformulações flexíveis que permitem a preservação de elementos importantes ligados ao cotidiano, como as tradições, costumes, o gosto, e também às experiências de um modo geral.

Durante a pesquisa, ficou claro ser necessário maior variedade de informações sobre alimentação e nutrição que complementem a informação de valor energético das preparações culinárias oferecidas nos restaurantes. 


\section{8 - REFERÊNCIAS}


ADA - American Dietetic Association. Position of the American Dietetic Association: nutrition education for the public. J Am Diet Assoc. 1996;96(11):1183-7.

ADA - American Dietetic Association. Position of the American Dietetic Association: food and nutrition misinformation. J Am Diet Assoc. 2002;102(2):260-6.

Almanza BA, Nelson D, Chai S. Obstacles to nutrition labeling in restaurants. J Am Diet Assoc. 1997;97(2):157-61.

Almeida MDV, Graça P, Lappalainen R, Giachetti I, Kafatos A, Winter AM, et al. Sources used and trusted by nationally-representative adults in the European Union for information on healthy eating. Eur J Clin Nutr. 1997;51(2 Suppl):16-22.

Almeida SS, Nascimento PCBD, Quaioti TCB. Quantidade e qualidade de produtos alimentícios anunciados na televisão brasileira. Rev Saúde Pública. 2002;36(3):353-5.

Araújo ACMF, Araújo WMC. Adequação à legislação vigente, da rotulagem de alimentos para fins especiais dos grupos alimentares para dietas com restrição de carboidratos e alimentos para dieta de ingestão controlada de açúcares. Higiene Alimentar. 2001a;1(82):52-70.

Araújo ACMF, Araújo WMC. Adequação à legislação vigente, da rotulagem de produtos lácteos enriquecidos com cálcio e ferro. Higiene Alimentar. 2001b;15(88):34-49. 
Avegliano RP. Custos de refeições em unidades de alimentação e nutrição: uma aplicação para a divisão de alimentação Coseas/USP, em 1997 [dissertação de mestrado]. São Paulo: Nutrição Humana Aplicada da USP; 1999.

Batista Filho M, Rissin A. A transição nutricional no Brasil: tendências regionais e temporais. Cad Saúde Pública. 2003;19(1 Supl):181-91.

Bobadilla JL, Frenk J, Lozano R, Frekja T, Stern C. The epidemiologic transition and health priorities. In: Jamison DT. Disease control priorities in developing countries. Washington DC: Oxford Medical Publications; 1993. p. 161-97.

Bonomo E, Caiaffa WT, César CC, Lopes ACS, Lima-Costa MF. Consumo alimentar da população adulta, segundo perfil socioeconômico e demográfico: projeto Bambuí. Cad Saúde Pública. 2003;19(5):1461-71.

Boog MCF. Educação nutricional: passado, presente, futuro. Rev Nutr. 1997;10(1):5-19.

Boog MCF. Dificuldades encontradas por médicos e enfermeiros na abordagem de problemas alimentares. Rev Nutr. 1999;12(3):261-72.

Brasil. Decreto-lei no 986 de 12 de outubro de 1969. Dispõe sobre normas básicas de alimentos [decreto-lei na internet]. [acesso em 17 fev 2006]. Disponível em: http://www.anvisa.gov.br/legis/decreto/986

Brasil. Lei n ${ }^{\circ} 8078$ de 11 de setembro de 1990. Dispõe sobre a proteção do consumidor e dá outras providências [lei na internet]. [acesso em 25 abr 
2006]. Disponível em: http:/ / www.planalto.gov.br/ccivil/leis/L8078.htm

Brug J, Oenema A, Kroeze W, Raat H. The internet and nutrition education: challenges and opportunities. Eur J Clin Nutr. 2005;59:S130-9.

Brunt AR, Schafer E. Helping consumers with low literacy interpret the new food label. J Nutr Educ. 1997;29:224A.

Buttriss J, Stanner S, McKevith B, Nugent AP, Kelly C, Phillips F, et al. Successful ways to modify food choice: lessons from the literature. Nutr Bull. 2004;29:333-43.

Byrd-Bredbenner C, Won A, Cotte P. Consumer understanding of US and EU nutrition labels. Br Food J. 2000;102(8):615-29.

Casotti L, Ribeiro A, Santos C, Ribeiro P. Consumo de alimentos e nutrição: dificuldades práticas e teóricas. Cad Debates. 1998;6:26-39.

Caspersen CJ, Pereira MA, Curran KM. Changes in physical activity patterns in the United States, by sex and cross-sectional age. Med Sci Sports Exerc. 2000;32(9):1601-9.

Castro VMF. Conteúdo informativo das embalagens de alimentos: um estudo exploratório internacional comparado, sob a ótica brasileira e norteamericana dos agentes de produção e consumo [tese de doutorado]. São Paulo: Faculdade de Saúde Pública da USP; 2000.

CDC - Centers for Disease Control and Prevention. Increasing physical activity. MMWR Recomm Rep. 2001;50(RR-18):1-14. 
Cohen S, Lichtenstein E, Prochaska JO, Rossi JS, Gritz ER, Carr CR, et al. Debunking myths about self-quitting: evidence from 10 prospective studies of person quitting smoking by themselves. Am Psychol. 1989;44:1355-65.

Coitinho D, Monteiro CA, Popkin BM. What Brazil is doing to promote healthy diets and active lifestyles. Public Health Nutr. 2002;5(1A):263-7.

Conselho Nacional de Saúde. Resolução n 196, de 10 de outubro de 1996. Dispõe sobre diretrizes e normas de pesquisa envolvendo seres humanos [resolução na internet]. [acesso em 04 dez 2005]. Disponível em: http:/ / conselho.saude.gov.br/docs/Reso196.doc

Coutinho JG, Monteiro RA. Uso e entendimento pela população adulta freqüentadora de supermercados do plano piloto, Distrito Federal, da informação nutricional de alimentos e bebidas embalados [monografia de especialista]. Brasília: Faculdade de Ciências da Saúde da UNB; 2002.

Crespo CJ, Smir E, Andersen RE, Carter-Pokras O, Ainswroth BE. Race/ethnicity, social class and their relation to physical inactivity during leisure time: results from the Third National Health and Nutrition Examination Survey, 1988-1994. Am J Prev Med. 2000;18(1):46-53.

Cunningham E. Where can I find resources on food labeling in restaurant setting? J Am Diet Assoc. 2003;103(2):199.

Daltroy LH, Iversen MD, Larson MG, Ryan J, Zwerling C, Fossel AH, et al. Teaching and social support: effects on knowledge, attitudes and behaviors to prevent low back injuries in industry. Health Educ Q. 1993;20:44-53. 
Department of Health and Human Services. The surgeon general's call to action to prevent and decrease overweight and obesity. Rockville, MD; 2001.

DiClemente CC, Hughes SL. Stages of change profiles in alcoholism treatment. J Sust Abuse. 1990;2:217-35.

DRH-USP - Departamento de Recursos Humanos da Universidade de São Paulo. Plano de classificação de funções. São Paulo. [acesso em 01 mar 2005]. Disponível em: http://www.usp.br/drh/novo/assessoria/novopcf.htm

Ell E, Camacho LAB, Chor D. Perfil antropométrico de funcionários de banco estatal no estado do Rio de Janeiro, Brasil: índice de massa corporal e fatores sócio-demográficos. Cad Saúde Pública. 1999;15(1):113-21.

Escamilla RP, Haldeman L. Food label use modifies association of income with dietary quality. J Nutr. 2002;132:768-72.

Ferraz RG, Soares NFF, Silva NM. Comportamento do consumidor frente à informação nutricional em rotulagem de produtos alimentícios: um estudo no varejo de Belo Horizonte - MG. Bol Soc Bras Cienc Tec Alimentos. 2003;37(2):106-12.

Ferreira ABH. Novo Aurélio século XXI: o dicionário da língua portuguesa. 3. ed. Rio de Janeiro: Nova Fronteira; 1999. verbete, p. 514.

Ferreira MN, Mantoanelli G, Colucci ACA, Philippi ST. Como as pessoas entendem a pirâmide alimentar [resumo]. In: 6. Congresso Nacional da Sociedade Brasileira da Alimentação e Nutrição; 2001 set 16-19; Santa Catarina, Brasil. Florianópolis: Sociedade Brasileira de Alimentação e 
Nutrição; 2001. p. SP-69.

Frary CD, Jonhson RK. Energia. In: Mahan LK, Escott-Stump S. Krause: alimentos, nutrição e dietoterapia. 11. ed. São Paulo: Roca; 2005. p. 20-34.

Freitas JF, Damasceno KSFSC, Calado CLA. Rotulagem de alimentos lácteos: a percepção do consumidor. Higiene Alimentar. 2004;18(125):17-23.

Frenk J. Health transition in middle-income countries: new challenges for health care. Health Policy Plan. 1989;4(1):29-39.

Frumkin P. House bill would force chains to serve up nutrition data. Natl Restaur. 2003; 37(43):1.

Fujimori E, Oliveira IMV, Soares MAL, Osso AC. Avaliação nutricional de estudantes universitários do sexo feminino. Rev Esc Enferm USP. 1994;28(1):72-82.

Gandra YR, Gambardella AMD. Avaliação de serviços de nutrição e alimentação. São Paulo: Sarvier; 1983. p. 1.

Garcia RWD. Representações sociais da alimentação e saúde e suas repercussões no comportamento alimentar. Physis Rev Saúde Coletiva. 1997;7(2):51-68.

Garcia RWD. Representações sobre consumo alimentar e suas implicações em inquéritos alimentares: estudo qualitativo em sujeitos submetidos à prescrição dietética. Rev Nutr. 2004;17(1):15-28. 
Glanz K, Patterson RE, Kristal AR, DiClemente CC, Heimendinger J, Linnan L, et al. Stages of change in adopting health diets: fat, fiber and correlates of nutrient intake. Health Educ Q. 1994;21:499-519.

Gomes VB, Siqueira KS, Sichieri R. Atividade física em uma amostra probabilística da população do município do Rio de Janeiro. Cad Saúde Pública. 2001;17(4):969-76.

Gomes ALC, Cyrillo DC. Utilização da rotulagem de alimentos embalados e a qualidade da alimentação de mulheres de uma região de São Paulo. Nutrire. 2006; 31. No prelo.

Gortmaker SL, Must A, Sobol AM, Peterson K, Coldiz GA, Dietz WH. Television viewing as a cause of increasing obesity among children in the United State, 1986-1990. Arch Pediatr Adolesc Med. 1996;150(4):356-62.

Grácia-Arnaiz M. Paradojas de la alimentacion contemporánea. Barcelona: Institut Català d’Antropologia; 1996.

Graciano RAS, Gonzalez E, Jorge LIF, Silva MLP. Avaliação crítica da rotulagem praticada pela indústria alimentícia brasileira. Higiene Alimentar. 2000;14(73):21-7.

Greene GW, Rossi SR, Reed GR, Willey C, Prochaska JO. Stage of change for reducing dietary fat to $30 \%$ of energy or less. J Am Diet Assoc. 1994;94:1105-10.

Guthrie JF, Fox JJ, Cleveland LE, Welsh S. Who uses nutrition labeling, and what effects does label use have on diet quality? J Nutr Educ. 
1995;27(4):163-72.

Hawkes C. Nutrition labels and health claims: the global regulatory environment. Geneve: World Health Organization; 2004. [acesso em 21 mar 2006]. Disponível em: http://www.whqlibdoc.who.int/publication/2004/9241591714.pdf

Health Canadá. Nutrition labelling: a strategic framework for public education acknowledgments. Otawa; 1998.

Holdsworth M, Gerber M, Haslam C, Scali J, Beardsworth A, Avallone MH, et al. A comparison of dietary behaviour in central England and a French Mediterranean region. Eur J Clin Nutr. 2000;54(7):530-9.

Kreuter MW, Brennan LK, Scharff DP, Lukwago SN. Do nutrition label readers eat healthier diets: behavioral correlates of adults' use of food label. Am J Prev Med. 1997;13(4):277-83.

Kronenberg F, Pereira MA, Kathryn M, Schmitz H, Arnett DK, et al. Influence of leisure time physical activity and television watching on atherosclerosis risk factrs in the NHLBI family heart study. Atherosclerosis. 2000;153:433-43.

Lima A, Guerra NB, Lira BF. Evolução da legislação brasileira sobre rotulagem de alimentos e bebidas embalados, e sua função educativa para promoção da saúde. Higiene Alimentar. 2003;17(110):12-7.

Marucci MFN, Barbosa AR. Estado nutricional e capacidade física. In: Lebrão ML, Duarte YAO, organizadores. SABE - Saúde Bem-Estar e Envelhecimento 
- o projeto SABE no município de São Paulo: uma abordagem inicial. Brasília DF: OPAS; 2003. p.95-117.

Matsudo SM, Matsudo VR, Araújo T, Andrade D, Andrade E, Oliveira L, et al. Nível de atividade física da população do estado de São Paulo: análise de acordo com o sexo, idade, nível socioeconômico, distribuição geográfica e de conhecimento. Rev Bras Cien Mov. 2002;10(4):41-50.

Miller JA. Labeling research: the state of the art. Mark Sci Inst. 1978;3:63-7.

Ministério da Agricultura e do Abastecimento. Portaria n 371 de 04 de setembro de 1997. Aprova regulamento técnico para rotulagem de alimentos embalados [portaria na internet]. [acesso em $01 \mathrm{fev}$ 2006]. Disponível em: http:/ / oc4j.agricultura.gov.br/agrolegis/do/consultaLei?op=viewTextual\& codigo $=3195$

Ministério da Saúde, Agência Nacional de Vigilância Sanitária. Resolução RDC $\mathrm{n}^{\circ} 40$ de 21 de março de 2001. Aprova regulamento técnico para rotulagem nutricional obrigatória de alimentos e bebidas embalados [resolução na internet]. [acesso em 17 fev 2006]. Disponível em: http://www.anvisa.gov.br/legis/resoluções/40

Ministério da Saúde, Agência Nacional de Vigilância Sanitária. Resolução RDC $n^{\circ} 259$ de 20 de setembro de 2002. Aprova regulamento técnico que se aplica à rotulagem de todo alimento que seja comercializado, qualquer que seja sua origem, embalado na ausência do cliente, e pronto para oferta ao consumidor [resolução na internet]. [acesso em 11 jul 2006]. Disponível em: http:/ /e-legis.anvisa.gov.br/leisref/public / showAct.php?id=1261\&word=informa \%C3\% A7\%C3\%A3o\%20nutricional 
Ministério da Saúde, Agência Nacional de Vigilância Sanitária. Resolução RDC n $n^{\circ} 360$ de 23 de dezembro de 2003. Aprova regulamento técnico sobre rotulagem nutricional de alimentos embalados, tornando obrigatória a rotulagem nutricional [resolução na internet]. [acesso em 04 abr 2006]. Disponível em: http:/ / elegis.anvisa.gov.br/leisref/public/showAct.php?id=9059\&word= Ministério da Saúde, Secretaria de Vigilância em Saúde, Secretaria de Atenção à Saúde. Inquérito domiciliar sobre comportamento de risco e morbidade referida e de doenças e agravos não transmissíveis. Brasil, 15 capitais e Distrito Federal, 2002-2003. Rio de Janeiro: INCA; 2004 [acesso em 25 jan 2006]. Disponível em:

http://www.inca.gov.br/inquerito/docs/completa.pdf

Ministério da Saúde, Secretaria de Atenção à Saúde, Coordenação Geral da Política de Alimentação e Nutrição. Guia alimentar para a população brasileira: promovendo a alimentação saudável. Brasília, DF; 2005 [acesso em 20 fev 2006]. Disponível em: http:// dtr2004.gov.br/nutricao/documentos/guia_alimentar_conteudo.pdf Misigoj-Durakovia M, Heimer S, Matkovia BR, Ruzia L, Prskalo I. Physical activity of urban adult population: questionnaire study. Croat Med J. 2000;41(4):428-32.

Monteiro CA, Conde WL, Popkin BM. Independent effects of income and education on the risk of obesity in the brazilian adult population. J Nutr. 2001;131(3):881S-6.

Monteiro CA, Conde WL, Castro IRR. A tendência cambiante da relação 
entre escolaridade e risco de obesidade no Brasil (1975-1997). Cad Saúde Pública. 2003;9(1 Suppl):67-75.

Neuhouser ML, Krista AR, Patterson RE. Use of food nutrition labels is associated with lower fat intake. J Am Diet Assoc. 1999;99(1):45-53.

NRC - National Research Council. Recommended dietary allowances. 10. ed. Washington DC: National Academy Press; 1989.

OMS - Organização Mundial de Saúde. CID - 10: Classificação Estatística Internacional de doenças e problemas relacionados à saúde. São Paulo; 1993 [acesso em 19 de julho de 2006]. Disponível em http://www.datasus.gov.br/cid10/webhelp/cid10.htm

Paterson D, Zappelli R, Chalmers A. Food labelling issues: consumer qualitative research. Camberra: Austrália and New Zeland Food Authority; 2002 [acesso em 27 abr 2006]. Disponível em: http:/ / foodstandards.gov.au/mediareleasespublications/publications/foodlabellin gissuesconsumerresearchdecember2001/index.cfm

Philippi ST, Latterza AR, Cruz ATR, Ribeiro LC. Pirâmide alimentar adaptada: guia para escolha de alimentos. Rev Nutr. 1999;12(1):65-80.

Prochaska JO, DiClemente CC, Norcross JC. In search of how people change: applications to addictive behaviors. Am Psychol. 1992a;47(9):1102-14.

Prochaska JO, Noreross JC, Fowler JL, Follick MJ, Abrams DB. Attendance and outcome in a work-site weight control program: processes and stage of change as process and predictor variables. Addct Behav. 1992b;17:35-45. 
Radaelli PG. Atitudes da população adulta do Distrito Federal, Brasil, relacionadas com alimentação saudável [dissertação de mestrado]. Brasília DF: Universidade de Brasília; 2003a. Benefícios e barreiras em seguir uma alimentação saudável, segundo população adulta do Distrito Federal, Brasil; p.81-122.

Radaelli PG. Atitudes da população adulta do Distrito Federal, Brasil, relacionadas com alimentação saudável [dissertação de mestrado]. Brasília DF: Universidade de Brasília; 2003b. Fonte de informação sobre alimentação e nutrição utilizadas pela população adulta do Distrito Federal, Brasília; p.174-218.

Reger B, Wootar MG, Booth-Butterfield S. Using mass media to promote healthy eating: a community-based demonstration Project. Prev Med. 1999;29(5):414-21.

RIPSA - Rede Internacional de Informações para a Saúde. Indicadores básicos de saúde no Brasil: conceitos e aplicações. Brasília DF; 2002.

Robinson TN, Chen HL, Killen JD. Television and music video exposure and risk adolescent alcohol use. Pediatrics. 1998;102(5):E54.

Satia JA, Galanko JA, Neuhouser ML. Food nutrition label use is associated with demografic, behavioral, and psychosocial factors and dietary intake among african americans in North Carolina. J Am Diet Assoc. 2005;105(3):392-402.

Seeley RJ, York DA. Fuel sensing and the Central Nervous System (CNS): implications for the regulation of energy balance and treatment for obesity. 
Obes Rev. 2005;6:259-65.

Seragini L. Embalagem: fruto do pensamento estratégico. F C Embalagem. 1990;3(30):28-32.

Shine A, O'Reilly S, O'Sullivan K. Consumer attitudes to nutrition labelling. Br Food J. 1997;99(8):283-9.

Silva DO, Recine EGIG, Queiroz EFO. Concepções de profissionais de saúde da atenção básica sobre alimentação saudável no Distrito Federal, Brasil. Cad Saúde Pública. 2002;18(5):1367-77.

Silverglade BA. The impact of international trade agreements on US food safety and labeling standard. Food Drug Law J. 1998;53(3):537-41.

Sizer FS, Whitney EN. Nutrição: conceitos e controvérsias. São Paulo: Manole; 2003. Escolhas alimentares e saúde humana; 1-26.

Sneed J, Burknalter JP. Marketing nutrition in restaurants: a survey of current practices and attitudes. J Am Diet Assoc. 1991;91:459-62.

Sorensen G, Stoddand A, Macario E. Social support and readness to make dietary chances. Health Educ Behav. 1998;25(5):586-98.

Steptoe A, Wijetung S, Dohert S, Wandie J. Stage of change for dietary fat reduction: associations with food intake, decisional balance and motives for food choice. Health Educ J. 1996;55:108-22. 
Stokes JW. How to manage a restaurant or institutional food service.

Dubuque: WMC Brown; 1982. Effective management; p. 19-31.

Teixeira ACC, Philippi ST, Lefévre F. Rótulo dos alimentos: como as pessoas entendem a informação nutricional? [resumo] In: 11. Simpósio Internacional de Iniciação Científica da Universidade de São Paulo; 2003 nov 06-07; São Paulo, Brasil. São Paulo: Universidade de São Paulo; 2003. p. 26.

Turrell G, Hewitt B, Patterson C, Oldenburg B, Gould T. Socioeconomic differences in food purchasing behavior and suggested implications for dietrelated health promotion. J Hum Nutr Dietet. 2002;15:355-64.

USP - Universidade de São Paulo. Regimento Geral; São Paulo; 1990.

Administração da Universidade: Coordenadoria de Assistência Social; Seção VI, p.21.

USP - Universidade de São Paulo, Coordenadoria de Assistência Social. Relatório de Avaliação Institucional. São Paulo: Coseas; 2004.

USP - Universidade de São Paulo. Anuário estatístico USP - 2005; São Paulo; 2005. Coordenadoria de Administração Geral: CODAGE/USP.

Waldman EA. A transição epidemiológica: tendências e diferenciais dos padrões de morbimortalidade em diferentes regiões do mundo. Mundo Saúde. 2000;24(1):10-8. 
Wandel M. Food labelling from a consumer perspective. Br Food J. 1997;99(6):212-9.

Welland D. RDs and restaurants: recipe for success. J Am Diet Assoc. 1993;93(10):1105-8.

Wheelock F. Food quality and consumer choice. Br Food J. 1992;94:39-43.

WHA - World Health Assembly. Global strategy on diet: physical activity and health. Washington, DC: World Health Organization; 2004. (WHA 57.17).

WHO - World Health Organization. Obesity: preventing and managing the global epidemic. Geneva; 2000. (WHO Technical Report Series, 894).

WHO - World Health Organization. Diet, nutrition and prevention of chronic diseases. Geneva; 2003. (WHO Technical Report Series, 916).

Yetley EA, Rudetruck C. Nutritional knowledge and health goals of young spouses. J Am Diet Assoc. 1993;77:31-41.

Yoshizawa N, Pospissil RT, Valentim AG, Seixas D, Alves FS, Cassou F, et al. Rotulagem de alimentos como veículo de informação ao consumidor: adequação e irregularidades. Bol Centro Pesqui Process Aliment. 2003;21(1):169-80. 
9 - ANEXOS 

ANEXO I - Cartaz de orientação: informação de valor energético das preparações culinárias oferecidas nos restaurantes universitários 


\section{Divisão de Alimentação COSEAS/USP}

As informações sobre valor calórico dos alimentos e preparações das refeições estarão disponíveis aos usuários por meio de etiquetas informativas, dispostas nos balcões de distribuição dos restaurantes.
Como utilizar as informações das etiquetas?

Atente para o valor calórico em cada etiqueta, relativo a uma porção. O somatório desses valores indica a quantidade de calorias oferecidas em sua refeição.

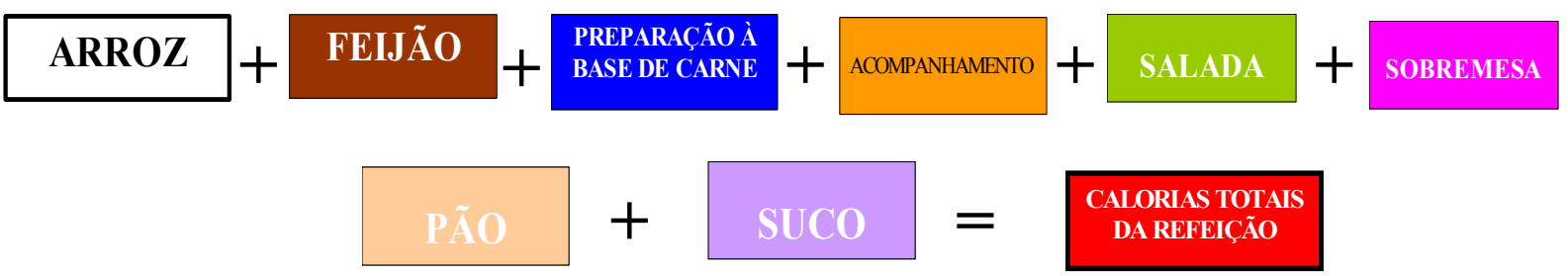

A Divisão de Alimentação planeja atender, em uma refeição, 40\% das necessidades diárias de energia do "usuário padrão Coseas/USP" dos restaurantes, isto é, 1.100 kcal por refeição (almoço ou jantar). As refeições são planejadas anualmente pela equibe de nutricionistas desta Divisão.

- NOME DO ALIMENTO OU

- PORÇÃO

- CALORIA POR
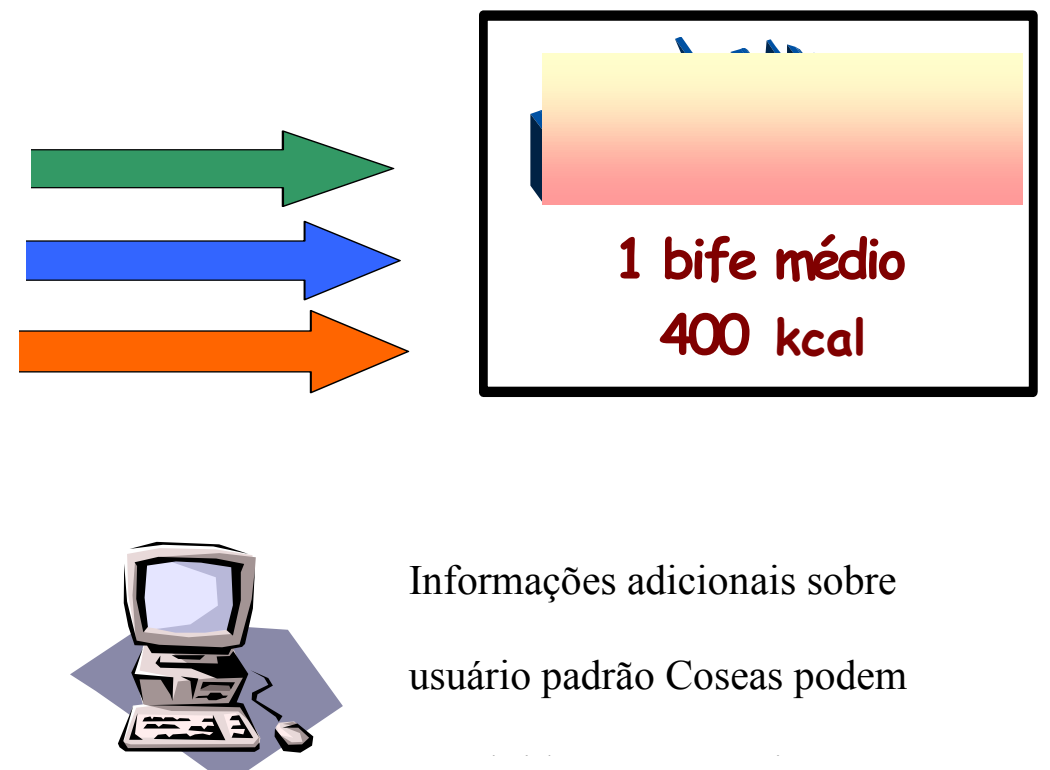

Informações adicionais sobre usuário padrão Coseas podem 
A - 3

ANEXO II - Formulário de entrevista da pesquisa 


\section{REPERCUSSÃO DA INFORMAÇÃO NUTRICIONAL SOBRE O COMPORTAMENTO DE CLIENTES DE RESTAURANTES UNIVERSITÁRIOS}

Restaurante:

Entrevistador:

Início da entrevista:

Término da entrevista:

Data:

Dia da semana:

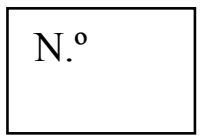

\section{I - Características demográficas}

1. Nome:

2. Sexo: ( )F; ( )M 3. Data de nasc.: ___ _

4. Endereço eletrônico:

5. Telefone de contato:

6. Caso não tenha end. eletrônico ou tel. preencher endereço completo:

II - Características: ocupacional e escolaridade

7. Qual sua ocupação na universidade?

\section{Aluno ( ) Docente ( ) Funcionário ( ) Aposentado ( )}

8. Caso seja aluno, qual o

curso?

9. Até que ano

estudou?

III - Informações: antropométrica, referência de saúde e atividade física

10. O Sr (a) pode me informar seu peso?

11. O Sr (a) pode me informar sua estatura?

IMC:

12. $\mathrm{O} \mathrm{Sr}(\mathrm{a})$ faz algum tipo de controle de peso?

$\operatorname{Sim}(\quad$ ) Caso afirmativa responder a 13

Às vezes ( ) Caso às vezes responder a 13

Não ( ) Caso negativo passar para 14

13. Por quê? Para controlar o peso ( ) Orientação profissional ( ) Outros:

14. Por quê? Não pensou a respeito ( ) Não precisa ( ) Não quer ( ) Não consegue ( ) Outros:

15. O Sr (a) apresenta algum problema em relação a sua saúde? diabetes ( ) colesterol elevado ( ) dor na coluna ( ) pressão alta ( ) obesidade ( ) Outros:

16. $\mathrm{O} \mathrm{Sr}(\mathrm{a})$ pratica alguma atividade física? $\operatorname{Sim}(\mathrm{)}$ Caso afirmativo responder a 17

Não ( ) Caso negativo passar para 18

17. Qual? quantas vezes por semana e quantos minutos por dia

\section{IV - Informações: restaurante e rótulo de alimentos}

18. Há quanto tempo o $\mathrm{Sr}(\mathrm{a})$ usa o restaurante? Desde: mês: ano:

19. Quantas vezes por semana o $\mathrm{Sr}$ (a) usa o restaurante?

< que $2 \times(\quad) 3 \times(;>4 \times(\quad)$

20. O Sr (a) faz compras de alimentos?

Sim ( ) Não ( )

21. O Sr (a) tem por hábito ler o rótulo das

embalagens de produtos alimentícios?

Sim ( ) Por quê?

Há quanto tempo?

Não ( ) Por quê?

Caso negativo passar para 24

Às vezes ( ) Por quê?

22. O que o $\mathrm{Sr}$ (a) observa no rótulo das embalagens de produtos alimentícios? Validade ( ) composição

( ) calorias ( ) gordura ( ) Fe ( ) Ca ( )

Outros:

23. A informação nutricional interfere em sua escolha?

Sim ( ) Por quê?

Há quanto tempo?

Não ( ) Por quê?

Às vezes ( ) Por quê?

\section{Pré-contemplação ( ) Contemplação ( )}

Preparação ( ) Ação ( ) Manutenção ( )

24. O Sr (a) observa a informação nutricional dos pratos servidos nos restaurantes?

Sim ( ) Por quê?

Não ( ) Por quê?

Às vezes ( ) Por quê?

25. O Sr (a) acha a informação de caloria importante?

Sim ( ) Por quê?

Não ( ) Por quê?

Caso negativo passar para 28

Às vezes ( ) Por quê?

26. Essa informação interfere em sua escolha ou no volume de alimento servido?

Sim ( ) Por quê?

Há quanto tempo?

Não ( ) Por quê?

Às vezes ( ) Por quê?

Pré-contemplação ( ) Contemplação ( )

Preparação ( ) Ação ( ) Manutenção ( )

27. De alguma forma o $\mathrm{Sr}(\mathrm{a})$ usa essa informação

fora do restaurante?

Sim ( ) Por quê?

Não ( ) Por quê?

Às vezes ( ) Por quê? 
28. Em sua opinião, quais informações nutricionais seriam importantes constar no rótulo dos pratos servidos no restaurante universitário?

29. Em sua opinião, qual seria a estratégia para dar maior visibilidade à informação nutricional do rótulo no restaurante universitário?

30. O $\mathrm{Sr}(\mathrm{a})$ sabe o que significa caloria?

Sim ( ) O que significa?

Não ( )

Errado ( ) Parcialmente Certo ( ) Certo ( )

31. O Sr (a) sabe a quantidade de caloria necessária para um dia?

Sim ( ) Quanto?

Não ( )

\section{Errado ( ) Parcialmente Certo ( ) Certo ( )}

32. Qual o total aproximado de caloria dos alimentos que o $\mathrm{Sr}$ (a) se serviu no almoço de hoje?

33. $\mathrm{O} \mathrm{Sr}(\mathrm{a})$ sabe o que significa alimentação saudável?

Sim ( ) Dê um exemplo:

Não ( )

Errado ( ) Parcialmente Certo ( ) Certo ( )

34. Sobre alimentação e nutrição, quais as fontes de informação que o Sr (a) tem?

Revistas ( ) TV( ) Família ( ) Internet ( ) Jornais ( ) Rádio ( ) Amigos ( )

Livros ( )

Médicos ( )

Nutricionistas ( ) Outros: 
ANEXO III - Manual de instruç̃es para treinamento dos entrevistadores 


\section{"REPERCUSSÃO DA INFORMAÇÃO NUTRICIONAL SOBRE O COMPORTAMENTO DE CLIENTES DE RESTAURANTES UNIVERSITÁRIOS"}

\section{Máurea Elena Missio da Silva \\ Manual de Treinamento dos Entrevistadores}

\section{Amostragem}

A população de estudo será constituída por funcionários e alunos que utilizam os restaurantes universitários do Campus da USP. Serão selecionadas duas amostras de 600 indivíduos cada.

Os restaurantes selecionados para o desenvolvimento do estudo serão as unidades: Central, Física, Escola de Enfermagem e Faculdade de Saúde Pública. Estes serão visitados em forma de rodízio, diariamente durante as semanas do estudo, no período do almoço (11h às $14 \mathrm{~h} 30 \mathrm{~min}$ ).

\section{Entrevistador}

O entrevistador deverá estar munido com: guarda-pó, carteirinha de identificação da USP em local visível, prancheta, Termo de Consentimento Livre e Esclarecido, Formulário de Entrevista e caneta.

- Iniciar a entrevista com o objetivo da pesquisa.

- Dar o nome da instituição de pesquisa.

- Falar da importância da sua colaboração na pesquisa.

- Deixar bem claro o caráter confidencial da entrevista.

\section{Formulário de Entrevista}

O formulário será composto por 34 perguntas fechadas, abertas e duplas. $\mathrm{O}$ entrevistador deverá preenchê-lo completamente e ficar atento às seguintes informações: 
1- $\mathrm{N}^{\circ}$ - do cartão.

2- Iniciais do entrevistador.

3- Nome - completo do entrevistado.

4- Telefone do entrevistado - o mais fácil para localizá-lo.

5- E-mail do entrevistado - mais usado.

6- Endereço - completo, caso não tenha e-mail ou telefone.

7- Ficar atento às indicações em vermelho no formulário.

8- Não preencher o que estiver em negrito.

9- Não mencionar as alternativas existentes no formulário ao entrevistado e sim anotar a primeira frase referida por ele.

\section{Instruções da Entrevista}

\subsection{Abordagem pessoal}

Os usuários serão abordados pessoalmente no momento de passagem pela catraca para controle da categoria (separação entre funcionário e aluno) e contagem do intervalo entre eles para a seleção do candidato na amostra.

O usuário escolhido será convidado a participar, aceitando responder à entrevista, receberá um cartão numerado que deverá ser considerado no campo $\underline{\mathrm{N}} \mathrm{.}^{\circ}$ do formulário no momento da entrevista.

O candidato selecionado que aceitar participar da entrevista será orientado a entregar o cartão numerado ao entrevistador na área externa do restaurante, após o término de seu almoço.

O entrevistador deverá fazer uma breve introdução ao candidato sobre a sua importância da participação desta pesquisa e informar lhe sobre o caráter confidencial dos dados coletados. Nesse momento será solicitada concordância formal de cada participante por meio do Termo de Consentimento Livre e Esclarecido.

\subsection{Abordagem por telefone}


Os candidatos selecionados que se apresentarem interessados em participar da pesquisa e por algum motivo não conseguirem participar da entrevista, será solicitado um telefone para contato posterior.

No momento da ligação, deverá ser informado o tempo médio da entrevista e verificar o melhor horário para a realização evitando assim intercorrências nesse período.

O entrevistador deve ter cautela para controlar a conversa evitando divagações que distanciem o foco principal da pergunta.

\section{Conduta na Entrevista}

\subsection{Entrevistador}

A conduta do entrevistador pode provocar alterações de comportamento dos entrevistados, interferindo na espontaneidade e produzindo resultados pouco confiáveis, para isso, atentar:

- A atmosfera deve ser de cordialidade e simpatia.

- O entrevistado deve se sentir livre de qualquer coerção, intimidade e pressão.

- As perguntas devem ser feitas com tranqüilidade.

- Caso o entrevistado negue a informar qualquer pergunta, anotar no formulário.

- Fazer uma pergunta de cada vez.

- O tom de voz não deve deixar implícita a resposta.

- Caso o entrevistado não entenda a pergunta, o entrevistador deve repeti-la textualmente. Não deve explicar a pergunta ao entrevistado.

- Transcrição imediata das respostas anotando textualmente o que o entrevistado responder. Não resumir a resposta dada pelo entrevistado.

- Anotar no formulário somente após o entrevistado começar a responder.

- O entrevistador deve evitar realizar movimentos que dispersem a atenção do entrevistado. 
- O entrevistado deve ser tratado de forma respeitosa do começo ao fim da entrevista.

- Agradecer a participação do entrevistado ao final da entrevista.

Frases que podem ser usadas na entrevista para não interferir na resposta:

- Poderia contar um pouco mais a respeito?

- Qual a causa, no seu entender?

- Qual a sua idéia em relação a este ponto?

- Qual o dado que the parece mais exato?

- Gostaria que me falasse um pouco mais a respeito!

\subsection{Abordagem para participação na entrevista}

- Cordialidade na abordagem.

- Poder de persuasão, clareza e agilidade para, num curto espaço de tempo, informar sobre o objetivo da pesquisa, pedir sua colaboração e instruí-lo a procurar os entrevistadores após o almoço no local definido.

\section{NÃO ESQUEÇA! \\ SEU PAPEL É MUITO IMPORTANTE DURANTE A ENTREVISTA!!!}

AO FINAL DA ENTREVISTA AGRADECER CORDIALMENTE A PARTICIPAÇÃO DO ENTREVISTADO E SOLICITAR-LHE QUE NÃO COMENTE O TEOR DA ENTREVISTA COM SEUS COLEGAS PARA QUE NÃO HAJA INTERFERÊNCIA NA PARTICIPAÇÃO DE OUTROS ENTREVISTADOS.

\section{Referências Consultadas}

Gil AC. Métodos e técnicas de pesquisa social. 4. ed. São Paulo: Atlas; 1995.

Kelsey JL, Whittemore AS, Evans AS, Thompson WD. Methods in observational epidemiology. 2. ed. New York: Oxford University Press; 1996.

Castro RCF. Comunicação científica na área de saúde pública: perspectivas para a tomada de decisões em saúde baseada em conhecimento [tese de doutorado]. São Paulo: Faculdade de Saúde Pública da USP; 2003. 
ANEXO IV - Pedido de autorização para realização de entrevista nos restaurantes universitários da Coseas/USP 
ANEXO V - Termo de consentimento livre e esclarecido 


\section{Universidade de São Paulo \\ Faculdade de Saúde Pública \\ Departamento de Nutrição}

São Paulo, de de 2005.

Prezado (a) Senhor (a)

Estou realizando uma pesquisa aprovada pelo Comitê de Ética da Faculdade de Saúde Pública e autorizada pela Coordenadoria de Assistência Social nos restaurantes administrados pela Coseas. A pesquisa intitulada "Repercussão da informação nutricional sobre o comportamento de clientes de restaurantes universitários" é parte de minha pesquisa de mestrado pelo Departamento de Nutrição/USP, que apresenta como objetivo verificar o entendimento e uso das informações nutricionais pelos usuários desses restaurantes.

A identidade os indivíduos entrevistados serão mantidas em sigilo. Os dados coletados não terão menção de nomes e serão utilizados apenas para fins desta pesquisa.

Sua participação é voluntária, podendo desistir a qualquer momento da pesquisa.

Para isso, gostaria de contar com sua amável atenção participando da entrevista.

Agradeço pela colaboração.

Nutricionista - Máurea Elena Missio da Silva

RG: 13.836 .345

Tel. para contato: $3066-7785$

N.

$\mathrm{Eu}$ nesta data

/2005,

aceito participar da entrevista da pesquisa "Repercussão da informação nutricional sobre o comportamento de clientes de restaurantes universitários" do Departamento de Nutrição/USP. 
ANEXO VI - Agradecimento pela participação na entrevista 
Sr.

Venho agradecer a importante colaboração de V. S. ${ }^{a}$ pela entrevista concedida.

Conforme informado, encaminho informações sobre o tema da entrevista.

Máurea Elena Missio da Silva

n. ${ }^{\circ}$ USP 2.179.410 
ANEXO VII - Material informativo encaminhado aos entrevistados adultos (20 a 59 anos): orientações básicas de alimentação e nutrição 


\section{Cálculo do IMC}

Com os dados de peso e altura referidos foi possível classificar seu estado nutricional pelo Índice de Massa Corporal (IMC).

Esse valor é obtido pela seguinte equação matemática: e pode ser classificado como demonstrado abaixo:

$$
\mathrm{IMC}=\frac{\text { peso }(\mathrm{em} \mathrm{kg})}{(\text { altura }(\mathrm{em} \mathrm{m}))^{2}}
$$

\begin{tabular}{r|l}
\hline Classificação & IMC (kg/m $\mathbf{~}^{\mathbf{~})}$ \\
\hline Baixo peso & $<18,5$ \\
\hline Peso normal & $18,5-24,9$ \\
\hline Excesso de peso & $>=25$ \\
\hline Pré-obeso & $25,0-29,9$ \\
\hline Obeso classe I & $30,0-34,9$ \\
\hline Obeso classe II & $35,0-39,9$ \\
\hline Obeso classe III & $>=40$ \\
\hline
\end{tabular}

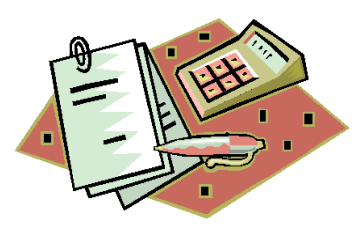

Fonte: WHO, 2003.

Seu IMC foi $\quad \mathrm{kg} / \mathrm{m}^{2}$, sendo classificado como

É também possível calcular o IMC pelo endereço eletrônico:

http://portalweb01.saude.gov.br/alimentacao/imc.cfm, do Ministério da Saúde, digitando peso e altura.

O controle do peso, durante todas as etapas da vida, é importante para a prevenção da obesidade que é um ' dos maiores fatores de risco para doenças do coração, hipertensão, diabetes tipo 2 e alguns tipos de câncer. Isto ocorre quando há um desequilíbrio da energia provida pela ingestão dos alimentos e aquela gasta nas atividades diárias. 


\section{Caloria (kcal= quilocaloria)}

É a unidade de medida de energia. A energia é necessária para o perfeito funcionamento de nosso corpo. Essa energia é proveniente dos alimentos ingeridos diariamente.

A quantidade necessária diária de energia depende da idade, sexo, peso e atividade física que o indivíduo gasta no trabalho, em casa, quando caminha, praticando esporte, no lazer e para o funcionamento do corpo.

É possível fazer esse cálculo pelo endereço eletrônico:

http://portalweb01.saude.gov.br/alimentacao/gasto cal.cfm, do Ministério da Saúde.

A energia é calculada pela quantidade de macronutrientes encontrados nos alimentos, isto é, gordura ou lipídeo, proteína e carboidrato ou hidrato de carbono.

$1 \mathrm{~g}$ de carboidrato fornece $4 \mathrm{kcal}$

$1 \mathrm{~g}$ de proteína fornece $4 \mathrm{kcal}$

$1 \mathrm{~g}$ de álcool fornece $7 \mathrm{kcal}$

$1 \mathrm{~g}$ de gordura fornece $9 \mathrm{kcal}$

$$
\}
$$

O alimento consumido em excesso pode se transformar em gordura e ser armazenado no organismo e, em decorrência, aumentar o peso corporal.

\section{Rótulo com informação nutricional}

A informação nutricional do rótulo de embalagem de um produto alimentício oferece a quantidade de energia e de nutrientes que uma porção daquele produto fornece ao organismo. Para calcular a quantidade relativa dessa porção sobre o total diário (\%VD percentual de valor diário) foi utilizado como padrão uma dieta de $2.500 \mathrm{kcal}$. A partir de agosto de 2006 a legislação substituirá esse padrão de referência para 2.000 kcal.

Exemplo do rótulo com informação nutricional:

Leite Desnatado - (1\% de gordura)

\begin{tabular}{|c|c|c|}
\hline \multicolumn{3}{|c|}{$\begin{array}{c}\text { INFORMAÇÃO NUTRICIONAL } \\
\text { Porção de } 200 \mathrm{~g} / \text { (medida caseira)(1) }\end{array}$} \\
\hline \multicolumn{3}{|c|}{ Quantidade por porção } \\
\hline & & $\% \operatorname{VD}\left({ }^{*}\right)$ \\
\hline Valor Calórico & $100 \mathrm{kcal}$ & $4 \%$ \\
\hline Carboidratos & $12 \mathrm{~g}$ & $3 \%$ \\
\hline Proteínas & $8 \mathrm{~g}$ & $16 \%$ \\
\hline Gorduras Totais & $3 \mathrm{~g}$ & $4 \%$ \\
\hline Gorduras Saturadas & $2 \mathrm{~g}$ & $8 \%$ \\
\hline Colesterol & $10 \mathrm{mg}$ & $3 \%$ \\
\hline Fibra Alimentar & $0 \mathrm{~g}$ & $0 \%$ \\
\hline Cálcio & $300 \mathrm{mg}$ & $37 \%$ \\
\hline Ferro & $\begin{array}{r}\text { quantidade não } \\
\text { significativa }\end{array}$ & $0 \%$ \\
\hline Sódio & $120 \mathrm{mg}$ & $5 \%$ \\
\hline \multicolumn{3}{|c|}{ Outros Minerais (1) mg ou mcg } \\
\hline \multicolumn{3}{|c|}{ Vitaminas (1) mg ou mcg } \\
\hline
\end{tabular}

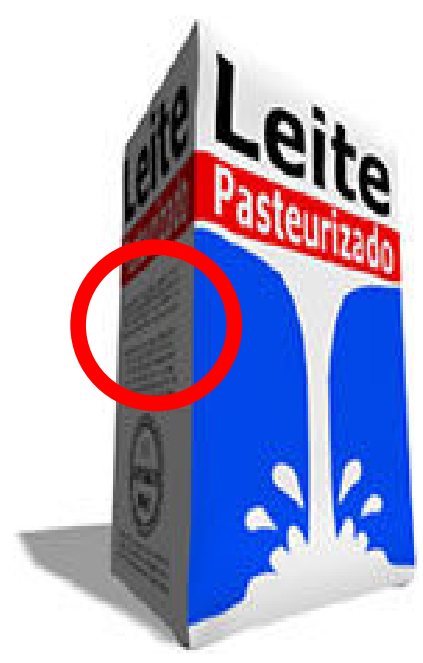

* Valores Diários de referência com base em uma dieta de 2.500 calorias.

(1) quando for declarado 
É aquela que contém alimentos fontes de nutrientes em quantidade suficiente para manutenção do organismo. No sentido de auxiliar a seleção desses alimentos foi proposto um guia sob a forma de uma pirâmide.

\section{PIRÂMIDE ALIMENTAR ADAPTADA}

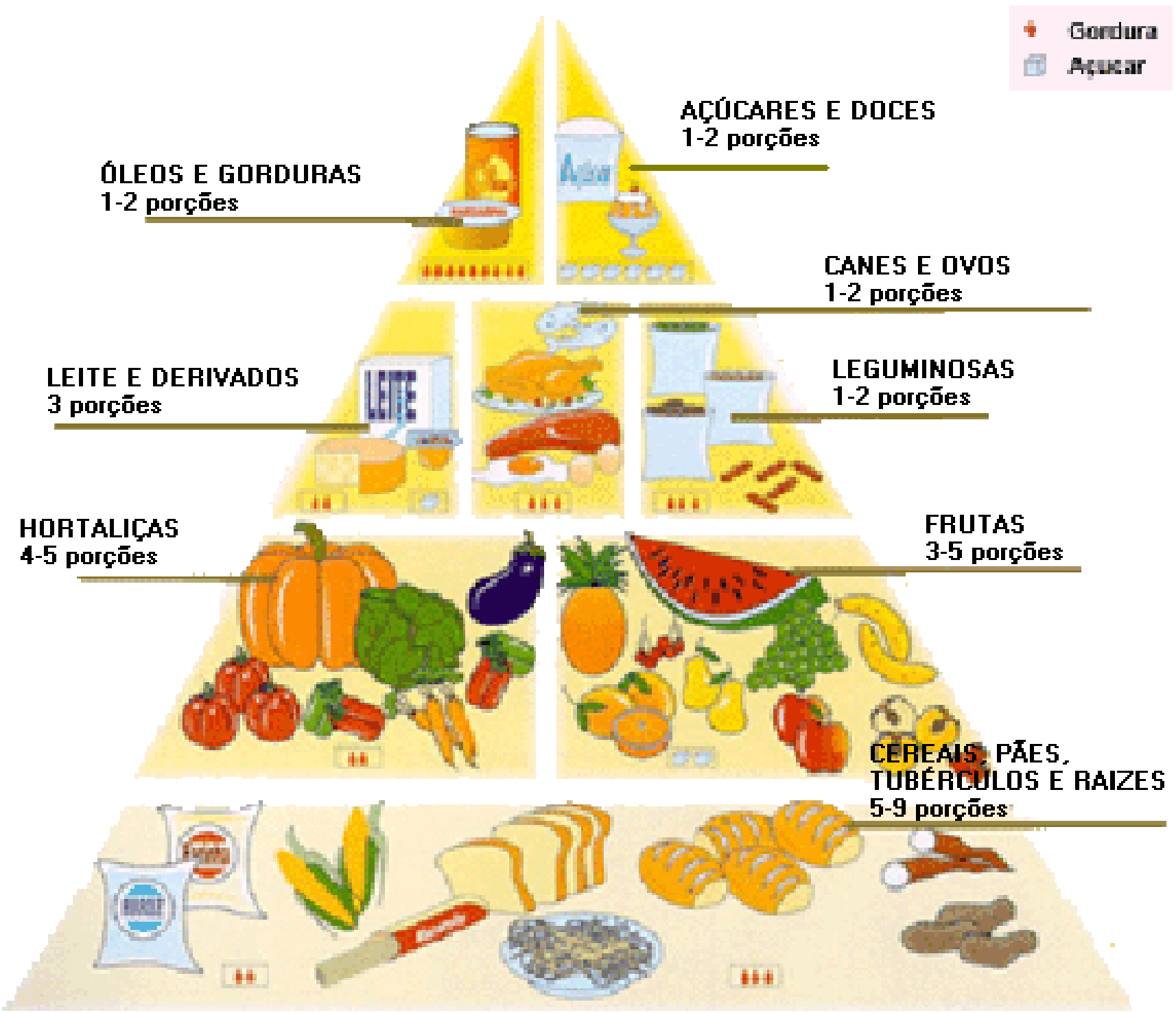

Fonte: PHILIPPI e col., 1999. 


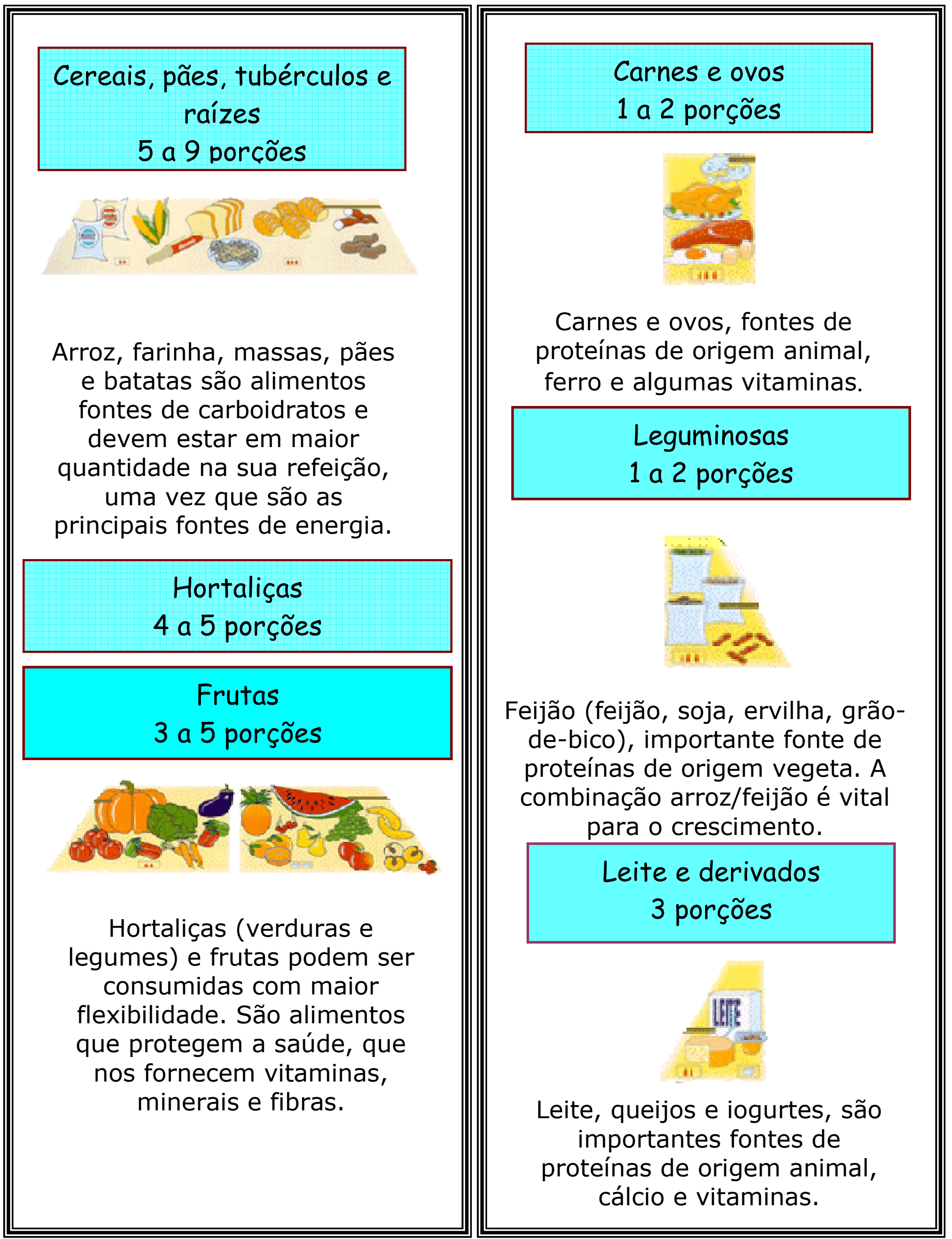




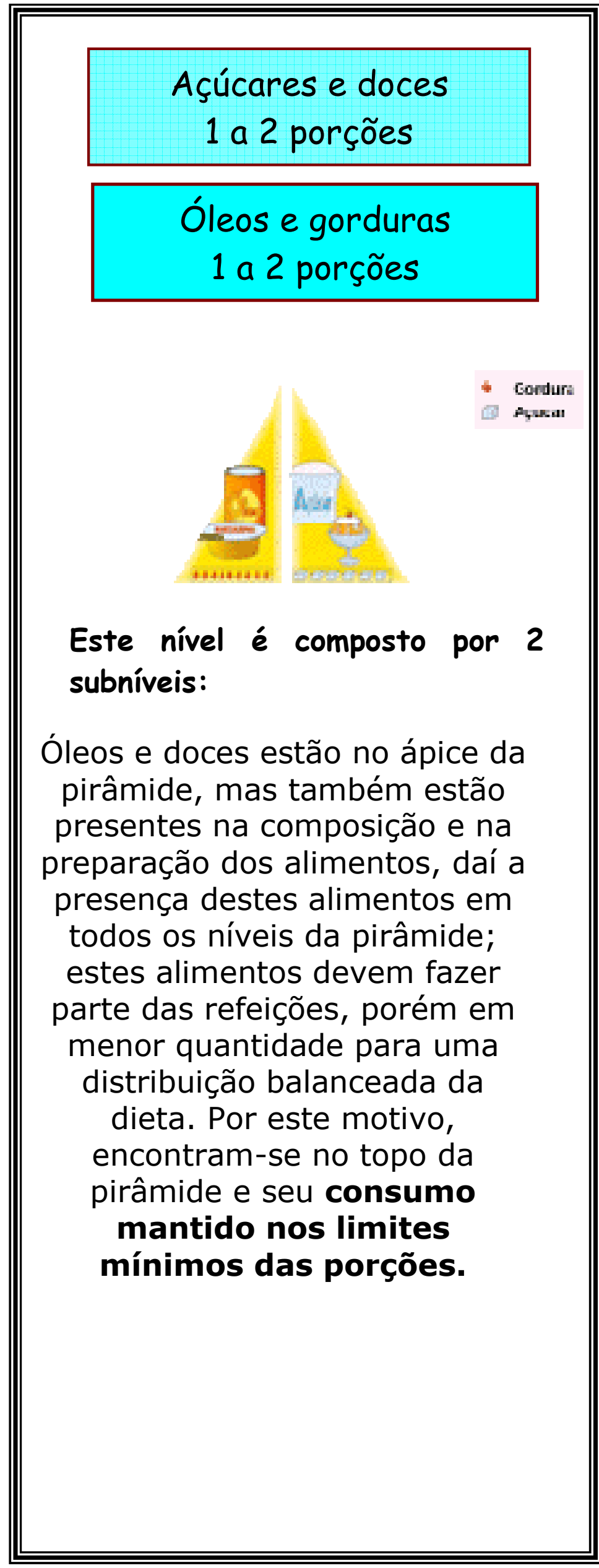

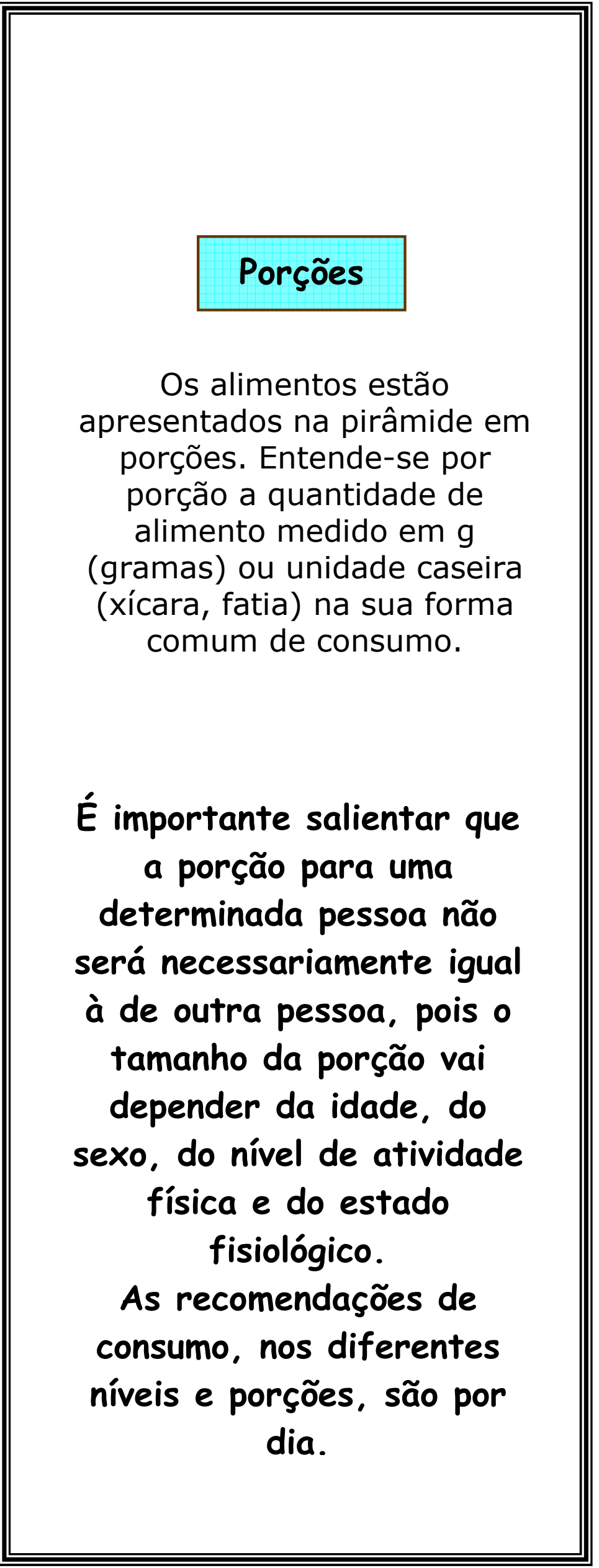




\section{Conselhos úteis!}

- Os alimentos de um grupo não podem ser substituídos pelos de outros grupos. Todos os alimentos são importantes e necessários.

- Escolha uma alimentação com diversos alimentos de todos os níveis da Pirâmide respeitando sempre o número de porções.

- Dê preferência aos alimentos em sua forma natural, preparando-os sob a forma de assados, cozidos em água ou vapor e grelhados.

- Verifique sempre a informação nutricional dos produtos industrializados constantes no rótulo da embalagem dos alimentos.

- Medidas radicais não são recomendadas. Se necessário, mude seus hábitos alimentares gradativamente.

- Tome no mínimo oito copos de água por dia. Esta deve ser fervida ou filtrada.

$\mathrm{Na}$ dúvida, procure sempre um nutricionista para uma orientação nutricional individualizada. 
Para uma vida saudável é necessário:

- Atividade física diária de no mínimo 30 minutos.

- Diminuir o consumo de alimentos gordurosos, como frituras; molho à base de maionese; embutidos, tais como salsicha, presunto, queijos gordurosos, como os mais amarelos, margarina.

- Diminuir o consumo de alimentos com grande concentração de açúcar, como refrigerantes, sucos industrializados prontos para beber com adição de açúcar, bolachas recheadas e doces em geral.

- O rótulo com informação nutricional é uma exigência de lei e é também uma boa referência para você fazer uma escolha mais saudável.

\section{Publicações interessantes e acessíveis na internet:}

Guia de bolso do consumidor -

www.anvisa.gov.br/alimentos/rotulos/guiadebolso.pdf

Manual sobre rotulagem de alimentos -

www.anvisa.gov.br/alimentos/rotulos/manual rotulagem.PDF

Além destes, um teste para verificar como está sua alimentação pode ser encontrado no endereço eletrônico

http://portalweb01.saude.gov.br/alimentacao/teste alimentacao.cfm, do Ministério da Saúde. 
ANEXO VIII - Material informativo encaminhado aos entrevistados idosos ( $\geq 60$ anos): orientações básicas de alimentação e nutrição 


\section{Cálculo do IMC}

Com os dados de peso e altura referidos foi possível classificar seu estado nutricional pelo Índice de Massa Corporal (IMC).

Esse valor é obtido pela seguinte equação matemática: Para pessoas de 60 anos e mais pode ser classificado como demonstrado abaixo:

$$
\mathrm{IMC}=\frac{\text { peso }(\mathrm{em} \mathrm{kg})}{(\text { altura }(\mathrm{em} \mathrm{m}))^{2}}
$$

\begin{tabular}{l|l}
\hline Classificação & IMC $\mathbf{( k g / \mathbf { m } ^ { 2 } )}$ \\
\hline Baixo peso & $<23,0$ \\
\hline Peso normal & $=23-28$ \\
\hline Excesso de peso & $>=28-30$ \\
\hline Obeso & $>=30$ \\
\hline
\end{tabular}

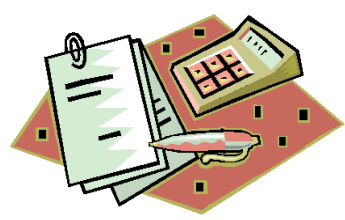

Fonte: Organização Pan Americana de Saúde, 2002

Seu IMC foi $\quad \mathrm{kg} / \mathrm{m}^{2}$, sendo classificado como

É também possível calcular o IMC pelo endereço eletrônico: http://portalweb01.saude.gov.br/alimentacao/imc.cfm, do Ministério da Saúde, digitando peso e altura.

O controle do peso, durante todas as etapas da vida,

é importante para a prevenção da obesidade, que é um dos maiores fatores de risco para doenças do coração, hipertensão, diabetes tipo 2 e alguns tipos de câncer. Isto ocorre quando há um desequilíbrio da energia provida pela ingestão dos alimentos e aquela gasta nas

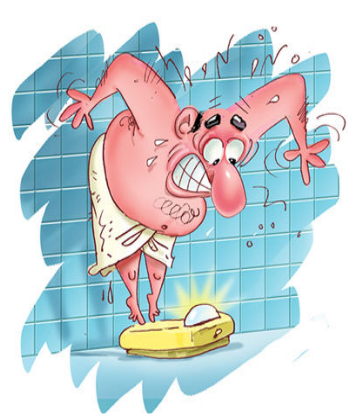
atividades diárias. 
Caloria (kcal= quilocaloria)

É a unidade de medida de energia. A energia é necessária para o perfeito funcionamento de nosso corpo. Essa energia é proveniente dos alimentos ingeridos diariamente.

A quantidade necessária diária de energia depende da idade, sexo, peso e atividade física que o indivíduo gasta no trabalho, em casa, quando caminha, praticando esporte, no lazer e para o funcionamento do corpo.

É possível fazer esse cálculo pelo endereço eletrônico:

http://portalweb01.saude.gov.br/alimentacao/gasto cal.cfm, do Ministério da Saúde.

A energia é calculada pela quantidade de macronutrientes encontrados nos alimentos, isto é, gordura ou lipídeo, proteína e carboidrato ou hidrato de carbono.

$1 \mathrm{~g}$ de carboidrato fornece $4 \mathrm{kcal}$

$1 \mathrm{~g}$ de proteína fornece $4 \mathrm{kcal}$

$1 \mathrm{~g}$ de álcool fornece $7 \mathrm{kcal}$

$1 \mathrm{~g}$ de gordura fornece $9 \mathrm{kcal}$

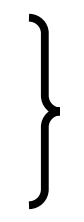

O alimento consumido em excesso pode se transformar em gordura e ser armazenado no organismo e, em decorrência, aumentar o peso corporal.

\section{Rótulo com informação nutricional}

A informação nutricional do rótulo de embalagem de um produto alimentício oferece a quantidade de energia e de nutrientes que uma porção daquele produto fornece ao organismo. Para calcular a quantidade relativa dessa porção sobre o total diário (\%VD percentual de valor diário) foi utilizado como padrão uma dieta de $2.500 \mathrm{kcal}$. A partir de agosto de 2006 a legislação substituirá esse valor padrão de referência para 2.000 kcal.

Exemplo do rótulo com informação nutricional:

Leite Desnatado - (1\% de gordura)

\begin{tabular}{|c|c|c|}
\hline \multicolumn{3}{|c|}{$\begin{array}{l}\text { INFORMAÇÃO NUTRICIONAL } \\
\text { Porção de } 200 \mathrm{~g} / \text { (medida caseira)(1) }\end{array}$} \\
\hline \multicolumn{3}{|c|}{ Quantidade por porção } \\
\hline & & $\% \operatorname{VD}\left({ }^{*}\right)$ \\
\hline Valor Calórico & $100 \mathrm{kcal}$ & $4 \%$ \\
\hline Carboidratos & $12 \mathrm{~g}$ & $3 \%$ \\
\hline Proteínas & $8 \mathrm{~g}$ & $16 \%$ \\
\hline Gorduras Totais & $3 \mathrm{~g}$ & $4 \%$ \\
\hline Gorduras Saturadas & $2 \mathrm{~g}$ & $8 \%$ \\
\hline Colesterol & $10 \mathrm{mg}$ & $3 \%$ \\
\hline Fibra Alimentar & $0 \mathrm{~g}$ & $0 \%$ \\
\hline Cálcio & $300 \mathrm{mg}$ & $37 \%$ \\
\hline Ferro & $\begin{array}{r}\text { quantidade não } \\
\text { significativa }\end{array}$ & $0 \%$ \\
\hline Sódio & $120 \mathrm{mg}$ & $5 \%$ \\
\hline \multicolumn{3}{|c|}{ Outros Minerais (1) mg ou mcg } \\
\hline \multicolumn{3}{|c|}{ Vitaminas (1) mg ou mcg } \\
\hline
\end{tabular}

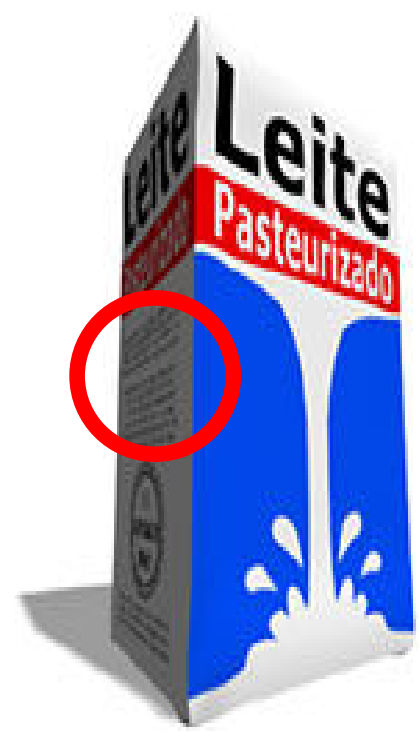

* Valores Diários de referência com base em uma dieta de 2.500 calorias.

(1) quando for declarado

Fonte: USDA 


\section{Alimentação saudável}

É aquela que contém alimentos fontes de nutrientes em quantidade suficiente para manutenção do organismo. No sentido de auxiliar a seleção desses alimentos foi proposto um guia sob a forma de uma pirâmide.

\section{PIRÂMIDE ALIMENTAR ADAPTADA}

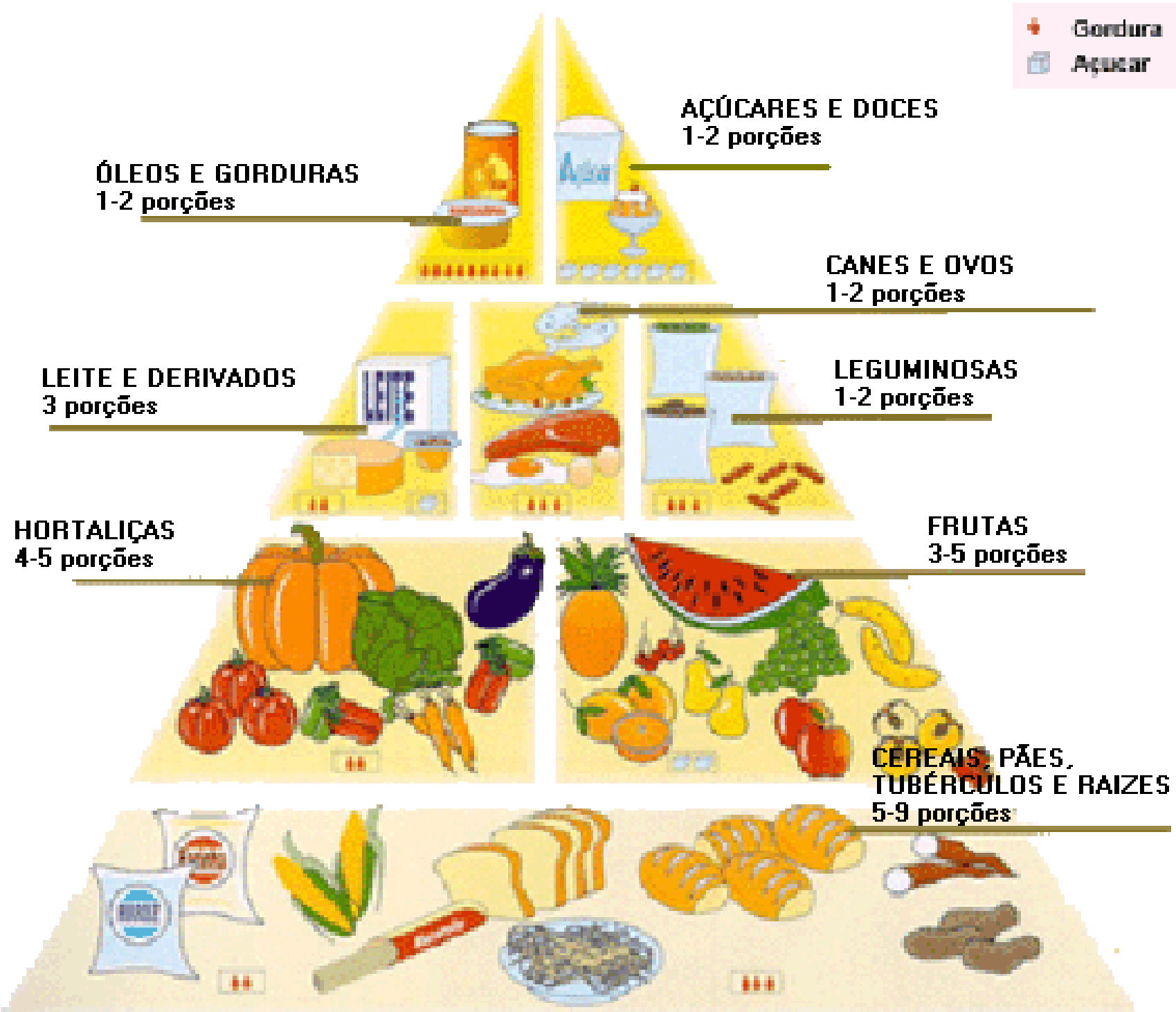

Fonte: PHILIPPI e col., 1999. 
Cereais, pães, tubérculos e raízes

5 a 9 porcões

Arroz, farinha, massas, pães e batatas são alimentos fontes de carboidratos e devem estar em maior quantidade na sua refeição, uma vez que são as principais fontes de energia.

\section{Hortaliças}

4 a 5 porções

\section{Frutas}

3 a 5 porções

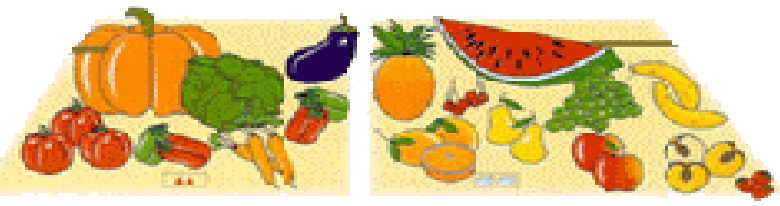

Hortaliças (verduras e legumes) e frutas podem ser consumidas com maior flexibilidade. São alimentos que protegem a saúde, que nos fornecem vitaminas, minerais e fibras.

\section{Carnes e ovos 1 a 2 porções}

Carnes e ovos, fontes de proteínas de origem animal, ferro e algumas vitaminas.

\section{Leguminosas \\ 1 a 2 porções}

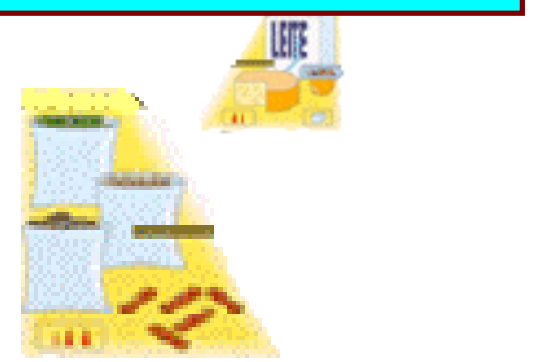

Feijão (feijão, soja, ervilha, grãode-bico), importante fonte de proteínas de origem vegetal. A combinação arroz/feijão é vital para o crescimento.

$$
\begin{gathered}
\text { Leite e derivados } \\
3 \text { porções }
\end{gathered}
$$

Leite, queijos e iogurtes, são importantes fontes de proteínas de origem animal, cálcio e vitaminas. 


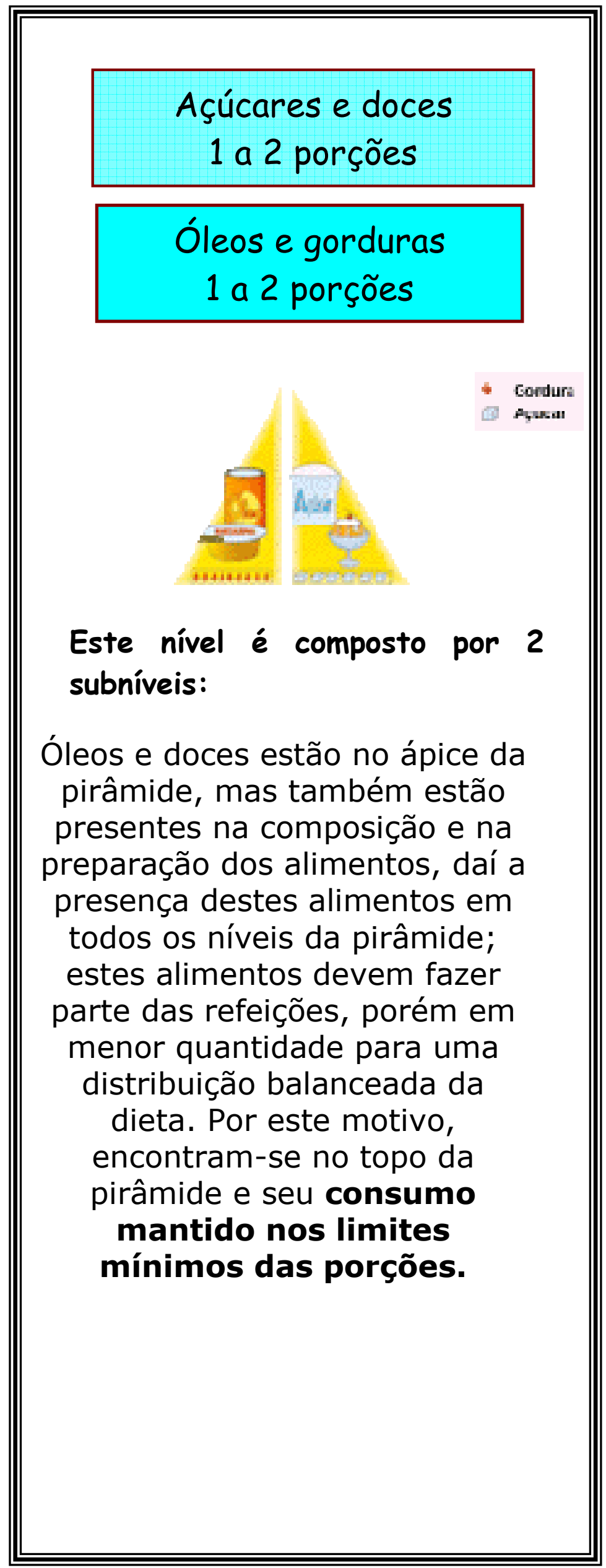

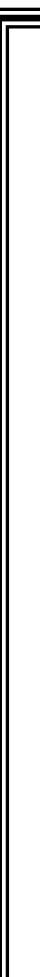

Porções

Os alimentos estão apresentados na pirâmide em porções. Entende-se por porção a quantidade de alimento medido em $\mathrm{g}$ (gramas) ou unidade caseira (xícara, fatia) na sua forma comum de consumo.

É importante salientar que a porção para uma determinada pessoa não será necessariamente igual à de outra pessoa, pois 0 tamanho da porção vai depender da idade, do sexo, do nivel de atividade física e do estado fisiológico.

As recomendações de consumo, nos diferentes niveis e porções, são por dia. 


\section{Conselhos úteis!}

- Os alimentos de um grupo não podem ser substituídos pelos de outros grupos. Todos os alimentos são importantes e necessários.

- Escolha uma alimentação com diversos alimentos de todos os níveis da Pirâmide respeitando sempre o número de porções.

- Dê preferência aos alimentos em sua forma natural, preparando-os sob a forma de assados, cozidos em água ou vapor e grelhados.

- Verifique sempre a informação nutricional dos produtos industrializados constantes no rótulo da embalagem dos alimentos.

- Medidas radicais não são recomendadas. Se necessário, mude seus hábitos alimentares gradativamente.

- Tome no mínimo oito copos de água por dia. Esta deve ser fervida ou filtrada.

$\mathrm{Na}$ dúvida, procure sempre um nutricionista para uma orientação nutricional individualizada. 
Para uma vida saudável é necessário:

- $\quad$ Atividade física diária de no mínimo 30 minutos.

- Diminuir o consumo de alimentos gordurosos, como frituras; molho a base de maionese; embutidos, tais como salsicha, presunto, queijos gordurosos, como os mais amarelos, margarina.

- Diminuir o consumo de alimentos com grande concentração de açúcar, como refrigerantes, sucos industrializados prontos para beber com adição de açúcar, bolachas recheadas e doces em geral.

- O rótulo com informação nutricional é uma exigência de lei e é também uma boa referência para você fazer uma escolha mais saudável.

\section{Publicações interessantes e acessíveis na internet:}

Guia de bolso do consumidor www.anvisa.gov.br/alimentos/rotulos/guiadebolso.pdf

Manual sobre rotulagem de alimentos www.anvisa.gov.br/alimentos/rotulos/manual rotulagem.PDF

Além destes, um teste para verificar como está sua alimentação pode ser encontrado no endereço eletrônico http://portalweb01.saude.gov.br/alimentacao/teste alimentacao.cfm, do Ministério da Saúde. 
ANEXO IX - Aprovação da pesquisa pelo Comitê de Ética da Faculdade de Saúde Pública 
ANEXO X - Localização dos restaurantes universitários no Campus da Cidade Universitária "Armando de Sales Oliveira" 


\section{Campus da Cidade Universitária "Armando de Sales Oliveira"}

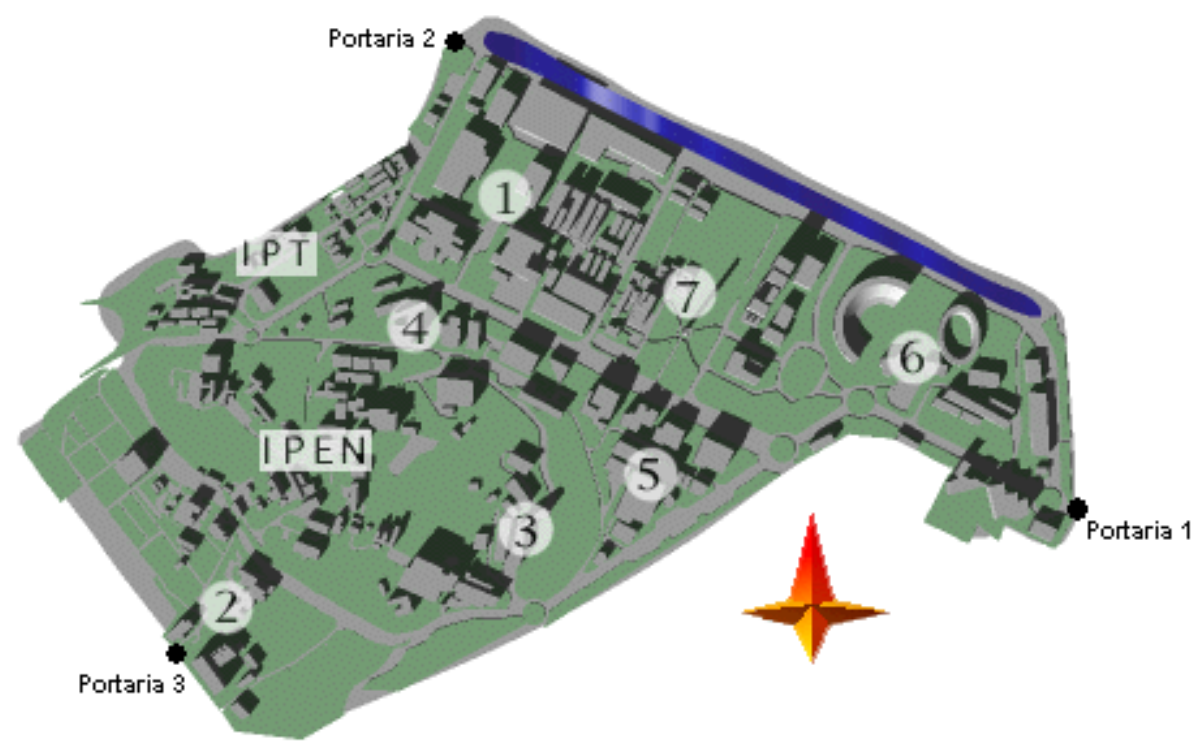

Fonte:

www2.usp.br/português/conteúdo.php?dir=ausp/infogeral/mapas/butanta.htm

1 - Politécnica, FEA, CCE, barracões (FUNBEC, Odontologia e Escola do Futuro)

2 - Hospital Universitário, Odontologia, Terapia Ocupacional e Fisioterapia, Veterinária e Instituto de Ciências Biomédicas

3 - Ciências Biológicas e Biomédicas

4 - $\quad$ Eletrotécnica, IAG, IME, FAU, FFLCH, Instituto Oceanográfico, Física, RESTAURANTE DA FÍSICA

5 - História, Geografia, Letras, Sociais, Poli-Química, Química, Farmácia e Biotério

6 - CEPEUSP, Faculdade de Educação, Escola de Aplicação, Educação Física, RESTAURANTE CENTRAL

7 - ECA, Instituto de Psicologia

IPT Instituto de Pesquisas Tecnológicas

IPEN Instituto de Pesquisas em Energia Nuclear 


\section{Mapa de localização do restaurante Central (1) e arredores}

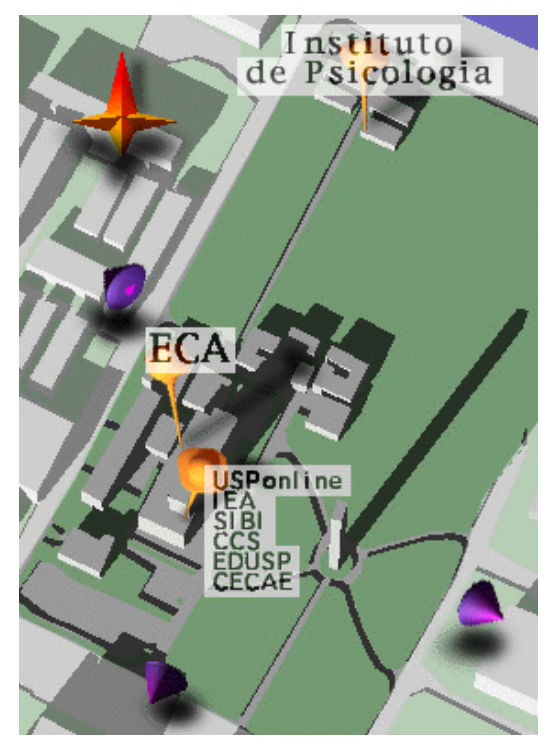

\section{Fonte:}

www2.usp.br/português/conteúdo.php?dir=ausp/infoger al/mapas/butanta $7 \mathrm{htm}$
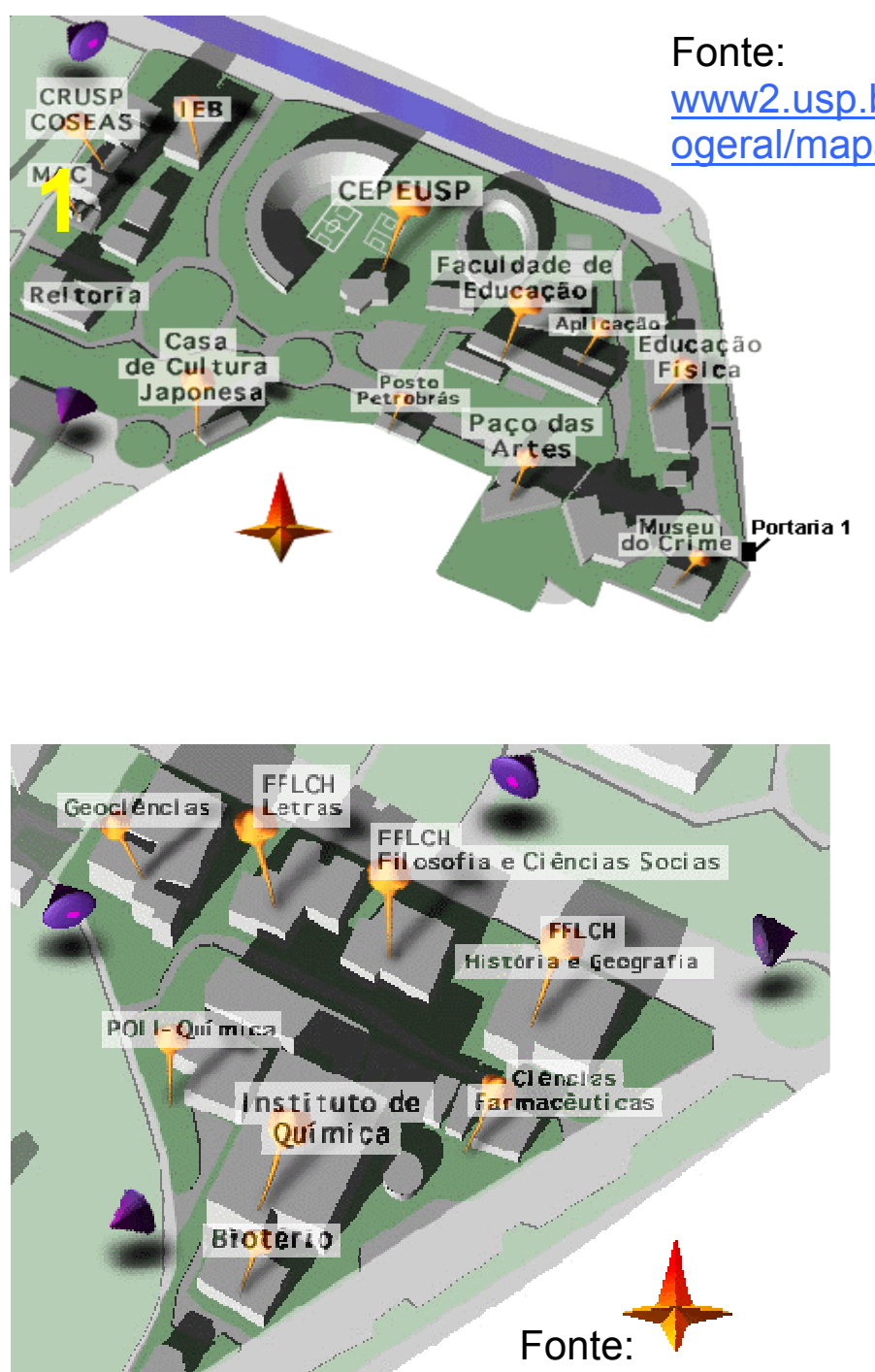

www2.usp.br/português/conteúdo.php?dir=ausp infogeral/mapas/butanta $5 \mathrm{htm}$ 


\section{Mapa de localização do restaurante da Física (2) e arredores}

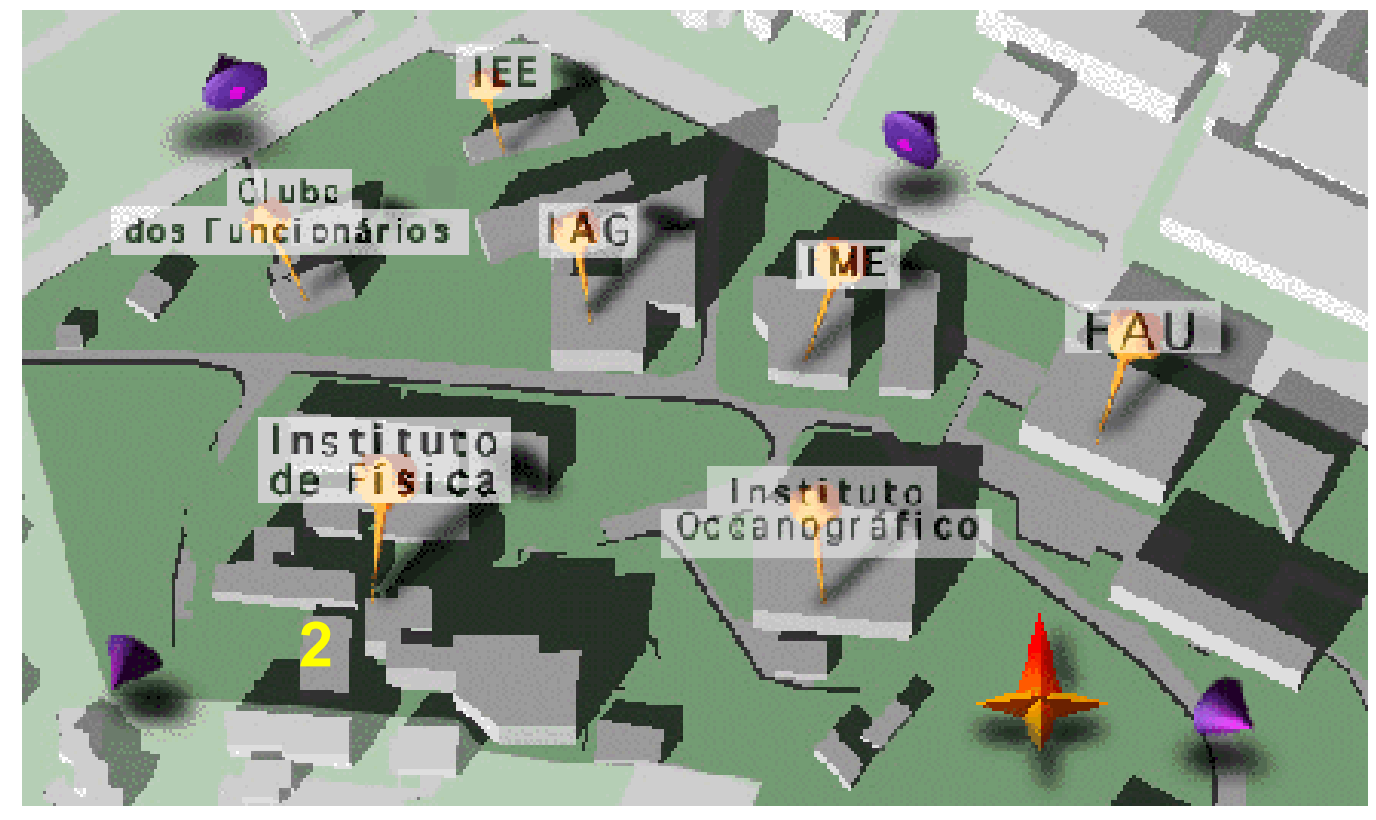

Fonte:

www2.usp.br/português/conteúdo.php?dir=ausp/infogeral/mapas/butanta 4htm 